\title{
Differential binding of hnRNP K, L and A2/B1 to an exonic splicing silencer element located within exon 12 of glucose -6 -phosphate dehydrogenase mRNA
}

\author{
Brian Nelson Griffith \\ West Virginia University
}

Follow this and additional works at: https://researchrepository.wvu.edu/etd

\footnotetext{
Recommended Citation

Griffith, Brian Nelson, "Differential binding of hnRNP K, L and A2/B1 to an exonic splicing silencer element located within exon 12 of glucose -6 -phosphate dehydrogenase mRNA" (2006). Graduate Theses, Dissertations, and Problem Reports. 2435.

https://researchrepository.wvu.edu/etd/2435

This Dissertation is protected by copyright and/or related rights. It has been brought to you by the The Research Repository @ WVU with permission from the rights-holder(s). You are free to use this Dissertation in any way that is permitted by the copyright and related rights legislation that applies to your use. For other uses you must obtain permission from the rights-holder(s) directly, unless additional rights are indicated by a Creative Commons license in the record and/ or on the work itself. This Dissertation has been accepted for inclusion in WVU Graduate Theses, Dissertations, and Problem Reports collection by an authorized administrator of The Research Repository @ WVU. For more information, please contact researchrepository@mail.wvu.edu.
} 


\title{
Differential binding of hnRNP K, L and A2/B1 to an Exonic Splicing Silencer element located within exon 12 of Glucose- 6-Phosphate Dehydrogenase mRNA
}

\author{
By \\ Brian Nelson Griffith \\ Dissertation submitted to the \\ School of Medicine at West Virginia University \\ in partial fulfillment of the requirements \\ for the degree of Doctor of Philosophy \\ in Biochemistry and Molecular Pharmacology
}

\section{Committee Members:}

Lisa M. Salati, Ph.D., Chair

Michael Miller, Ph.D.

Janet Cyr, Ph.D.

Aaron Timperman, Ph.D.

Thomas Elliott, Ph.D.

Department of Biochemistry and Molecular Pharmacology

Morgantown, WV

2006 


\section{ABSTRACT}

\section{Differential binding of hnRNP K, L and A2/B1 to an Exonic Splicing Silencer element located within exon 12 of Glucose-6-Phosphate Dehydrogenase mRNA Brian Nelson Griffith}

The expression of most lipogenic enzymes is regulated through the effects of dietary polyunsaturated fatty acids on transcription. However, we have observed that the regulation of Glucose-6-phosphate dehydrogenase (G6PD) by polyunsaturated fatty acids occurs through a novel posttranscriptional mechanism. RNA reporter assays were used to map the cis-acting element by measuring the regulation of each RNA reporter construct transfected into primary rat hepatocytes. All RNA reporter constructs were regulated by polyunsaturated fatty acids with the exception of RNA reporter constructs lacking exon 12. Therefore, polyunsaturated fatty acids regulate the constitutive splicing of G6PD mRNA through a cis-acting element located within exon 12. Likewise, G6PD expression is regulated by a similar mechanism in intact animals. Mice fed a high polyunsaturated fatty acid diet inhibit G6PD mRNA expression by 2-4 fold as compared to a low fat diet. Accordingly, starvation of mice induces a 12-15 fold inhibition of G6PD mRNA expression as compared to the refed mice.

The proteins that differentially bound to an exon 12 RNA element were observed and identified in nuclear extracts from starved and refed animals. The cis-acting element was identified as a region between 50 and 79 nucleotides of exon 12. Identification and purification of proteins differentially bound to the cis-acting element within exon 12 were identified by LCMS/MS analysis, MALDI-TOF analysis and Western blot analysis. The proteins were identified as hnRNP K, L, and A2/B1. The 30 nucleotide binding site was further narrowed down to a region within nucleotides 65-79. HnRNP K, L and A2/B1 were shown to differentially bind in nuclear extracts of starved versus refed animals and this pattern of protein binding could potentially regulate G6PD mRNA splicing. All protein identifications were confirmed by Western blot analysis. Furthermore, a region within nucleotides 65-79 of exon 12 contained a 
strong C-rich patch located at nucleotides 65-67 and 69-71 of exon 12. C-rich patches found within mRNA sequences are thought to be potential binding sites for hnRNP K, L, A2/B1 proteins. The mutation of each of these $\mathrm{C}$-rich patches disrupted protein binding to this region suggesting that the C-rich patch within 65-79 nucleotides is essential for hnRNP K, L, and A2/B1 protein binding. The binding of hnRNP K, L, and A2/B1 binding to the region of 65-79 nucleotides suggest the presence of an exon splicing silencer sequence within exon 12 . The characterization of protein binding to this exon splicing silencer will be fundamental in providing new evidence on a novel lipogenic regulatory mechanism by polyunsaturated fatty acids. 


\section{ACKNOWLEDGEMENTS}

I would like to thank all those people that encouraged me in my life and have help make my dream a reality. I would first like to thank Lisa M. Salati for taking me under her guidance for my masters and my doctorate degree. Dr. Lisa M. Salati has been an inspiration and an excellent scientific colleague. I would like to thank her for her support and her guidance throughout my graduate career at West Virginia University. I would also like to thank the American Heart Association who sponsored my pre-doctorate fellowship. All of this work would not have been possible without their financial support. I want to thank all those organizers at the RNA and Rustbelt meeting for allowing me the opportunity to present my research at their meeting.

My graduate career would not have been possible without the support of my family. My mother, father, grandmother, grandfather and my brother were very supportive and provided both financial and emotional support throughout my graduate career. I want to especially thank my brother who has spent the last several years of my graduate career traveling the world and protecting this country from terrorist and has not spent much time home with his family. My brother and I are exact opposites but his support was very instrumental in me fulfilling my dream of becoming a doctor. I want to especially thank Jason Morgan my best-friend in the whole world for the friendship and scientific knowledge he provided for me during my undergraduate and graduate career. In addition, no doctorate defense would be possible without the support of fellow graduate students like Jason Morgan, Jason Waggoner, Indrani Talukdar, Saswata Talukdar and most importantly my friend and scientific colleague Wioletta Szeszel-Fedorowicz for her powerful assistance and guidance during my graduate career.

I want to thank all my committee members for taking time to read my dissertation and allowing me the opportunity to present my research. I also want to thank the Proteomics facility for technical support and especially want to thank Drs. Vincent and Timperman for their discussions of my data. 


\section{TABLE OF CONTENTS}

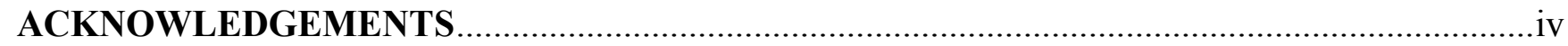

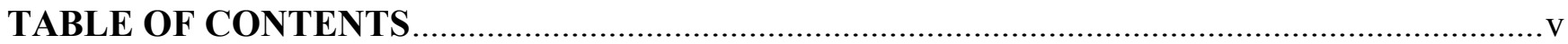

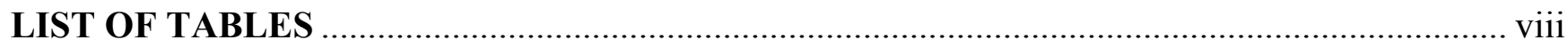

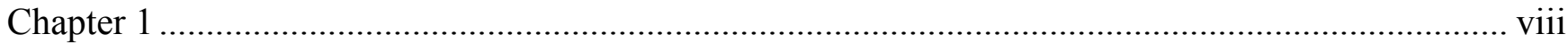

Table 1: The effect of polyunsaturated fatty acids on the gene expression involved ....................... viii

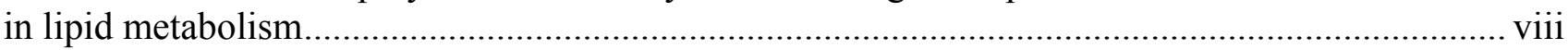

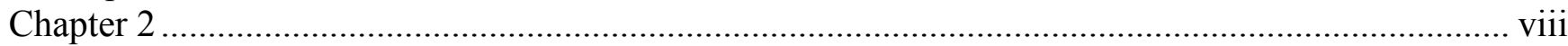

Table 1: The identification of HeLa cell nuclear extract proteins bound to the ............................... viii

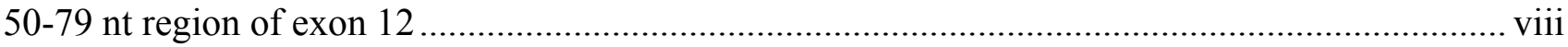

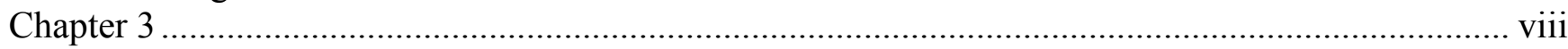

Table 1: The identification of Mouse liver proteins bound to the 50-79 $\mathrm{nt}$ region of exon $12 \ldots \ldots \ldots$ viii

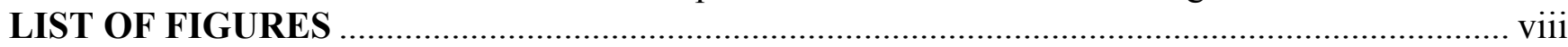

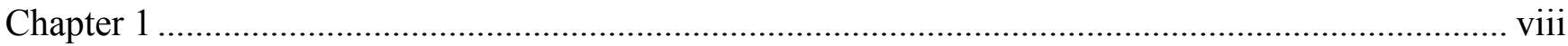

Figure 1: The role of G6PD in the cell .......................................................................... viii

Figure 2: A model of G6PD's regulation ...................................................................... viii

Figure 3: A model of mRNA splicing. ................................................................................. viii

Figure 4: Exon splicing enhancer and silencer sequences regulate splicing .............................. viii

Figure 5: G6PD regulation occurs through a cis-acting element within exon 12 of G6PD ........viii

Figure 6: The current model of G6PD gene regulation ......................................................... viii

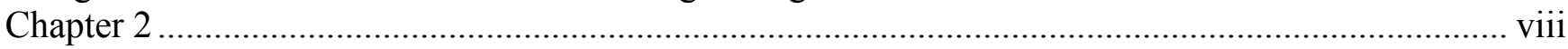

Figure 1: The detection of RNA binding proteins by UV crosslinking analysis......................... viii

Figure 2: The mapping of the cis-acting element within exon 12 of G6PD mRNA .................... viii

Figure 3: The protein purification of bands $\mathrm{A}$ and $\mathrm{B}$ by RNA affinity purification..................... viii

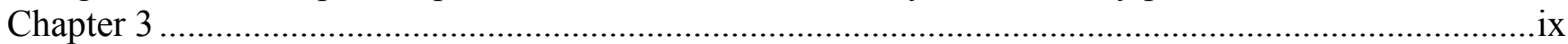

Figure 1: The structure of the G6PD probes used to characterize protein binding sites ............... ix

Figure 2: Identification of RNA binding proteins using UV crosslinking analysis ...................... ix

Figure 3: $\quad$ Mapping the cis-acting element binding site within exon 12 ..................................... ix

Figure 4: Isolation and purification of proteins bound to regions within exon 12 ....................... ix

Figure 5: Specificity of RNA binding proteins to the 50-79 nt region within exon $12 \ldots \ldots \ldots \ldots \ldots \ldots . . .$. ix

Figure 6: Purification of proteins prior to LC MS/MS analysis ................................................ ix

Figure 7: MALDI-TOF analysis of the purified proteins ......................................................... ix

Figure 8: The binding of hnRNP K, L, A2/B1 to the 50-79 nt................................................. ix

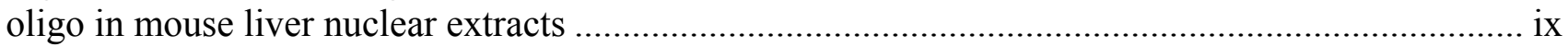

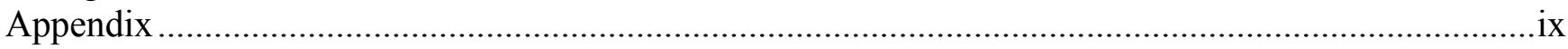

Figure 1: Detection of RNA binding proteins in primary rat hepatocytes....................................... ix

Figure 2: Detection of RNA binding proteins to nucleotides 50-93 of exon $12 \ldots \ldots \ldots \ldots \ldots \ldots \ldots \ldots \ldots \ldots \ldots \ldots . . . . .1 x$

Figure 3: Detection of RNA binding proteins to mouse liver nuclear extracts.................................. ix

Figure 4: Detection of a C-rich patch within nucleotides 65-79 are .............................................. ix

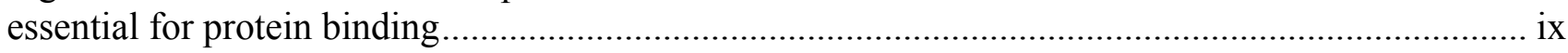

Figure 5: Detection of a C-rich patch within nucleotides 65-79 are ................................................ ix

essential for protein binding ................................................................................................ ix

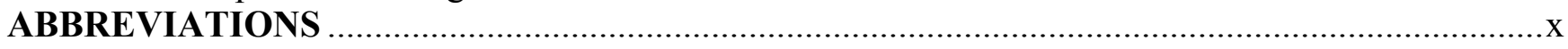


CHAPTER 1

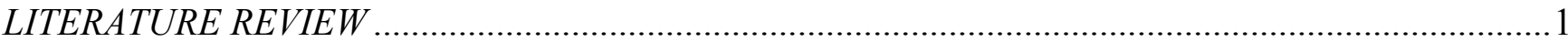

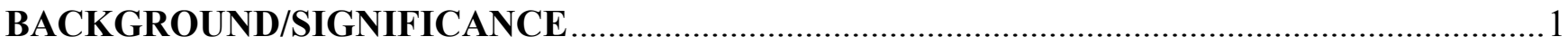

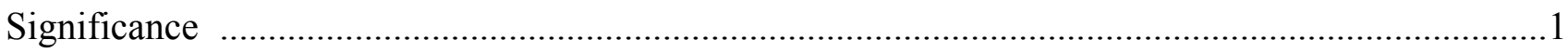

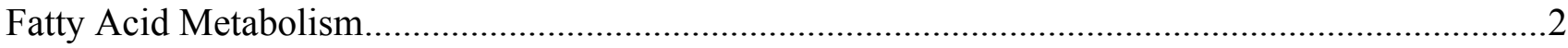

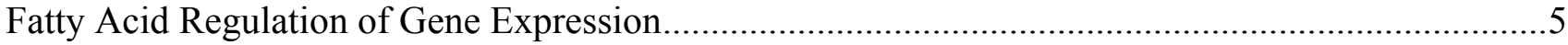

Transcriptional and Posttranscriptional Regulation of Lipogenic Genes .....................................

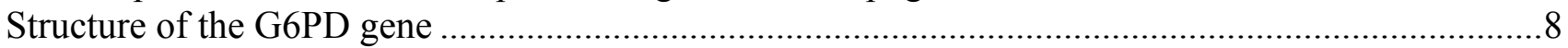

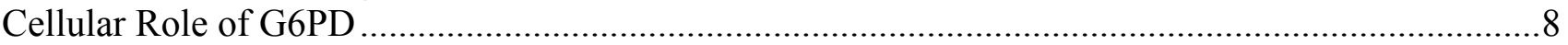

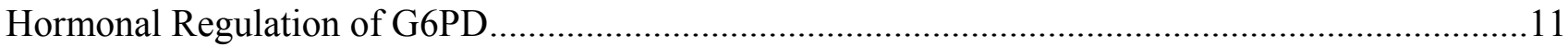

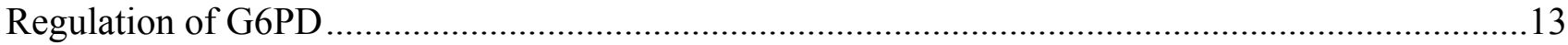

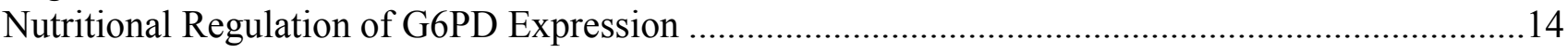

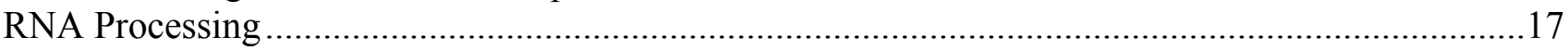

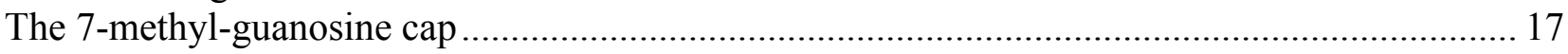

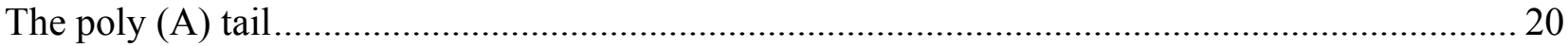

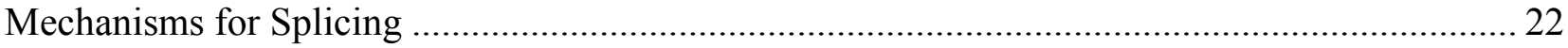

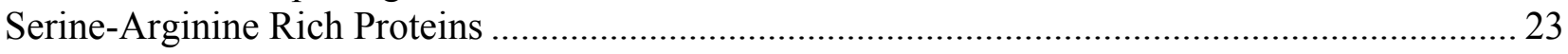

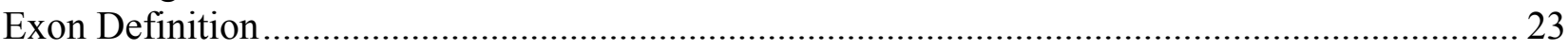

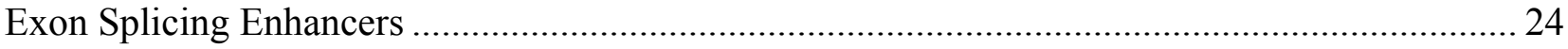

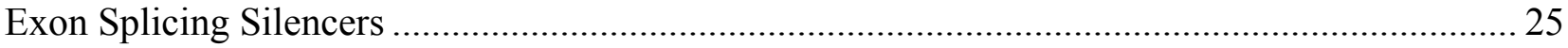

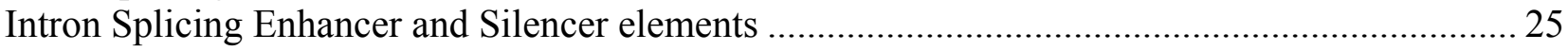

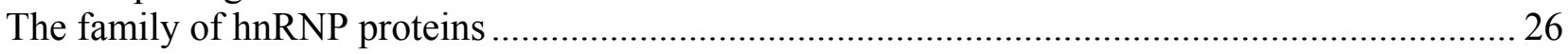

Regulation of RNA splicing by Exon Splicing Enhancers and Silencers ................................ 30

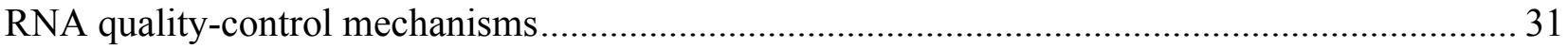

The Molecular Pathway of Nonsense Mediated Decay ….................................................... 32

Identifying the Mechanism for the Posttranscriptional Gene Regulation of G6PD.........................35

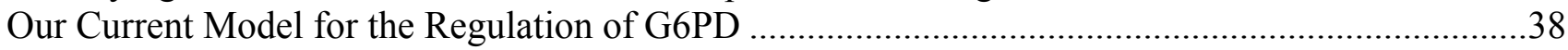

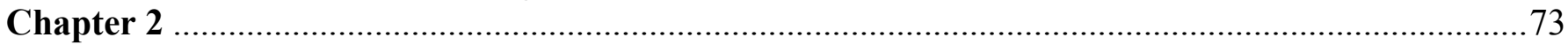

Development of Techniques to Identify RNA Binding Proteins …..................................................73

Development of Techniques to Identify RNA Binding Proteins .............................................74

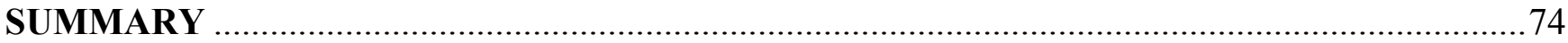

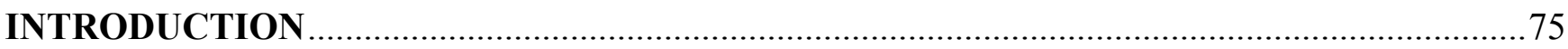

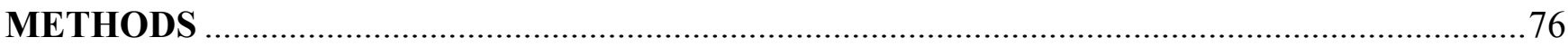

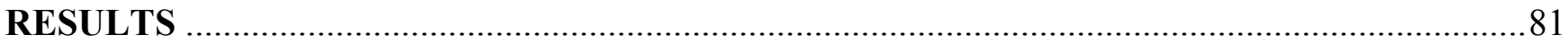

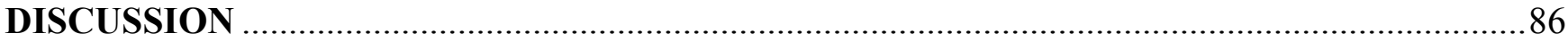

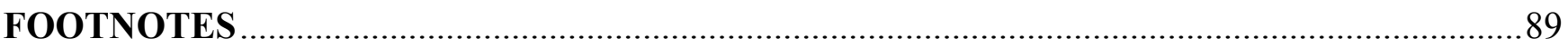

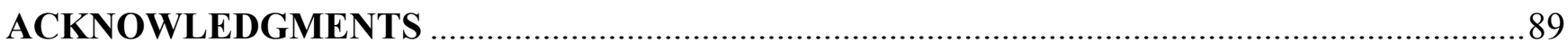

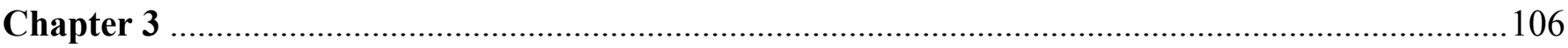

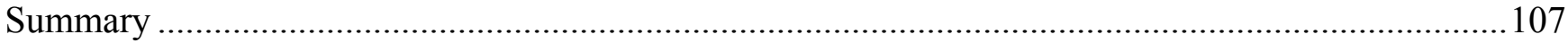

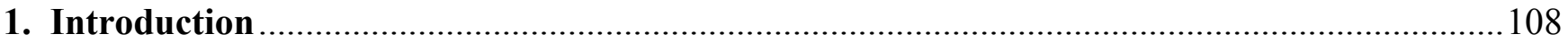

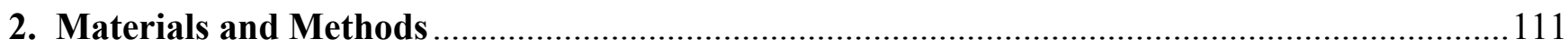

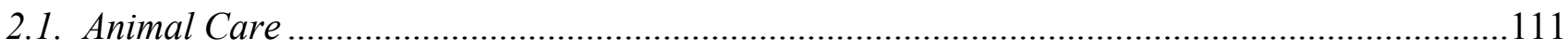

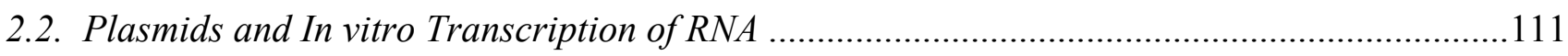

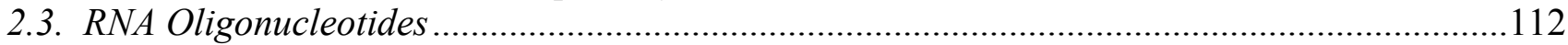

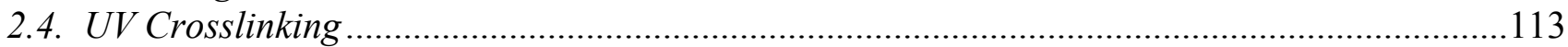


2.5. RNA Affinity Purification of Binding Proteins .................................................................113

2.6. Two-Dimensional Gel Electrophoresis ........................................................................114

2.7. Liquid Chromatography-Tandem Mass Spectrometry (LC-MS/MS) Analysis.........................115

2.8. Matrix-Assisted Laser Desorption/Ionization-Time of Flight (MALDI-TOF) ..........................116

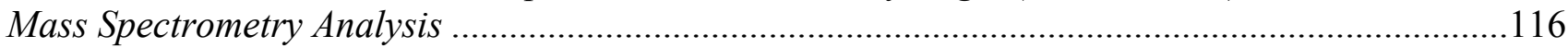

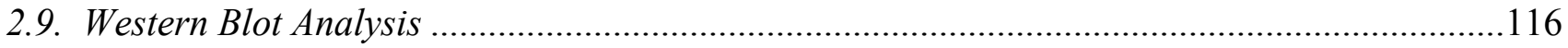

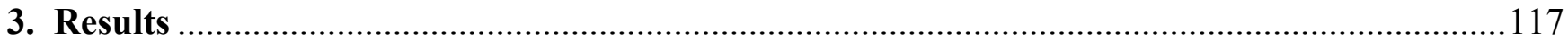

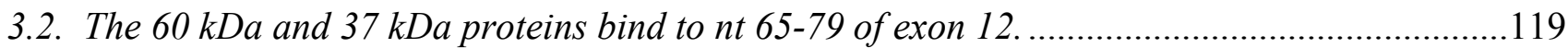

3.3. RNA affinity purification of proteins binding to $n t$ t $55-79$ of exon 12.....................................121

3.4. HnRNPs $K, L$ and A2/B1 bind to exon 12, and the binding is regulated by nutritional status. 122

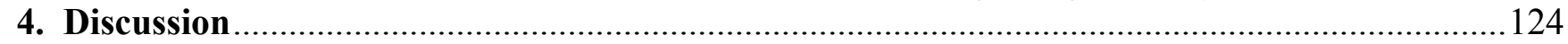

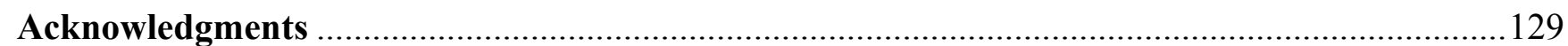

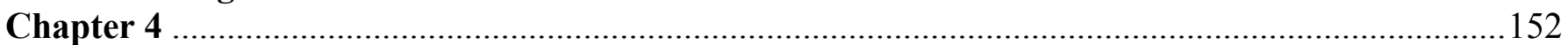

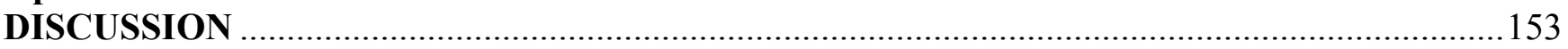

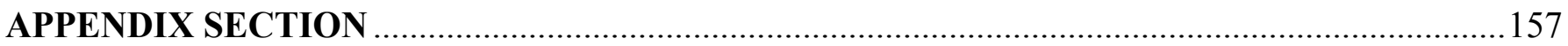

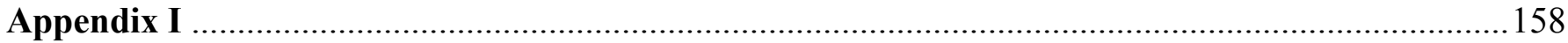

Identification of RNA Binding Proteins in Nuclear Extracts from Primary Rat Hepatocytes..................158

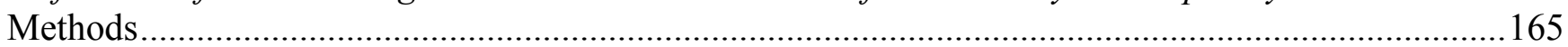

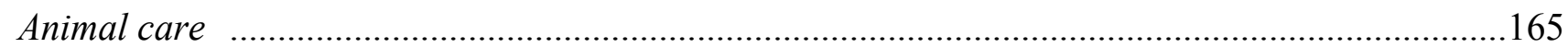

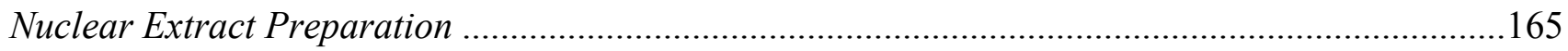

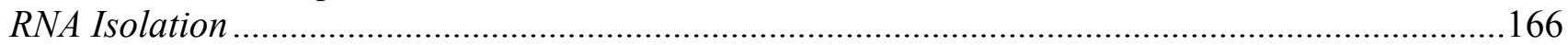

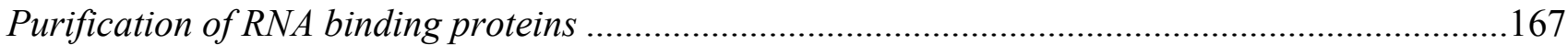

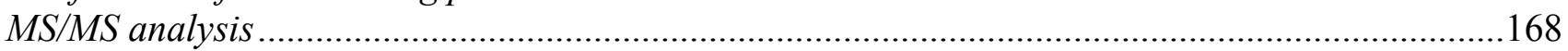

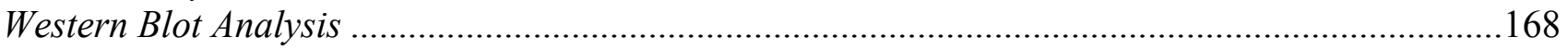

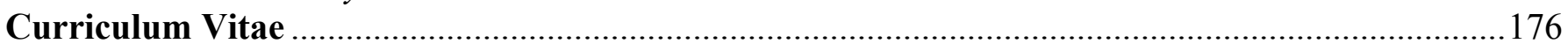




\section{LIST OF TABLES}

\section{Chapter 1}

Table 1: The effect of polyunsaturated fatty acids on the gene expression involved in lipid metabolism

\section{Chapter 2}

Table 1: The identification of HeLa cell nuclear extract proteins bound to the 50-79 nt region of exon 12

\section{Chapter 3}

Table 1: The identification of Mouse liver proteins bound to the 50-79 nt region of exon 12

\section{LIST OF FIGURES}

Figure 1: The role of G6PD in the cell

Figure 2: A model of G6PD's regulation

Figure 3: A model of mRNA splicing.

Figure 4: Exon splicing enhancer and silencer sequences regulate splicing

Figure 5: $\quad$ G6PD regulation occurs through a cis-acting element within exon 12 of G6PD

Figure 6: The current model of G6PD gene regulation

\section{Chapter 2}

Figure 1: The detection of RNA binding proteins by UV crosslinking analysis

Figure 2: $\quad$ The mapping of the cis-acting element within exon 12 of G6PD mRNA

Figure 3: The protein purification of bands A and B by RNA affinity purification

Figure 4: $\quad$ Detection of hnRNP K, L, I, and A2/B1 by Western Analysis 


\section{Chapter 3}

Figure 1: The structure of the G6PD probes used to characterize protein binding sites

Figure 2: Identification of RNA binding proteins using UV crosslinking analysis

Figure 3: $\quad$ Mapping the cis-acting element binding site within exon 12

Figure 4: Isolation and purification of proteins bound to regions within exon 12

Figure 5: Specificity of RNA binding proteins to the 50-79 nt region within exon 12

Figure 6: Purification of proteins prior to LC MS/MS analysis

Figure 7: $\quad$ MALDI-TOF analysis of the purified proteins

Figure 8: $\quad$ The binding of hnRNP K, L, A2/B1 to the 50-79 nt

oligo in mouse liver nuclear extracts

\section{Appendix}

Figure 1: Detection of RNA binding proteins in primary rat hepatocytes

Figure 2: Detection of RNA binding proteins to nucleotides 50-93 of exon 12

Figure 3: Detection of RNA binding proteins to mouse liver nuclear extracts

Figure 4: Detection of a C-rich patch within nucleotides 65-79 are essential for protein binding

Figure 5: Detection of a C-rich patch within nucleotides 65-79 are essential for protein binding 


\section{ABBREVIATIONS}

ACC

$\mathrm{Bp}$

cAMP

$\mathrm{CBC}$

cDNA

DEPC

DNA

DTT

EDTA

EGTA

ESE

ESS

FAS

G6PD

HEPES

hnRNP

IPG

$\mathrm{kDa}$

LC MS/MS

MALDI-TOF

MEM
Acetyl CoA carboxylase

Base pair

Cyclic adenosine monophosphate

Cap binding complex

Coding deoxyribonucleic acid

Diethyl pyrocarbonate

Deoxyribonucleic acid

Dithiothreitol

Ethylenediaminetetraacetic acid

Ethyleneglycol-bis( $\beta$-aminoethyl)-N,N,N',N'-tetraacetic Acid

Exonic splicing enhancer

Exonic splicing silencer

Fatty acid synthetase

Glucose-6-phophate dehydrogenase

N-2-hydroxyethyliperazine-N'-2-ethanesulfonic acid

Heterogeneous nuclear ribonuclear protein

Immobilized $\mathrm{pH}$ gradient

Kilo-Dalton

Liquid chromatography mass spectrometry/mass spectrometry

Matrix-assisted laser desorption time of flight mass spectrometry

Minimal essential media 


\begin{tabular}{ll} 
mRNA & Messenger ribonucleic acid \\
NADP+ & Nicotinamide adenine dinucleotide phosphate, oxidized \\
NADPH & Nicotinamide adenine dinucleotide phosphate, reduced \\
NCBI & National center for biotechnology information \\
NMD & Nonsense mediated decay \\
nt & Nucleotide \\
PCR & Polymerase chain reaction \\
PMSF & Phenylmethylsulfonyl fluoride \\
Pre-mRNA & Precursor mRNA \\
PTC & Premature termination codon \\
PUFA & Polyunsaturated fatty acid \\
RNA & Ribonucleic acid \\
RNase & Ribonuclease \\
SDS & Sodium dodecyl sulfate \\
SDS-PAGE & Sodium dodecyl sulfate-polyacrylamide gel electrophoresis \\
snRNPs & Small nuclear ribonucleoprotein particles \\
SR protein & Serine-arginine protein \\
ss & splice site \\
TAG & Triacylglycerol \\
tRNA & Transfer ribonucleic acid \\
UTR & Sntranslated region \\
\hline
\end{tabular}




\section{CHAPTER 1}

\section{LITERATURE REVIEW}

\section{BACKGROUND/SIGNIFICANCE}

\section{Significance}

Cardiovascular disease associated with heart disease and stroke account for nearly $40 \%$ of all deaths in the United States. According to the Center for Disease Control (CDC), "cardiovascular disease accounts for nearly one million deaths every year and more then 70 million Americans currently live with cardiovascular disease." [1] For the last five decades researchers have been characterizing the relationship between dietary fat and cardiovascular disease referred to as the "diet heart" hypothesis. The "diet heart" hypothesis has been a central tenet of strategies for risk reduction in individuals and populations. Individuals have been encouraged to decrease total dietary fat in their diet and conversely, increase their ratio of polyunsaturated fatty acids compared to saturated fatty acids within the diet. These recommendations have resulted in the production of new "low-fat" foods and have changed the way people think about fat in their diet. However, the molecular pathway by which fat alters intracellular metabolism is crucial to understanding the molecular basis of cardiovascular disease, obesity, diabetes, and atherosclerosis. Characterization of these pathways will lead to a better understanding of diet interaction and risk factors as well as improving strategies for the treatment of these diseases through drug intervention. Among the intracellular metabolic pathways affected are those genes involved in lipogenesis and genes involved in cholesterol 
metabolism. Characterization of these pathways affected by polyunsaturated fatty acids will help to elucidate the pathway in which polyunsaturated fatty acids decrease cardiovascular disease, obesity, diabetes, and atherosclerosis. Understanding the mode of interaction will also provide new insight into drug development and possible a better understanding of diet affects on cardiovascular disease. Therefore we have set out to determine the molecular mechanism of regulation of one of these lipogenic genes, glucose-6-phosphoate dehdyrogeanse (G6PD) by polyunsaturated fatty acids.

\section{Fatty Acid Metabolism}

Fatty acids synthesized de novo or absorbed in the diet are converted to fatty acyl-CoA thioesters by acyl-CoA synthetase [5]. Fatty acids converted to fatty acyl-CoAs are bound via fatty acyl-CoA binding proteins [6]. The final modification of fatty acyl-CoA is to incorporate those thioesters into various lipids, triglycerides, and phospholipids and/or further oxidize them into metabolites such as epoxy- or hydroxyl- fatty acids. Some of these downstream metabolites have direct effects on gene expression. For example, minor phospholipid components of cell membranes are the phosphatidylinositols, a class of phospholipids, which serve as substrates for phospholipase C. The products of phospholipase $\mathrm{C}$ yield inositol-triphosphate (IP3) and diacylglycerol, cell signaling molecules [7] . For example, IP3 and diacylglycerol are required for $\mathrm{Ca}^{+2}$ release from the endoplasmic reticulum. Another class of lipids used for neurotransmitters are the sphingomyelins and ceramide lipids [8].

An alternative of fatty acid metabolism is the oxidation of fatty acid-CoA molecules by the cyclooxygenase or lipoxygenase pathway [9]. Arachidonic acid, the main polyunsaturated fatty acid, is metabolized through the cyclooxygenase and lipoxygenase pathways to give rise to 
prostaglandins and thromboxanes, respectively. Prostaglandins and thromboxanes are autocrine and paracrine lipid mediators that affect platelet, endothelial, uterine and mast cells among others. In addition, prostaglandins and thromboxanes act locally through G-protein coupled receptors to activate intracellular $\mathrm{Ca}^{+2}$ and cAMP levels [10-12]. Therefore, changes in the overall concentration of these second messengers will lead to changes in the overall gene expression pattern of a multitude of cell signaling molecules.

The most important fate of fatty acids produced in the diet or by de novo synthesis is $\beta$ oxidation to produce energy. Fatty acid oxidation is essential for muscle activity and in times of energy deprivation like starvation or during times of illness. Fatty acid oxidation is essential for the production and generation of acetyl-CoA molecules during times of starvation. The $\beta$ oxidation of fatty acids requires the fatty acid to be modified by acyl-CoA synthetase to fatty acyl-coA thioesters [13]. The fatty acyl-CoA is transferred through the mitochondrial membrane via carnitine palmitoyltransferase I and II [14,15]. Fatty acyl-CoAs formed from the carnitine palmitoyltransferse II on the inner face of the mitochondrial are substrates for $\beta$-oxidation. The $\beta$-oxidation reactions proceeds step-wise through acyl-coA dehdyrogenase, enoyl-CoA hydratases, L-3-hydroxyacyl-CoA dehydrogenases, and finally thiolases which convert 3ketoacyl-CoA to acetyl-CoA and an acyl-CoA that reenters the fatty acid oxidation cycle [reviewed in [16]. Acetyl CoA's are eventually used to synthesize ketone bodies like $\beta$ hydroxybutyrate and acetoacetate, which are used as alternative fuel sources for extra hepatic organs, including the brain during times of starvation.

Fatty acid synthesis is essential during the fed state to store energy within the cell. In general, a diet high in polyunsaturated fatty acids decreases lipogenesis by repressing gene expression in the liver 
Table 1: The effect of polyunsaturated fatty acids on metabolic regulation. Modified from [17].

\begin{tabular}{|c|c|c|c|}
\hline Pathway gene & $\begin{array}{l}\text { Transcription } \\
\text { Regulation }\end{array}$ & $\begin{array}{l}\text { Genetic Effects of Poly- } \\
\text { Unsaturated Fatty Acids }\end{array}$ & References \\
\hline \multicolumn{4}{|l|}{ Lipogenesis } \\
\hline Stearoyl CoA desaturase 1 & YES & $\downarrow$ & {$[18]$} \\
\hline Sterol-regulatory element & & $\downarrow$ & \\
\hline binding protein & YES & & {$[19-22]$} \\
\hline Fatty acid synthase & YES & $\downarrow$ & {$[20,23]$} \\
\hline Acetyl CoA carboxylase & YES & $\downarrow$ & [24] \\
\hline Phosphoenol pyruvate & YES & $\downarrow$ & {$[25,26]$} \\
\hline \multicolumn{4}{|l|}{ Carboxykinase (adipose) } \\
\hline Spot 14 & YES & $\downarrow$ & {$[23]$} \\
\hline Glucose-6-Phosphate & NO & $\downarrow$ & {$[27,28]$} \\
\hline \multicolumn{4}{|l|}{ Dehdyrogenase } \\
\hline \multicolumn{4}{|l|}{ Fatty acid transport/metabolism } \\
\hline Acyl CoA synthetase & YES & 4 & {$[29]$} \\
\hline Fatty acid transport protein & YES & 4 & {$[30]$} \\
\hline \multicolumn{4}{|l|}{ Energy Utilization/fatty acid oxidation } \\
\hline Carnitine palmitoyl & YES & 4 & {$[31]$} \\
\hline Transferase-1 & & & \\
\hline Uncoupling protein 1 & YES & 4 & {$[32]$} \\
\hline Acyl CoA oxidase & YES & 4 & [33] \\
\hline \multicolumn{4}{|l|}{ Cholesterol metabolism } \\
\hline Cyp $7 \alpha$ hydroxylase & YES & $\downarrow$ & [34] \\
\hline HMG CoA synthase & YES & 4 & [35] \\
\hline ApoCIII & YES & $\downarrow$ & [36] \\
\hline TNF $\alpha$ & YES & $\downarrow$ & [37] \\
\hline
\end{tabular}

* Abbreviations: Apo, apolipoprotein, Cyp, cytochrome P; HMG, hydroxymethylglutaryl; HNF-4 $\alpha$, hepatocytes nuclear factor-4 alpha, TNF $\alpha$, tumor necrosis factor alpha 
[38]. Conversely, a diet rich in carbohydrates stimulates lipogenesis in both liver and adipose tissue, leading to elevated plasma triglyceride levels [38]. The inhibition of lipogenic genes in the liver by polyunsaturated fatty acids is a much stronger signal than insulin stimulation. Polyunsaturated fatty acid diets in rodents have been shown to inhibit expression of a variety of genes including those encoding G6PD, acetyl CoA carboxylase (ACC), fatty acid synthetase (FAS), stearoyl CoA desaturase 1 (SCD1), L-pyruvate kinase (L-PK), $\Delta-5$ and $\Delta-6$ desaturases in the liver, and insulin-sensitive glucose transporter (GLUT-4) in adipose tissue $[23,24,39,40,40-44]$. The regulation of SCD1, ACC and FAS by polyunsaturated fatty acids occurs at the level of transcription, whereas G6PD is controlled via a post-transcriptional regulatory mechanism [24,41]. Most lipogenic genes are inhibited by both $n-3$ and $n-6$ polyunsaturated fatty acid. An alternative hypothesis is that prostaglandins synthesized by polyunsaturated fatty acids inhibit lipogenic genes; however, the addition of prostaglandin inhibitors has limited or no effect on regulation of the lipogenic genes $[44,45]$.

\section{Fatty Acid Regulation of Gene Expression}

Polyunsaturated fatty acids are a key control device for fatty acid metabolism within the cell. Mostly polyunsaturated fatty acids affect gene expression through changes in the transcriptional rate of the genes of fatty acid transport, energy utilization, fatty acid oxidation, lipogenesis and cholesterol metabolism (Table 1). Polyunsaturated fatty acids can affect gene expression by multiple mechanisms but the best characterized are the transcriptional changes in gene expression. Currently, three different nuclear receptors have been characterized to regulate gene expression by polyunsaturated fatty acids. The first is the peroxisome proliferator-activated receptor (PPAR). The PPARs are a steroid hormone nuclear receptor family. The retinoic acid 
receptors (RAR), liver $\mathrm{X}$ receptor (LXR) and the ubiquitous retinoid $\mathrm{X}$ receptor (RXR) are members of the steroid hormone nuclear receptor family [46]. Multiple isoforms of PPAR exist and each isoform of the PPAR family can have different DNA binding sites and thus regulatory mechanisms to regulate gene expression [46]. Generally, PPAR is an enhancer of fatty acid transport, energy utilization and fatty acid oxidation genes.

The second main transcription factor is the sterol-regulatory element binding protein (SREBP). SREBP is a helix-loop-helix family of transcription factors originally identified to bind the sterol response element found in the genes of cholesterol metabolism [47,48]. Three main isoforms of SREBP have been isolated and characterized. The first isoform of SREBP is SREBP-1a, the activated isoform associated with glucose metabolism and insulin metabolism [47-49]. The second isoform is the SREBP-1c. SREBP-1c is produced from an alternative spliced mRNA that results in differences in the N-terminal region of these two proteins. The only difference is the 28 amino acids missing from SREBP-1c that are present in SREBP-1a and the four unique amino acids present in SREBP-1c. These differences result in differences in gene regulation. The third isoform is the SREBP-2 protein and it is the most important for cholesterol homeostasis $[47,48,50]$. The SREBP family of transcription factors is known to primarily affect lipid and cholesterol homeostasis.

The last transcriptional factor that regulates lipid metabolism is the hepatocyte nuclear factor $4 \alpha(\mathrm{HNF}-4 \alpha)$. The HNF- $4 \alpha$ gene is a highly conserved nuclear receptor that modulates hepatic functions such as cholesterol and lipoprotein secretion [36]. The expression pattern of HNF- $4 \alpha$ is limited to the liver, kidney, intestine, and the pancreas [36]. HNF-4 $\alpha$ is an important transcription factor regulated by polyunsaturated fatty acids, for example polyunsaturated fatty acids activate HNF-4 $\alpha$ through a protein kinase A pathway (Table 1). HNF-4 $\alpha$ is a known 
regulator of ApoCIII and Cyp7 $\alpha$ hydroxylase through transcriptional changes of ApoCIII and Cyp $7 \alpha$. HNF-4 $\alpha$ is an important transcription factor involved in glucose and lipid metabolism and as a consequence genetic knockouts of HNF-4 $\alpha$ result in diabetes [36].

\section{Transcriptional and Posttranscriptional Regulation of Lipogenic Genes}

The family of lipogenic enzymes includes G6PD, fatty acid synthase, acetyl-CoA carboxylase, stearoyl-CoA desaturase-1, S14, malic enzyme, tricarboxylate carrier and ATPcitrate lyase (Table 1). All lipogenic genes are coordinately regulated with the rate of fatty acid synthesis. Lipogenic enzymes are regulated predominantly in the liver by the nutritional status of the animal and G6PD is no exception. The starved state and/or consumption of a diet high in polyunsaturated fat will inhibit lipogenic genes; however, a diet high in carbohydrates will increase the activity of lipogenic genes. Inhibition of lipogenic genes by dietary fat is specific for polyunsaturated fatty acids such as arachidonic acid [3]; in addition, most lipogenic genes are not regulated by saturated fatty acids [reviewed in 51].

Regulation of the expression of most lipogenic proteins occurs at a transcriptional level [52,52-59]; however, G6PD is unique because its regulation occurs solely by nuclear posttranscriptional mechanisms $[27,28,60,61]$. Incidentally, the malic enzyme [62] and stearoylCoA desaturase $[63,64]$ are also regulated by changes in mRNA stability. The S14 mRNA is regulated by polyunsaturated fatty acids by a posttranscriptional mechanism, that appears to involve mRNA processing [65]. In addition the tricarboxylate (citrate) carrier has been shown to exhibit both transcriptional and posttranscriptional changes due to polyunsaturated fatty acids. Thus, this supports our contention that other genes may utilize a nuclear posttranscriptional gene regulatory mechanism similar to our model system of G6PD gene regulation. The absence of 
transcriptional regulation of G6PD makes it an ideal model for studying the nuclear events involved in regulating pre-mRNA processing by polyunsaturated fatty acids.

\section{Structure of the G6PD gene}

The G6PD gene spans $18.5 \mathrm{~kb}$ on the $\mathrm{X}$ chromosome (xq 28) and contains 13 exons and 12 introns [66,67]. The protein produced from the G6PD mRNA can either contain two or four subunits per molecule of active enzyme. The protein has an approximately molecular weight of $59 \mathrm{kDa}[68]$. The G6PD promoter is embedded in a $\mathrm{CpG}$ island that is conserved among mice, rats and humans $[66,67]$. The promoter of G6PD contains a TATA like element and numerous stimulatory protein 1 (Sp1) elements, but no CAAT element $[66,67,69,70]$. The translational start site of G6PD is located in exon 2 and has been mapped in mice, rats, and humans [66,7173]. The cDNA sequence is greater then $87 \%$ identical between mice (Mus musculus) and humans (Homo sapiens) and greater then 93\% identical between rats (Rattus norvegicus) and mice (Mus musculus). In addition, the number of exons and introns in conserved among species. There are three main unique characteristics about the G6PD gene. The first feature is the size of the second intron, $11 \mathrm{~kb}$, which accounts for over half the size of the gene. The second is the large size of exon 13, 811 nucleotides. The last is the larger than average length of the 3' untranslated region (3'UTR; $720 \mathrm{nt}$ ) 60].

\section{Cellular Role of G6PD}

Our studies of G6PD are the first to describe a nuclear posttranscriptional mechanism for the inhibition of gene expression by polyunsaturated fatty acids $[27,28,61]$. This posttranscriptional regulatory mechanism is the only known mechanism for regulation of G6PD 


\section{The Role of G6PD in the Cell}

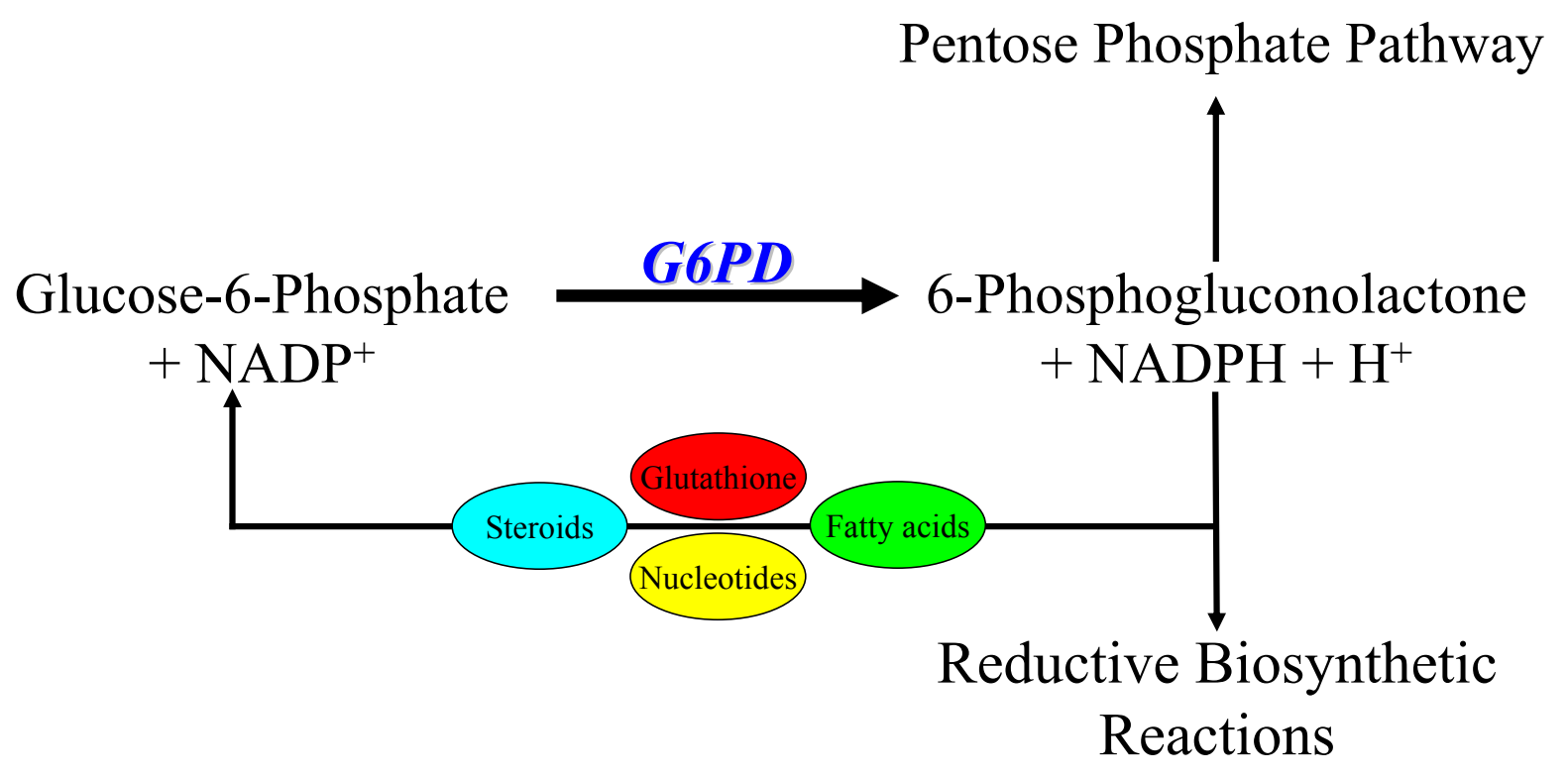

Figure 1: A chemical reaction diagram describing the fate of NADPH in the cell and the role that G6PD plays in the pentose-phosphate pathway. 
expression by nutritional factors. This posttranscriptional regulatory mechanism could possibly be shared throughout the entire lipogenic gene family, even those genes regulated by transcriptional regulation. This additional level of regulation would provide a more rapid response to environmental changes and would allow cells to contain multiple regulatory pathways to tightly control gene regulation. Glucose-6-phosphate dehydrogenase converts glucose-6-phosphate to 6-phosphogluconate in the first step of the pentose phosphate pathwaywhich is the rate-determining step in the pentose phosphate pathway (Figure 1). This reaction produces reduced nicotinamide adenine dinucleotide phosphate (NADPH), a source of reducing equivalents for biosynthetic reactions. Another molecule of NADPH is produced when 6-phosphogluconate is oxidized to ribulose-5-pohosphate by 6-phosphogluconate dehydrogenase. Both enzymatic steps are result in the production of 2 moles of NADPH during each cycle of the pentose phosphate pathway; NADPH is important for reductive biosynthetic reactions like fatty acid synthesis, cholesterol synthesis, and amino acid synthesis (Figure 1). Fatty acid synthesis requires NADPH for the $\beta$-ketoacyl-ACP reductase and the enoyl-ACP reductase reactions in the fatty acid synthesis pathway. The NADPH needed for fatty acid synthesis comes from both the pentose phosphate pathway and from the malic enzyme. In mammals, $50 \%$ of the NADPH for fatty acid biosynthesis is supplied from the pentose pathway and the additional $50 \%$ from the malic enzyme. In addition, NADPH is also required for the detoxification of free radicals and peroxides [74,75]. Specifically, NADPH produced by the G6PD reaction maintains reduced glutathione concentration within the cell. In addition to the production of NADPH, the pentose phosphate pathway produces ribose-5-phosphate. Ribose-5phosphate is an important precursor for both pyrimidine and purine nucleotide synthesis. In 
general, proliferating cells require an increase in G6PD activity for ribose-5-phosphate production and NADPH production.

G6PD provides $100 \%$ of the NADPH in mature erythrocytes, and in its absence, erythrocytes are at risk to reactive oxygen species. G6PD deficiencies are among the most common enzymatic deficiencies $[74,76]$. Mutations resulting in a decrease in the activity of G6PD result in chronic, drug and food induced hemolytic anemia in humans [77]. Symptomatic individuals have a risk of neonatal jaundice and acute hemolytic anemia, triggered by an infection or the ingestion of certain drugs or fava beans (favaism). Ingestion of primaquine, sulfonamides, sulfones, nitrofurantoin, vitamin $\mathrm{K}$ analogues and some anti-diabetic drugs can cause symptomatic individuals to have neonatal jaundice and acute hemolytic anemia. A rare but more severe form of G6PD deficiency is associated with chronic non-spherocytic hemolytic anemia [78]. G6PD deficiency is also associated with a lack of NADPH production in the liver thereby decreasing in lipogenic rate resulting in a decrease in serum lipoproteins levels in affected individuals [79].

\section{Hormonal Regulation of G6PD}

Hormones control the expression of all lipogenic genes and G6PD is no exception. For example, insulin increases the activity of G6PD in intact animals and in cultures of primary rat hepatocytes $[80,81]$. Rats treated with streptozotocin, which destroys the pancreatic $\beta$-cells, fail to induce G6PD activity upon refeeding a high carbohydrate diet confirming the requirement for insulin signaling [82]. In addition, diabetic rats show a decrease in G6PD levels; however, treatment with insulin induces G6PD activity in diabetic rats [83-85]. Glucagon and cAMP have 


\section{A Model of G6PD Regulation}

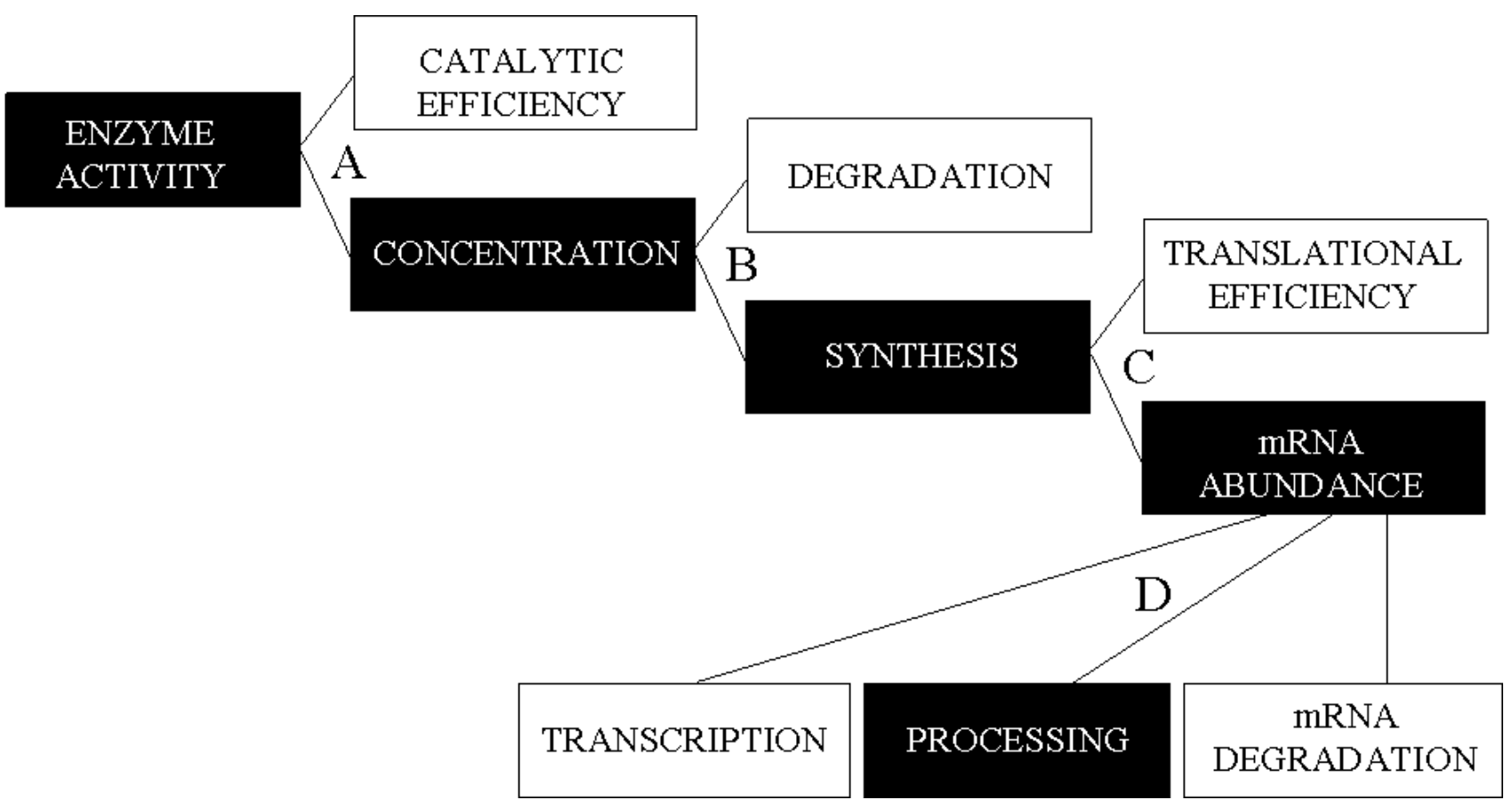

Figure 2: A model of G6PD regulation by polyunsaturated fatty acids occurs through a nuclear posttranscriptional mechanism. (A) The change in G6PD protein concentration changes in parallel to a change in enzyme activity. (B) Protein synthesis changes in parallel to changes in the protein concentration. (C) The net change in protein synthesis can be accounted for by a change in the mRNA abundance. (D) The change in mRNA abundance is regulated by a change in the processing efficiency of the G6PD pre-mRNA. 
the opposite effect compared to insulin because glucagon is a primary hormone of starvation and thereby decreases the activity of G6PD in starved animals [86].

Other hormones, such as, thyroid hormone (T3) and glucocorticoids regulate G6PD activity. Thyroidectomy decreases G6PD activity and treatment with T3 induces G6PD expression. However, the mechanism for this increase does not seem to involve changes in G6PD mRNA levels [86]. On the other hand, changes in G6PD levels are accompanied by a similar increase in enzyme synthesis and mRNA abundance [87]. In addition, adrenalectomy, removal of the adrenal glands, attenuates the increase seen in G6PD activity upon refeeding and addition of exogenous glucorticoids reverses this effect [reviewed in 88].

A similar G6PD regulation is observed in primary cultures of rat hepatocytes. The induction of G6PD activity and mRNA level in response to glucose and insulin in hepatocyte culture mimics the effect observed in intact animals $[28,80,81,89,90]$. Hepatocytes incubated with insulin induce G6PD activity 3-4 fold and this increase is accompanied by a parallel change in the rate of synthesis and mRNA abundance [91]. Glucocorticoids increase G6PD expression and the addition of glucocorticoids seems to have an additive effect on the insulin induced increase in G6PD expression [92]. However, T3 and glucagon alone do not change G6PD activity in cultured hepatocytes [81,93], suggesting that the effect of T3 and glucagon in the intact animals is an indirect or a compensatory effect.

\section{Regulation of G6PD}

G6PD is not only regulated by insulin and glucocorticoids but also by diet. The starved state and/or consumption of a diet high in polyunsaturated fat (6\% safflower oil) will inhibit G6PD activity [61]. In contrast, a diet that is high in carbohydrates or the refed state will 
increase the activity of G6PD. During the refeeding of a high carbohydrate diet following a $24 \mathrm{~h}$ starvation, G6PD activity increases above the level observed in the animal fed ad libitum resulting in a phenomenon termed enzyme "overshoot"; the molecular basis for this "overshoot" is not well understood $[94,95]$. The high carbohydrate diet consists of glucose or fructose and the greatest activation of G6PD activity is observed with fructose as compared to glucose alone $[96,97]$. The mechanism of action by which glucose increases G6PD activity could be a direct mechanism of action or indirect mechanism via a change in the redox state of the cell. The intracellular environment of the cell is much reduced and small changes in the redox state of the cell could potentially alter the cell environment. In turn these small changes in redox state of the cell could affect G6PD expression by indirect mechanisms of action. [96,97]. A diet containing a high ratio of polyunsaturated fat inhibits G6PD activity $[98,99]$. However, saturated fatty acids like palmitate (16:0) and stearate (18:0) do not regulate G6PD activity, similar to all lipogenic enzymes. The addition of polyunsaturated fatty acids seems to inhibit G6PD activity through a direct mechanism and not by an indirect mechanism of an essential fatty acid deficiency, or by a decrease carbohydrate intake $[98,99]$. This inhibition of G6PD by polyunsaturated fatty acids is only exclusively observed in the liver and adipose tissue $[98,99]$.

\section{Nutritional Regulation of G6PD Expression}

The effect of nutrients on the activity, the amount of protein, the rate of synthesis and the degradation of G6PD has been widely studied. Using antibodies against the G6PD protein and liver supernatants from rats that were fed a high-carbohydrate diet, the diet-induced increase in G6PD enzyme activity was shown to parallel the increase in amount of G6PD protein $[100,101]$ (Figure 2, step A). When examined over a variety of nutritional and hormonal conditions in both 
liver and adipose tissue, changes in G6PD activity could be accounted for by changes in the rate of enzyme synthesis [84,86,87,100-104] (Figure 2, step B). For instance, a 13-fold increase was observed in both the relative rate of synthesis for G6PD and the G6PD enzyme activity in the liver of rats switched from a chow to a high-sucrose diet $[87,105]$. In addition, the rate of enzyme degradation is also altered by diet; consumption of a high-fat diet decreases the half-life of the enzyme from $16 \mathrm{~h}$ to $6 \mathrm{~h}$ [100]. These changes in enzyme protein turnover will enhance the rate at which the cell can alter the amount of G6PD activity. Changes observed in the rate of G6PD protein synthesis due to nutritional or hormonal factors are accompanied by similar changes in the amount of mature mRNA $[27,28,87,92,95,106]$ (Figure 2, step C). These changes have been observed during regulation by dietary carbohydrate [87,107], fasting and refeeding $[95,106]$, dietary polyunsaturated fat $[28,108]$ and hyperthyroidism $[87,107]$ and in rat hepatocytes in primary culture in response to insulin $[28,91,92]$, glucocorticoids [91,92], and polyunsaturated fatty acids [61]. These results are consistent with regulation occurring at a pretranslational step (Figure 2, step D).

During starvation and refeeding, the accumulation of G6PD mRNA in mice occurs after a lag of $12 \mathrm{~h}$ before a two-fold increase is observed [28]. The maximal increase of 27-30 fold is observed after $24 \mathrm{~h}$ of refeeding. In contrast, the effect of dietary polyunsaturated fatty acids is very rapid. Within $4 \mathrm{~h}$ of consumption of a high-fat meal a $20 \%$ decrease is observed in G6PD mRNA amount. The maximal decrease of $80 \%$ is observed at $8 \mathrm{~h}$ [28]. A similar time course is observed in primary rat hepatocytes incubated with and without arachidonic acid [28]. This lag in accumulation of G6PD mRNA during refeeding is consistent with a requirement for the synthesis of an intermediary protein involved in the induction. A change in mRNA amount can be due to several factors including transcriptional regulation, processing efficiency of the mRNA 
or degradation of the mRNA. Processing efficiency can be regulated by three separate but simultaneous events like splicing, polyadenylation, or mRNA capping.

The transcriptional activity of the G6PD gene was measured using nuclear run-on assays [27]. The rate of G6PD transcription is not regulated by starvation, refeeding a high carbohydrate diet, or by the inclusion of polyunsaturated fat in the diet [28]. Similar results were obtained for G6PD regulation by insulin, glucose and arachidonic acid in rat hepatocytes in primary culture [61]. Furthermore, the transcriptional activity of the G6PD gene occurs at a very low rate compared to constitutively expressed genes, such as $\beta$-actin and GAPDH [27]. The rate of G6PD transcription is as low as the transcriptional rate of the FAS or stearoyl-CoA desaturase genes measured during starvation. Upon refeeding, G6PD gene transcription remained at the same low level despite the 27 - to 30- fold increases in G6PD mRNA accumulation [28]. Similarly, transcription of the gene remains unchanged in mice fed a high-fat diet ( $6 \%$ safflower oil) despite an $80 \%$ decrease in mRNA accumulation [27]. The nuclear run-on assays employed several controls including probes for both the 5' and 3' ends of the gene, as well as, single stranded probes that would only hybridize to G6PD RNA and not to transcripts produced from the opposite strand. All probes were free of repetitive elements that could increase the background hybridization. Together, these results indicate that regulation of G6PD gene expression by nutritional and hormonal factors occurs at a posttranscriptional step [28] (Figure 2D). Posttranscriptional gene regulation can occur at four steps: the addition of the 7' methylguanosine cap, the formation of the poly (A) tail, splicing, and the export of the mature mRNA through the nuclear pore complex. 


\section{$\underline{\text { RNA Processing }}$}

\section{The 7-methyl-guanosine cap}

Posttranscriptional regulation can occur at many different steps. RNA polymerase II facilitates the recruitment of processing factors through the C-terminal domain (CTD) [reviewed in 109]. The CTD provides a scaffold for protein-protein interaction whereby processing proteins assemble on the transcription apparatus. The CTD contains a tandem heptad repeat of YSPTSPS throughout the CTD domain [110]. The fifth serine is phosphorylated by the TFIIH associated kinase and creates a scaffold domain whereby proteins assemble on the CTD domain of RNA polymerase II $[111,112]$. The three characterized binding domains are the CTD interacting domain [113], the WW domain [114], and the FF domain [115]. Coincident with transcription of the DNA into RNA the 5'cap is being placed on the message. The first proteins that assemble on the CTD of RNA polymerase II after transcription are the three capping proteins, RNA triphosphtase, guanylyl transferase, and the 7-methyltransferase [116,117]. The 5' cap is a 7 methyl-guanosine structure that is added after transcription proceeds about 20-30 nt downstream of the transcriptional start site $[118,119]$. The function of the cap is to prevent 5 , exonucleases from degrading the message [120]. The cap-binding complex (CBC) binds to the 7-methyl-guanosine cap and stabilizes the message by both protecting the cap from decapping enzymes 


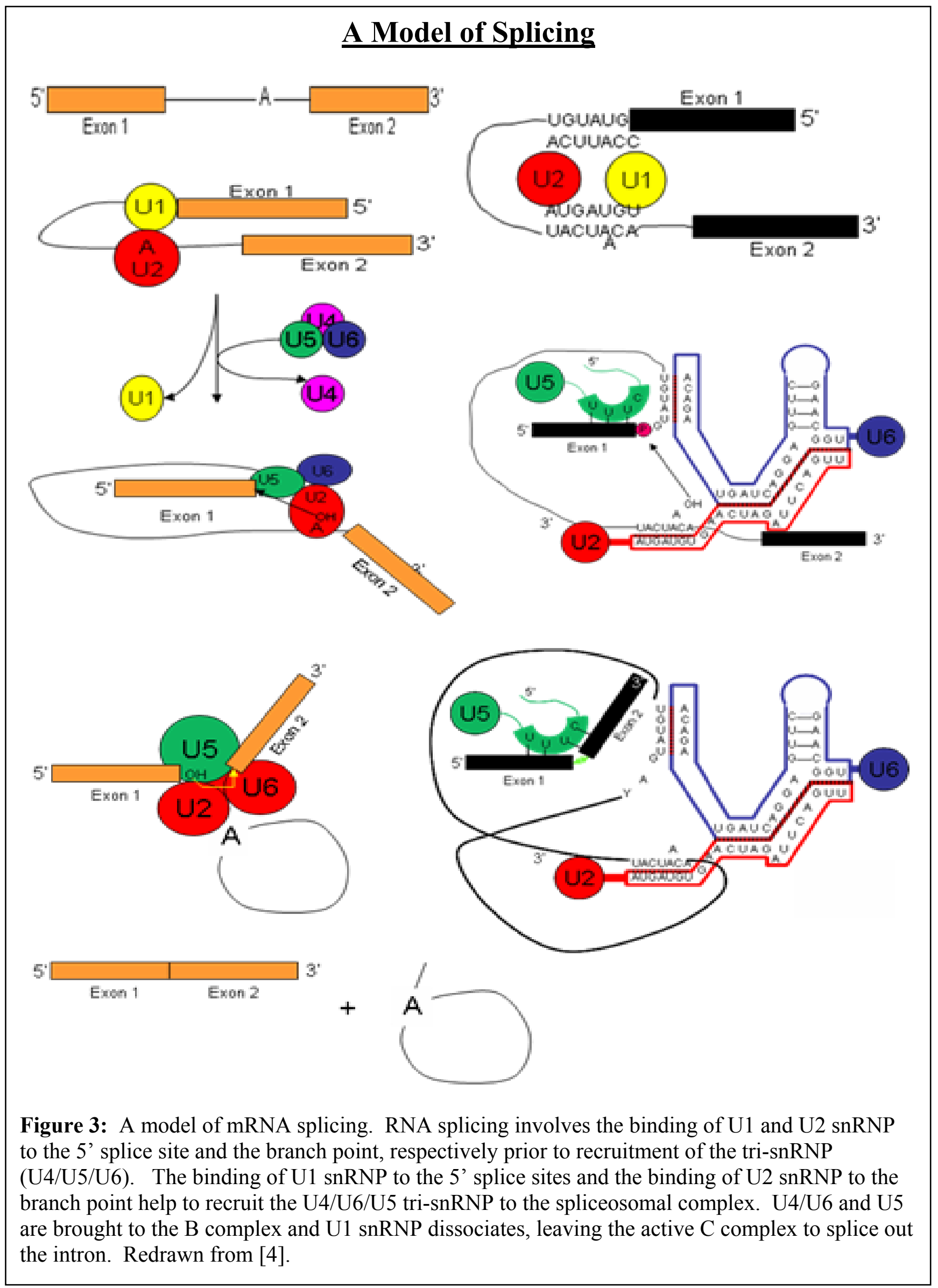




\section{Exonic Splicing Enhancer and Silencer Sequences}

A. Recruiting function: RS-domain dependent

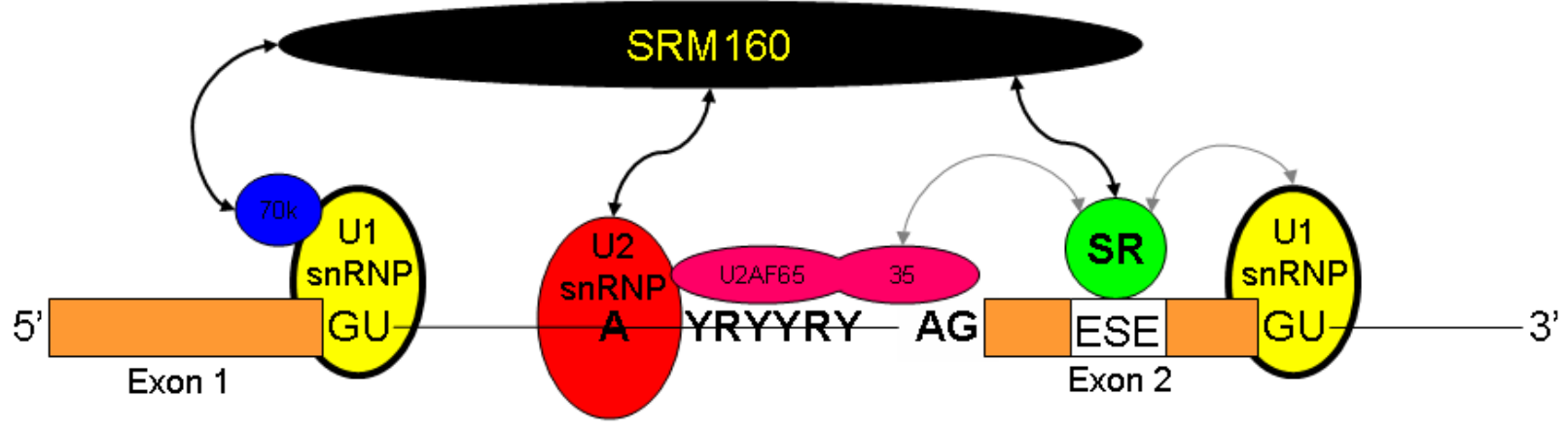

B. Antagonist function: RS domain indepedent

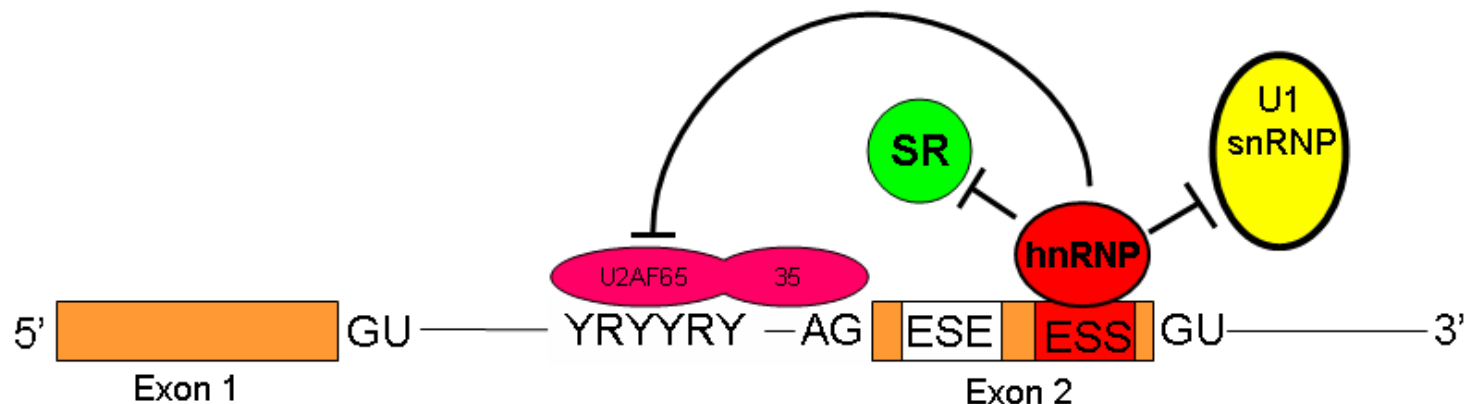

Figure 4: A diagram representing protein binding to exonic splicing enhancer sequences (ESE) within an exon. (A) The protein binding of an SR protein (Serine/Arginine protein) is known to bind to ESE's and recruit U1snRNP and U2AF35 as well as splicing coactivators like SRM-160. (B) The binding of hnRNP proteins to ESS sequences inhibits the recruitment of the U1 snRNP and the U2AF65/35 to the 5' splice site and the 3' splice site, respectively. Redrawn from [2]. 
and by binding to the poly (A) tail. Regulating the 5 ' cap could regulate gene expression; however, the addition of the cap occurs within the first 20 to 30 nucleotides thus regulation of the capping would result in degradation of the message very early in the transcription stage of the formation of the RNA. For example, the CBC was shown to be activated by heregulin in HeLa cells by nerve growth factor in PC12 cells, during the G1/S phase of the cell cycle and when cells are stressed with UV irradiation [121]. In addition, the CBC is a known nuclear target for growth factor-coupled signal transduction and has provided a new mechanism for the regulation of capping.

\section{The poly (A) tail}

The second possible step for posttranscriptional regulation would be the poly (A) tail. The length of the poly (A) tail is important for preventing degradation of mRNA transcripts, which can occur by shortening of the poly (A)-tail via exonuclease and subsequent loss of interaction between the poly (A) tail binding proteins and the $\mathrm{CBC}$ [reviewed in [122]. After the poly (A) tail is shortened in length, the cap is removed, and then 5' -3 ' exonucleases are able to degrade the mRNA. Degradation of the mRNA is an important regulator of mRNA half-life. The poly (A) tail is added to the 3' end of the message to prevent 3' to 5' exonucleases from degrading the message. The addition of a poly (A) tail involves endonucleolytic cleavage of the 3 ' terminal noncoding fragment and then polymerization reviewed in [122]. Higher eukaryotes use either of two signals for polyadenylation; one is the sequence of AAUAAA or AUUAAA. Either sequence is found about $30 \mathrm{nt}$ upstream of the cleavage site. The other poly (A) site is a $\mathrm{U}$ or a GU- rich region located 3' of the cleavage site [122]. The mRNA sequence is first cleaved 20-30 nucleotides downstream of a conserved poly (A) site, [reviewed in 109]. Cleavage of mRNA involves several cleavage/polyadenylation factors (CstF, CPSF, CFIm, and CFIIm) for 
cleavage and polyadenylation, [reviewed in [109]. The second chemical reaction is the addition of the poly (A) tail at the free 3' hydroxyl group by poly (A) polymerase, [reviewed in 123]. The RNA downstream of the cleavage site is still attached to the RNA polymerase and recent studies have shown the binding of Xm2 to the ${ }^{3}$ ' region of this RNA and hypothesized that $\mathrm{Xm} 2$ is essential for degradation of RNA downstream of the cleavage site and mRNA release from the polymerase $[124,125]$.

The poly (A) tail has multiple functions including increasing the efficiency of splicing of pre-mRNA, transport of mRNA to the cytoplasm increasing translational efficiency, and cytoplasmic mRNA stability. A message with a long poly (A) tail has a longer half-life than a mRNA with a short poly (A) tail [126]. Two ideas have suggested that the poly (A) tail protects the mRNA from degradation. First, the shortening of the poly (A) tail is the initial step in degradation of the mRNA. Second, the poly (A) tail binds many proteins that protect it from degradation, such as the poly (A) binding protein described above [127]. Regulation of the poly (A) tail occurs through the length of the poly (A) tail. A message with a long poly (A) tail has a longer half-life than a mRNA with a short poly (A) tail [126]. First, alternative polyadenylation/cleavage signals could be used to change in the length of the 3' untranslated region included in the mRNA. Second, the length of the poly (A) tail can vary from a few nucleotides to as many as several hundred nucleotides. The third possibility is that the same polyadenylation signal is used, but the site of cleavage downstream of the poly (A) site changes as in the thyroglobulin pre-mRNA [128]. Moreover, hormonal stimuli regulate the polyadenylation and cleavage site selection and thereby indirectly regulate the length of the poly (A) tail [128]. 


\section{Mechanisms for Splicing}

Eukaryotes have a unique structure to their genes called introns, non-coding sequences with many stop codons and highly repetitive sequences that are removed by intron splicing events in the nucleus. These introns must be properly spliced before the message can be transported out of the nucleus [reviewed in [129]. Splicing involves five small nuclear ribonucleoproteins (snRNPs) U1, U2, U4/U6 and U5 and numerous splicing co-activators (>100) now known to be essential regulators of both constitutive and alternative splicing (Fig. 3). Splicing factors are rapidly recruited to nascent transcripts and thus many introns are removed co-transcriptionally, while others are marked by splicing factors and eventually removed posttranscriptionally [130]. Currently, two different scenarios suggest that splicing factors are brought to the transcription machinery by the CTD of RNA polymerase II (cf. U1snRNP) [131] or the that snRNPs are recruited to the RNA through protein-protein interaction independent of the CTD of RNA polymerase II, cf. [132].

Spliceosome assembly requires a series of interactions prior to the actual spliceosome assemble. The components that are recruited to the intron are snRNP, which are composed of a single uridine-rich small nuclear RNA (snRNA) and multiple other proteins. The U1 snRNP binds the 5 ' splice site, and the U2 snRNP binds the branch site via RNA: RNA interactions between the snRNA and the pre-mRNA (Figure 3). The U1 and U2 snRNP help to recruit other proteins to the spliceosome including the tri-snRNP U4/U6/U5 snRNP, referred to as the catalytic component of the spliceosome (Figure 3). The final assembly of the spliceosome requires other proteins whose functions are unknown. 


\section{$\underline{\text { Serine-Arginine Rich Proteins }}$}

The current theory about SR proteins is that they act as splicing co-activators and can be highly regulated through their phosphorylation state. SR proteins are characterized by an RNA recognition motif and an SR rich domain $[133,134]$. SR protein(s) bind to an exonic sequence and help to directly or indirectly recruit components of the spliceosome to the exon [133-138] (Figure 4). SR protein binding is essential for splicing of mRNAs with weak consensus sequences $\left(5^{\prime}, 3^{\prime}\right.$, branch point, and the polypyrimidine tract). The phosphorylation state of the SR domain determines the activity of the SR protein. For example, when the SR domain is phosphorylated the protein becomes active; altering nuclear compartmentalization within the nucleus. Unphosphorylated SR proteins are predominantly found within speckles within the nucleus and during phosphorylation they migrate to sites of active transcription [139-142]. SR proteins can bind to sequences in the exons of the pre-mRNA and aid in the recruitment of snRNPs to the splice sites [143] (Figure 4). An additional form of regulation is achieved in alternatively spliced mRNAs by regulating SR protein binding [144].

\section{Exon Definition}

The splicing reaction itself has been well characterized, however much less is known about how splice sites are appropriately paired. RNA sequences must be properly recognized by RNA binding proteins and therefore the current hypothesis is that recognition occurs through exon definition. The 'exon definition model' applies in most cases, but may not be an absolute in all splicing events in higher eukaryotes [145]. Sequences around the splice junctions- $5^{\prime}$ and $3^{\prime}$ splice sites (5' ss and 3' ss) are clearly important for splice site recognition. However, these signals appear to contain only about half of the information required for exon and intron recognition in human transcripts [146]. The sequence or structural context in the vicinity of the 
5' ss and 3' ss motifs is known to play an important role in splice site recognition [147-149].

Additional support for the exon definition model is found through the discovery of exonic enhancer sequences that help to define an exon [145]. The SR proteins are known to bind these exon splicing enhancer sites [150]. In addition to binding exon sequences via their RNA binding domains, the SR proteins also create protein-protein binding via their SR domains with U2AF 35/65 and U1 snRNPs bound to the 5' splice site [151-154]. Such recognition makes the SR proteins ideal candidates for an exon-bridge complex that helps to define exon splice sites and also helps in the recruitment of the spliceosomal complex. Therefore, the exon splicing enhancer sequence serves as a control point for constitutive and alternative splicing events.

\section{Exon Splicing Enhancers}

In recent years considerable knowledge has been accumulating on cis-acting elements as well as on the trans-acting factors that bind them, however little is known about the mechanisms of splicing regulation [155]. Most mammalian RNA introns are suboptimal, lacking conserved consensus sequences within splice sites; therefore enhancer sequences are required for splicing. The lack of strong consensus sequences within the 5', 3' splice sites, the branch point and the polypyrimidine tract would lead to inefficient splicing of those exons flanking that intron. The polyprimidine tract is located between a branch site and a 3' splice site (AG) dinucleotide in mammalian RNA introns; a weak polyprimidine tract contains lots of purines and therefore has a low binding affinity for the U2AF splicing factor, which is essential for proper splicing. The two main classes of exon splicing enhancers are the purine rich ESEs and the non-purine rich ESEs. The purine rich ESEs are usually located downstream of a weak 3' splice site [156-159]. The purine-rich ESEs found in mammalian exons consist of a core motif of alternating A's and G's, 
generally 6 nucleotides and longer, however an A-repeat or a G-repeat does not function as an ESE [156-159].

The second class of ESEs is the non-purine-rich ESE. The AC-rich enhancers were first identified by in vivo selection. AC-rich ESEs have been shown to be involved in the regulated splicing of both viral and cellular genes. For example, recent studies have shown the protein binding of the Y box protein (YB-1) to an AC-rich ESE to stimulate the splicing of the CD44 exon [160]. In addition, exonic pyrimidine-rich enhancers have been found in $\beta$-globin RNA [161] and other mammalian RNAs [162,163].

\section{Exon Splicing Silencers}

The identification of exon splicing silencers was a novel discovery made through the characterization of exon splicing enhancer sequences [150,164-166]. An ESS sequence binds specific proteins that inhibit the binding of U2AF65/35 to a weak 3' splice site, thus inhibiting splicing. ESS sequences are often found connected with ESEs, but can also function upstream of an ESE $[150,163,167]$. The proteins most commonly associated with ESSs are the hnRNP A/B, hnRNP I (PTB), hnRNP K and the hnRNP H protein. These proteins are known to repress splicing of many exons by binding to UAGG, UCUC, C-rich patches, and poly G motifs, respectively. These proteins are presumed to function through blocking the earliest steps of the spliceosome assembly complex [168-170].

\section{Intron Splicing Enhancer and Silencer elements}

Intron elements exist as binding sites for regulatory proteins to stimulate or inhibit exon definition. The intron elements are located within introns and act very similar to ESS or ESE's. Intronic splicing enhancers (ISE) and intronic splicing silencers (ISS) are often found in both 
constitutive and alternative spliced mRNAs [171]. Most ISE/ISS sequences are found surrounded by alternatively spliced exons $[172,173]$. The function of these ISE/ISS elements is to bind accessory proteins to facilitate or prevent splicing at nearby splice sites, respectively. Additional information was achieved through structural analysis of intronic regions surrounding those alternatively spliced exons. The elements are less well characterized then most ESE/ESS but recent information on the alternative splicing of the fibroblast growth factor receptor-2 (FGFR2) has identified multiple ISE and ISS elements within introns flanking both exons IIIb and IIIc $[174,175]$. Both of these exons in the fibroblast growth factor receptor-2 are alternatively spliced exons. The regulation of exon IIIb and IIIc splicing is dependent on those proteins bound to the ISE/ISS within fibroblast growth factor receptor-2 mRNA [174,175].

\section{The family of hnRNP proteins}

Heterogeneous nuclear ribonucleoproteins (hnRNPs) are reported to be involved in multiple aspects of mRNA metabolism [176]. HnRNPs belong to a large family of RNA binding proteins that are found primarily within the nucleus [177]. However, some hnRNPs are also involved in nucleo-cytoplasmic shuttling [177]. The movement of hnRNPs between the nucleus and the cytoplasm could be a form of regulation within the hnRNP family of proteins. HnRNPs were originally thought to be non-specific proteins that bound to RNA and DNA irrelevant of sequence specificity. However, hnRNPs have been found to regulate both constitutive and alternative splicing events. For example, hnRNP L and E2/E1, two members of the hnRNP family have been shown to regulate the alternative splicing of CD45, a gene involved in T-cell maturation [170]. 
The oldest discovered RNA-binding factor, hnRNP K, is involved in a multitude of processes including transcriptional control of gene expression, mRNA processing, as well as translational control mechanisms [178-181]. The mode of interaction with RNA seems to lie within its KH domain as a site for nucleotide binding [178]. The hnRNP K protein contains three $\mathrm{K}$ homology domains $(\mathrm{KH})$ that mediate RNA binding through C-rich patches within the RNA sequence [182-184]. The unique feature of hnRNP K is its ability to become phosphorylated in response to insulin, Erk, protein kinase C $\delta$, as well as other factors [185-187]. As such, hnRNP K has the potential to sense and integrate signals from multiple kinase cascades and to generate output targeting factors that regulate nucleic acid-dependent processes [186].

The hnRNP L protein was first discovered as a abundant nuclear protein associated with lampbrush chromosomes [188]. Traditionally, it was thought that hnRNP L served as a more global regulator of translation, and mRNA stability and was not thought to play a role in mRNA splicing. For example, hnRNP L was shown to regulate the translation of the internal ribosomal entry site within hepatitis C virus [189]. HnRNP L was shown to affect mRNA stability of the vascular endothelial growth factor and the glucose transporter 1, specifically [190,191]. Recently, hnRNP L was shown to induce the splicing of the nitric oxide synthase pre-mRNA and conversely to inhibit the alternative splicing of the human CD45 mRNA [170,192,193]. Although the mechanisms by which hnRNP L affects splicing have yet to be elucidated, the ability of hnRNP L to regulate constitutive and alternative splicing shows the functional diversity of hnRNP L.

The most abundant hnRNPs belong to a family of $\mathrm{A} / \mathrm{B}$ proteins. These two family members are composed of multiple and unique isoforms. The family of A/B proteins is composed of four main proteins referred to as hnRNP A1/A1B, A2/B1, B2 and A3. The hnRNP 
A/B family includes paralogous which means that these proteins are derived from two different genes on different chromosomes. The paralogs within the $\mathrm{A} / \mathrm{B}$ family consist of $\mathrm{A} 0, \mathrm{~A} 1, \mathrm{~A} 2$, and $\mathrm{A} 3$ and three of these forms have multiple isoforms, for example hnRNP A2. The protein HnRNP A2 is an isoform of hnRNP B1 created through alternative splicing [194]. The hnRNP A2 gene is located on chromosome $7 \mathrm{p} 15$ and contains 12 exons of which exon 2 is alternatively spliced to give rise to hnRNP B1 protein. The only sequence difference in B1 and A2 is a 12 amino acid insertion at amino acids 3-14 [195]. In addition the two proteins, A2 and B1 are both highly similar to the hnRNP A1 family member $[195,196]$. The great diversity within the hnRNP A/B family members yet each protein is very similar to other members of the same family provides flexibility in the regulation of gene expression.

The hnRNP A1 protein has been the most studied member of the hnRNP A/B family. For example, the appropriate binding site of hnRNP A1 has been shown by systematic evolution of ligands by exponential enrichment (SELEX) and was identified as UAGGGA/U [176]. HnRNP A1 not only can bind to mRNA via a UAGGG sequence but can also facilitate as a protein scaffold to recruit other proteins to the ESS sequence forming a large macromolecule complex called the hnRNP complex [155].

Another hnRNP family member is hnRNP I, also known as polyprimidine tract binding protein (PTB). HnRNP I has been projected to be a comprehensive inhibitor of weak or regulated exon splicing [197]. HnRNP I binds to a UCUU sequence separated one or more pyrimidines $[198,199]$. The regulation of hnRNP I and the diversity hnRNP I is difficult to fully elucidate because hnRNP I can act not only as a silencer protein but can also act as an enhancer [200-202]. Moreover, Wagner and Garcia Blanco have suggested that hnRNP I acts as a general 
repressor of all weak exons, including those pseudoexons, and could play a role in constitutive splicing [197].

The hnRNP H family includes the hnRNP F, H, H', and 2H9 proteins [203]. HnRNP H has been shown to act as both a splicing repressor and activator. For example, hnRNP H can promote the inclusion of the c-src exon N1 in neuronal cells by binding to an ISE [204]. Conversely, the hnRNP $\mathrm{H}$ acts as a powerful splicing repressor in the rat $\beta$-tropomyosin ( $\beta$-TM) gene by binding to the UGUGGG motif and causing exon 7 skipping in nonmuscle cells [205]. Identification and characterization of new members of the hnRNP family members increases the complexity of the information we already have on the members of the hnRNP family members. For example, current evidence about the hnRNP H family suggest they can act as both a repressor of exon inclusion and an activator of exon inclusion depending on sequence specific binding within exons or introns.

The last main class of hnRNP proteins is the hnRNP G members which are unique to the hnRNP family. HnRNP G is encoded by two genes located on the Y chromosome and is only expressed in the germline cells of the testis [206]. In addition to the role hnRNP G protein plays in splicing regulation of two mutually exclusive exons in the $\alpha$-tropomyosin 3 gene, hnRNP G has been shown to promote skipping of the skeletal muscle (SK)-specific exon and to enhance inclusion of the nonmuscle (NM) exon [207]. The family of hnRNP family members is not exclusive to those discussed in this review but currently there are approximately 27 members of the hnRNP family ranging from hnRNP A to $\mathrm{Z}$ family members. However, hnRNP family members are a functionally diverse class of proteins that seem to be involved in different processes like replication, transcription, and translation as well as RNA transport and therefore at 
this present time the hnRNP A, B, F, G, H, I, L, K are the best documented and characterized proteins involved in regulated mRNA splicing.

\section{$\underline{\text { Regulation of RNA splicing by Exon Splicing Enhancers and Silencers }}$}

The regulation of constitutive and alternative splicing is controlled through trans-acting factors associated to exon splicing enhancers or silencers. Currently, there are two models of how these cis-acting sequences control splicing. First, an ESE-dependent RNA splicing mechanism is thought to regulate mRNA splicing by regulating the binding of SR proteins to an ESE site. The SR protein recruits U2AF-35 and U2AF-65 via its SR domain. In this model the U2AF-35 serves as a bridge complex between the SR protein and U2AF65 [208,209]. The second published model is an ESE competition model. Here the ESE sites compete with the ESS site for protein binding partners [210]. For example, the HIV-1 tat exon 2 contains two protein binding sites for SC35 and hnRNP A/B proteins (hnRNP A1 \& A2; [211]. The binding of the SC35 protein to the SC35 binding site overlaps the proximal binding site for hnRNP A1 [211]. Therefore, the regulation of hnRNP A/B binding and SC35 protein binding in turn regulate each other through juxtaposed binding sites. In this model the ESE site competes for protein binding with the ESS site and depending on the composition of proteins bound to the ESE or ESS the splicing is enhanced or silenced, respectively. This model is further supported by ESS deletions within a spliceable construct that activates splicing even in the absence of an ESE binding protein. [150].

In constitutive splicing, SR proteins have been proposed to promote cross-talk between neighboring exons by promoting the recruitment of snRNPs activating the spliceosome [154]. As far as alternative splicing is concerned, SR proteins have been shown to bind ESEs and enhance the splicing of adjacent introns [212,213]. Consequently, SR proteins can also serve as 
silencer proteins as in the case of CD45, where inclusion of three alternative exons (A, B and C) is regulated upon T cell activation and is dependent on SR protein interaction with an ESS $[212,213]$. However, most SR proteins bind ESE sites and assist the binding of U2AF35 and thus increase splicing efficiency of the constitutive or alternative spliced exon [135,161,214]. The regulation of splicing involves a multitude of pathways but the best characterized is the through activation of SR proteins. For example, insulin stimulates SR protein phosphorylation and thus increases the alternative splicing of protein kinase $\mathrm{C}$, a downstream target of insulin signaling [215-217]. All of these events serve to regulate alternative and constitutive splicing as is the case for thymidylate synthase. Thymidylate synthase is regulated during the cell cycle by changes in the rate of splicing of one intron [218]. Another example of constitutive splicing regulation is G6PD which seems to be regulated by polyunsaturated fatty acid by the splicing of intron 11 or 12 [3].

\section{$\underline{R N A \text { quality-control mechanisms }}$}

Eukaryotic cells exhibit quality-control mechanisms that recognize and degrade mRNA that have not completed nuclear pre-mRNA processing or that fail to encode an accurate polypeptide to the gene sequence [219]. Such aberrant mRNAs are degraded rapidly, presumably before the accumulation of deviant protein products that could have adverse effects on the cell. MRNAs that contain premature termination codons are degraded within the cell by nonsense mediated decay (NMD) [219]. Nonsense mediated decay can occur at two sites within the cell. The first site of degradation is presumed to occur within the nucleus at the site of transcription $[220,221]$. The second site of degradation occurs within the cytoplasm after the ribosomes bind to the mRNA to be translated and requires three main proteins, Upf 1, 2, and 3 [222-224]. However, the recognition of an mRNA as a nonsense-containing mRNA can affect 
splicing, abundance of the nuclear mRNA pool, and retention of transcripts at the site of transcription [225]. Understanding these issues should define the pathways of NMD in the cell and reveal a novel aspect of mRNA biology in eukaryotic cells.

\section{The Molecular Pathway of Nonsense Mediated Decay}

RNA that is incompletely spliced or processed is degraded within the nucleus $[220,221,226]$. Degradation within the nucleus can occur by multiple mechanisms including the NMD pathway and the nuclear exosome pathway. Nonsense mediated decay has been shown to occur in yeast (S. cerevisiae) [227-229] and higher eukaryotes [223].

Deficiency in the NMD pathway can lead to alterations in the genome and eventually disease, for example $\beta$-thalassemia, which is a heritable anemia due to a nonsense mutation within the $\beta$-globin gene [230]. The recognition of a nonsense codon takes place by a surveillance system during translation of the $\beta$-globin mRNA. The NMD pathway in higher eukaryotic organisms involves a similar mechanism as in yeast. Nonsense-mediated decay is initiated by the removal of the 7-methyl cap, and 5' $\rightarrow$ 3' decay of the mRNA by exonucleases [reviewed in [223].

The major importance of a cell based surveillance system is to prevent aberrant or truncated proteins from being produced that would have a deleterious effect [231-233]. For example, the NMD pathway is essential to maintain the genetic code and a few examples where mutations within genes cause NMD are the human triose phosphate isomerase [234,235], the hamster dihydrofolate reductase, and T-cell receptor $\beta$-transcript [236,237].

Incomplete splicing of RNA sequences results in degradation of RNA by the NMD pathway. A requirement for recognition of the NMD pathway is the presence of at least one intron downstream of the nonsense codon [238]. It has been proposed that splicing of the 3' 
most intron from the human triose phosphate isomerase gene pre-mRNA "marks" the 3' most exon-exon junction of the mRNA product so that only nonsense codons located more than 50-55 nucleotide upstream of the "mark" can mediate mRNA decay [238]

Despite the evidence that NMD involves the translation machinery, most premature termination codons (PTC) containing mRNAs in metazoans are eliminated prior to their release from the nucleus [reviewed in $[223,233]$. Models put forward to explain how NMD could influence mRNA levels in the nuclear fraction of the cell include: (1) cotranslational export and (2) nuclear scanning. Both of these models depend on the existence of a "mark." The cotranslational export model contends that cytoplasmic ribosomes can trigger NMD before a PTC mRNA has completely transversed the nuclear pore; therefore, lower PTC levels are detected in the nuclear fraction even though NMD is technically occurring in the cytoplasm [reviewed in [129]. In contrast, the nuclear-scanning model necessitates the existence of a nuclear frame reader, possibly nuclear ribosomes, which is contrary to the widely accepted belief that only the cytoplasmic translation machinery is capable of detecting and responding to an ORF [reviewed in [129]

Recent observations by fluorescent in situ hybridization have concluded quantitatively and qualitatively that mRNA that has a premature reading frame termination accumulates at the site of transcription. TCR- $\beta$ gene constructs containing premature termination codons were shown to accumulate near the site of transcription $[129,239]$. Therefore, two possibilities have been proposed to answer the question of what are the components of the nonsense mediated decay pathway. The first possibility is through the recognition by translation machinery in the nucleus. The possibility of nuclear translation has been rekindled by the discovery of charged tRNAs and translation initiation factors in the nucleus [240]. Furthermore, nuclear ribosomes 
actively undergoing translation have been identified [241]. Additional evidence that NMD involves translation machinery includes its requirement for the initiator AUG in a transcript undergoing nonsense mediated decay and a decrease in nonsense mediated decay with protein synthesis inhibitors [242].

An alternative to the NMD pathway is the nuclear exosome pathway whereby RNAs are degraded by riboexonucleases. Incomplete processing of mRNA by defects in capping, splicing or polyadenylation leads to degradation of mRNA transcripts by the nuclear exosome pathway [243]. The nuclear exosome is composed of nine $3^{\prime}->5$ ' riboexonucleases that appear to function in both the nucleus and the cytoplasm. Current studies indicate that RNA binding proteins play an essential role in activation of the nuclear exosome. For example AU-rich elements in the 3' UTR destabilize the mRNA by activating the nuclear exosome pathway [244]. The nuclear exosome is a separate nuclear complex with its major constituent being Rrp6p, a 3'->5' riboexonuclease $[243,245,246]$. An alternative function of the nuclear exosome is found in the nucleolus where its main role is in degradation of rRNA molecules [243]. The function of the nuclear exosome seems to be in surveillance of pre-mRNA that fail to complete splicing, 3 ' end formation, and transport of the mRNA out of the nucleus [243].

The NMD pathway and the nuclear exosome pathway serve as a surveillance mechanism to monitor RNA processing in order to ensure proper coding of the genetic material. Therefore, if a message was incompletely spliced or transported then the NMD or nuclear exosome pathway would degrade that message before it was translated into protein. Inefficient spliced mRNAs generated by incomplete splicing by both alternative and constitutive splicing would degrade these aberrant mRNAs presumably by the NMD pathway. 


\section{Identifying the Mechanism for the Posttranscriptional Gene Regulation of G6PD}

Current research in our laboratory is to define the mechanism for the posttranscriptional regulation of G6PD. The components of RNA processing and pre-mRNA are associated with an insoluble portion of the nucleus referred to as the "nuclear matrix". The nuclear matrix was isolated in order to measure differences in the rates of accumulation of mature mRNA and premRNA during RNA processing [60]. In this regard, changes in G6PD mRNA in the cytoplasm are accompanied by similar changes in the amount of nuclear matrix pre-mRNA while there is no change in transcriptional activity of the gene [60]. The nuclear matrix fraction is a fibrous fraction that is thought to contain processing factors including those involved in splicing.

Specific probes were used that crossed intron-exon boundaries in order to measure the amount of more processed versus less-processed mRNA for G6PD [60]. A change in the amount of less processed RNA was measured as exon 2-intron 2 and exon 9-intron 9 protected fragments [60]. The amount of more processed RNA was measured as exon 2 and exon 9. The amount of mRNA in the cytoplasm accompanied similar changes in the amount of nuclear RNA. These results suggest that processing efficiency is regulated through controlling the rates of splicing of G6PD mRNA [60]. Using probes that cross 2 intron/exon boundaries permit the detection of partially spliced RNA [60]. Feeding a high-carbohydrate diet increased the abundance of G6PD pre-mRNA in the nuclear matrix fraction. These results suggest that once again the processing efficiency is changed during the feeding of a high-carbohydrate diet [60]. The amount of spliced RNA compared to unspliced RNA was 5 fold higher in the mice that were refed as compared to the mice that were starved [60]. The data suggests that dietary carbohydrate regulates the efficiency of processing of the pre-mRNA. However, this could be due to changes in the 


\begin{tabular}{|c|c|c|}
\hline \multirow{2}{*}{ Constructs for Transfection } & \multicolumn{2}{|c|}{$\%$ INHIBITION } \\
\hline & Transgene & Endo. gene \\
\hline $9 \quad 10 \quad 11 \quad 12 \quad 133^{\prime}$ UTR & $42 \pm 7$ & $43 \pm 23$ \\
\hline $\begin{array}{llllll}\text { CMV } & 10 & 11 & 12 & 13 & 3^{\prime} \text { UTR }\end{array}$ & $62 \pm 15$ & $62 \pm 13$ \\
\hline $\begin{array}{lllll}\text { CMV 10 } & 11 & 12 & 13 & 3^{\prime} \text { UTR }\end{array}$ & $44 \pm 25$ & $53 \pm 13$ \\
\hline $\begin{array}{llllll} & & & & & \\
\mathrm{CMV} & 12 & 13 & 3^{\prime} \text { UTR }\end{array}$ & $41 \pm 13$ & $44 \pm 16$ \\
\hline $\begin{array}{lllll} & & & \\
\text { CMV } 12 & 13 & 3^{\prime} \text { UTR }\end{array}$ & $57 \pm 12$ & $40 \pm 10$ \\
\hline $\begin{array}{llll} & & & \\
\text { CMV } & 13 & 3 & \\
\end{array}$ & 0 & $63 \pm 9$ \\
\hline 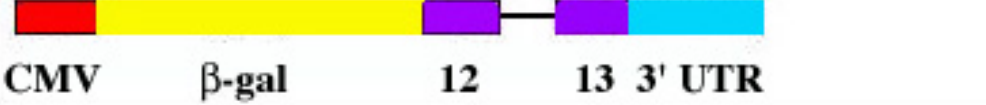 & $91(90,92)$ & $53(58,48)$ \\
\hline
\end{tabular}

Figure 5: A chart representing the constructs transfected into rat hepatocytes and each constructs relative rate of inhibition. The constructs contained the CMV promoter in red and the G6PD 3' UTR in teal. The genomic portions of 
efficiency of splicing or 3' end formation. The extent of polyadenylation was measured using a probe that binds across the poly (A) signal and the cleavage site within the mRNA. The length of the poly (A) tail was measured using RNase $\mathrm{H}$ assays, to determine if there is a change in the length of the poly (A) tail during starvation and refeeding (data not shown). The rate of accumulation of polyadenylated RNA could not account for the high rates of accumulation of mature G6PD mRNA [60]. Furthermore, the length of the poly (A) tail was not affected by starvation or refeeding [60]. Changes in protein levels observed with dietary manipulation must be due to a changes in the mRNA accumulation in the nuclear matrix fraction by a regulated constitutive splicing event [60].

An alternative dietary manipulation of adding polyunsaturated fat to the diet decreases the abundance of G6PD mature mRNA by $50 \%$ or more in the cytoplasm and in the nucleus, consistent with a nuclear regulation of gene expression [27]. The abundance of G6PD premRNA was similar during the first $2 \mathrm{~h}$ of the daily eating cycle in mice fed either the low-fat or the high-fat diet. Yet, the amount of mature G6PD mRNA was inhibited in mice consuming the high-fat diet [3]. The abundance of pre-mRNA increased after $4 \mathrm{~h}$ of the low-fat diet and this increase was attenuated by the high-fat diet. These results suggest that polyunsaturated fatty acids decrease the processing efficiency of G6PD pre-mRNA [60].

To determine the potential regulatory sequence in G6PD pre-mRNA, we have used RNA reporter constructs containing various portions of the G6PD gene and transfected these constructs into rat hepatocytes [3]. The amount of reporter RNA was measured after incubation of the cells with or without arachidonic acid. RNA produced from constructs containing intron 6 through the end of the G6PD gene was decreased in cells incubated with arachidonic acid [3]; Figure 5]. In contrast, RNA expressed from the G6PD cDNA construct (lacking introns) was not 
inhibited by arachidonic acid; therefore, this regulation is consistent with the need for splicing. The removal of introns and exons from the 5' end of the RNA reporter constructs did not abrogate regulation until exon 12 was removed from the transfected constructs [3; Figure 5]. Furthermore, the region of DNA from exon 12 through the end of the gene could confer regulation of RNA amount onto the heterologous mRNA, beta-galactosidase and the G6PD cDNA [3]. Additional experiments in intact mice support these findings. In the livers of mice fed a high-fat diet, pre-mRNA retaining intron 11 accumulates in the nucleus while the amount of mature G6PD mRNA in the cytoplasm is decreased 50\% or more [3]. Thus, exon 12 contains a potential exon splicing enhancer sequence. Current experiments in this project involve the precise mapping of proteins to exon 12 .

\section{Our Current Model for the Regulation of G6PD}

The dietary paradigm of starvation and refeeding results in a robust change of 12-15 fold in G6PD mRNA expression. The change in G6PD mRNA accumulation can be accounted for by a change in the splicing efficiency of the pre-mRNA. A cis-acting element has been localized to exon 12 of the G6PD mRNA sequence using RNA reporter constructs transfected into primary rat hepatocytes. Therefore exon 12 was predicated to contain either an ESE or an ESS element within exon 12 (Figure 6). The protein binding of an SR protein by insulin (primary rat hepatocytes) or refeeding would result in the recruitment of the U1snRNP and U2AF35/65 to the 5' and 3' splice site, respectively. The SR protein would serve to enhance splicing of the G6PD pre-mRNA during the presence of insulin (primary hepatocytes) or refeeding (Figure 6). The large changes observed in animals refed would suggest that this protein would be regulated by the insulin signal transduction pathway. The presence of fatty acids (primary hepatocytes) or 
starvation would result in a decrease of G6PD processing efficiency. The decrease in splicing could be mediated through an ESS element within exon 12. The binding of essential proteins to the ESS element would inhibit the splicing of G6PD mRNA. The incompletely spliced mRNA would be degraded by the NMD or the nuclear exosome pathway. The identification of proteins bound to either an ESE or an ESS would facilitate a novel discovery of nutritional regulation of G6PD mRNA. Crucial to the proof of this mechanism is the identification of those relevant nuclear proteins involved in the regulation of G6PD RNA splicing. 


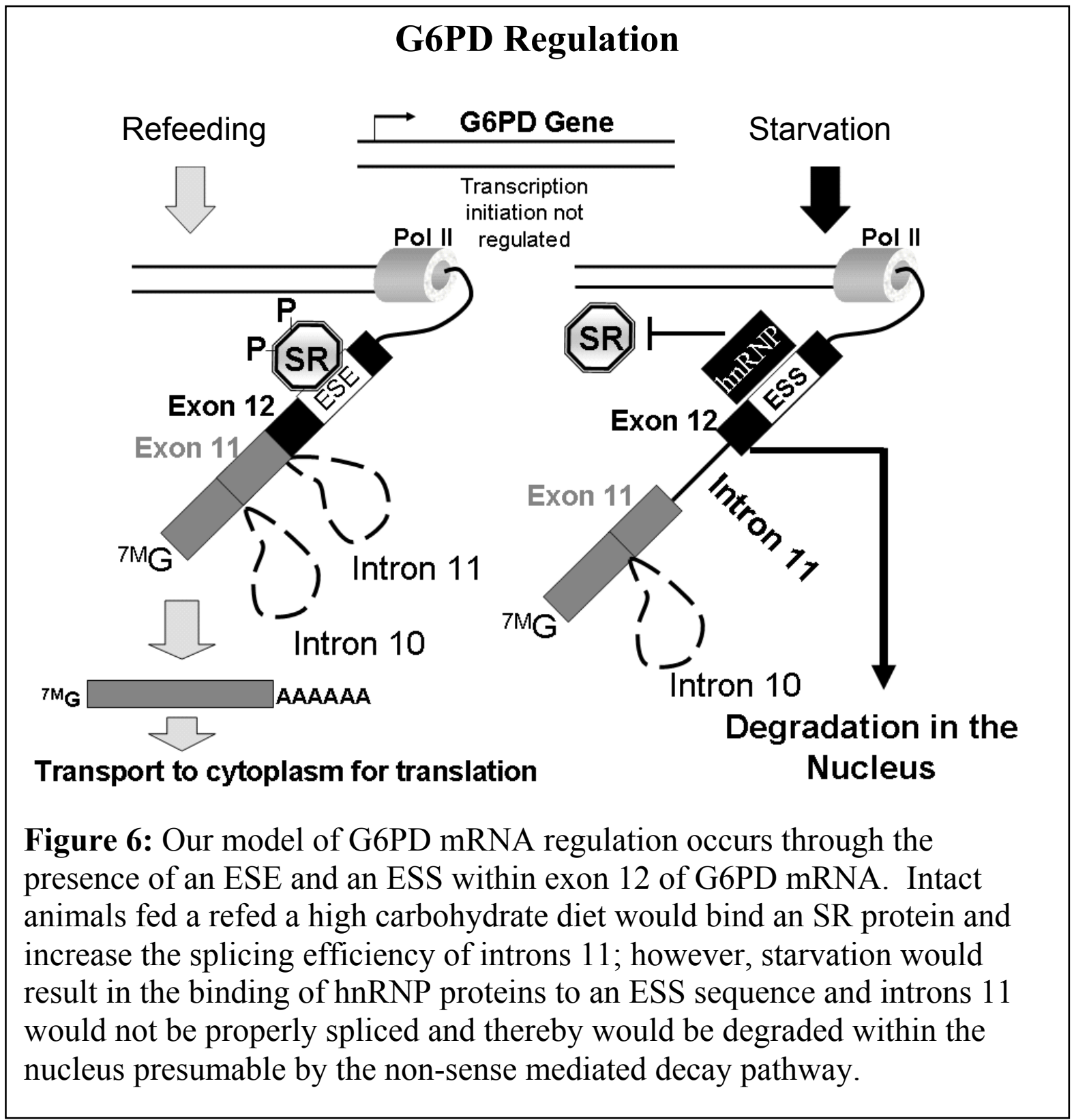




\section{Reference List}

[1] J.L.Gerberding, Heart Disease and Stroke: The Nation's Leading Killers, 2006.

[2] L.Cartegni, S.L.Chew, and A.R.Krainer, Listening to silence and understanding nonsense: exonic mutations that affect splicing, Nat. Rev. Genet. 3 (2002) 285-298.

[3] H.Tao, W.Szeszel-Fedorowicz, B.mir-Ahmady, M.A.Gibson, L.P.Stabile, and L.M.Salati, Inhibition of the splicing of glucose-6-phosphate dehydrogenase precursor mRNA by polyunsaturated fatty acids, J. Biol. Chem. 277 (2002) 31270-31278.

[4] K.Nagai, Y.Muto, D.A.Pomeranz Krummel, C.Kambach, T.Ignjatovic, S.Walke, and A.Kuglstatter, Structure and assembly of the spliceosomal snRNPs. Novartis Medal Lecture, Biochem. Soc. Trans. 29 (2001) 15-26.

[5] R.A.Coleman, T.M.Lewin, and D.M.Muoio, Physiological and nutritional regulation of enzymes of triacylglycerol synthesis, Annu. Rev. Nutr. 20 (2000) 77-103.

[6] R.E.Gossett, A.A.Frolov, J.B.Roths, W.D.Behnke, A.B.Kier, and F.Schroeder, Acyl-CoA binding proteins: multiplicity and function, Lipids 31 (1996) 895-918.

[7] L.A.Brown and M.Chen, Vasopressin signal transduction in rat type II pneumocytes, Am. J. Physiol 258 (1990) L301-L307.

[8] L.Colombaioni and M.Garcia-Gil, Sphingolipid metabolites in neural signalling and function, Brain Res. Brain Res. Rev. 46 (2004) 328-355. 
[9] M.P.Reilly, J.A.Lawson, and G.A.FitzGerald, Eicosanoids and isoeicosanoids: indices of cellular function and oxidant stress, J. Nutr. 128 (1998) 434S-438S.

[10] J.Geiger, C.Nolte, E.Butt, S.O.Sage, and U.Walter, Role of cGMP and cGMP-dependent protein kinase in nitrovasodilator inhibition of agonist-evoked calcium elevation in human platelets, Proc. Natl. Acad. Sci. U. S. A 89 (1992) 1031-1035.

[11] J.Geiger and U.Walter, Properties and regulation of human platelet cation channels, EXS 66 (1993) 281-288.

[12] J.Geiger, C.Nolte, and U.Walter, Regulation of calcium mobilization and entry in human platelets by endothelium-derived factors, Am. J. Physiol 267 (1994) C236-C244.

[13] P.H.Groot, H.R.Scholte, and W.C.Hulsmann, Fatty acid activation: specificity, localization, and function, Adv. Lipid Res. 14 (1976) 75-126.

[14] J.Bremer, Carnitine in intermediary metabolism. Reversible acetylation of carnitine by mitochondria, J. Biol. Chem. 237 (1962) 2228-2231.

[15] I.B.Fritz and K.T.Yue, Effects of carnitine on acetyl-CoA oxidation by heart muscle mitochondria, Am. J. Physiol 206 (1964) 531-535.

[16] W.H.Kunau, V.Dommes, and H.Schulz, beta-oxidation of fatty acids in mitochondria, peroxisomes, and bacteria: a century of continued progress, Prog. Lipid Res. 34 (1995) 267342.

[17] H.Sampath and J.M.Ntambi, Polyunsaturated fatty acid regulation of gene expression, Nutr. Rev. 62 (2004) 333-339. 
[18] J.M.Ntambi, M.Miyazaki, J.P.Stoehr, H.Lan, C.M.Kendziorski, B.S.Yandell, Y.Song, P.Cohen, J.M.Friedman, and A.D.Attie, Loss of stearoyl-CoA desaturase-1 function protects mice against adiposity, Proc. Natl. Acad. Sci. U. S. A 99 (2002) 11482-11486.

[19] A.Pawar, D.Botolin, D.J.Mangelsdorf, and D.B.Jump, The role of liver X receptor-alpha in the fatty acid regulation of hepatic gene expression, J. Biol. Chem. 278 (2003) 40736-40743.

[20] J.Xu, M.T.Nakamura, H.P.Cho, and S.D.Clarke, Sterol regulatory element binding protein-1 expression is suppressed by dietary polyunsaturated fatty acids. A mechanism for the coordinate suppression of lipogenic genes by polyunsaturated fats, J. Biol. Chem. 274 (1999) $23577-23583$.

[21] T.Yoshikawa, H.Shimano, M.memiya-Kudo, N.Yahagi, A.H.Hasty, T.Matsuzaka, H.Okazaki, Y.Tamura, Y.Iizuka, K.Ohashi, J.Osuga, K.Harada, T.Gotoda, S.Kimura, S.Ishibashi, and N.Yamada, Identification of liver $\mathrm{X}$ receptor-retinoid $\mathrm{X}$ receptor as an activator of the sterol regulatory element-binding protein 1c gene promoter, Mol. Cell Biol. 21 (2001) 2991-3000.

[22] T.Yoshikawa, T.Ide, H.Shimano, N.Yahagi, M.memiya-Kudo, T.Matsuzaka, S.Yatoh, T.Kitamine, H.Okazaki, Y.Tamura, M.Sekiya, A.Takahashi, A.H.Hasty, R.Sato, H.Sone, J.Osuga, S.Ishibashi, and N.Yamada, Cross-talk between peroxisome proliferator-activated receptor (PPAR) alpha and liver X receptor (LXR) in nutritional regulation of fatty acid metabolism. I. PPARs suppress sterol regulatory element binding protein-1c promoter through inhibition of LXR signaling, Mol. Endocrinol. 17 (2003) 1240-1254.

[23] S.D.Clarke, M.K.Armstrong, and D.B.Jump, Dietary polyunsaturated fats uniquely suppress rat liver fatty acid synthase and S14 mRNA content, J. Nutr. 120 (1990) 225-231. 
[24] L.M.Salati and S.D.Clarke, Fatty acid inhibition of hormonal induction of acetyl-coenzyme A carboxylase in hepatocyte monolayers, Arch. Biochem. Biophys. 246 (1986) 82-89.

[25] P.Tontonoz, E.Hu, R.A.Graves, A.I.Budavari, and B.M.Spiegelman, mPPAR gamma 2: tissue-specific regulator of an adipocyte enhancer, Genes Dev. 8 (1994) 1224-1234.

[26] P.Tontonoz, E.Hu, J.Devine, E.G.Beale, and B.M.Spiegelman, PPAR gamma 2 regulates adipose expression of the phosphoenolpyruvate carboxykinase gene, Mol. Cell Biol. 15 (1995) 351-357.

[27] D.L.Hodge and L.M.Salati, Nutritional regulation of the glucose-6-phosphate dehydrogenase gene is mediated by a nuclear posttranscriptional mechanism, Arch. Biochem. Biophys. 348 (1997) 303-312.

[28] L.P.Stabile, D.L.Hodge, S.A.Klautky, and L.M.Salati, Posttranscriptional regulation of glucose-6-phosphate dehydrogenase by dietary polyunsaturated fat, Arch. Biochem. Biophys. 332 (1996) 269-279.

[29] K.Schoonjans, M.Watanabe, H.Suzuki, A.Mahfoudi, G.Krey, W.Wahli, P.Grimaldi, B.Staels, T.Yamamoto, and J.Auwerx, Induction of the acyl-coenzyme A synthetase gene by fibrates and fatty acids is mediated by a peroxisome proliferator response element in the $\mathrm{C}$ promoter, J. Biol. Chem. 270 (1995) 19269-19276.

[30] B.I.Frohnert, T.Y.Hui, and D.A.Bernlohr, Identification of a functional peroxisome proliferator-responsive element in the murine fatty acid transport protein gene, J. Biol. Chem. 274 (1999) 3970-3977. 
[31] J.M.Brandt, F.Djouadi, and D.P.Kelly, Fatty acids activate transcription of the muscle carnitine palmitoyltransferase I gene in cardiac myocytes via the peroxisome proliferatoractivated receptor alpha, J. Biol. Chem. 273 (1998) 23786-23792.

[32] I.B.Sears, M.A.MacGinnitie, L.G.Kovacs, and R.A.Graves, Differentiation-dependent expression of the brown adipocyte uncoupling protein gene: regulation by peroxisome proliferator-activated receptor gamma, Mol. Cell Biol. 16 (1996) 3410-3419.

[33] L.Berthou, R.Saladin, P.Yaqoob, D.Branellec, P.Calder, J.C.Fruchart, P.Denefle, J.Auwerx, and B.Staels, Regulation of rat liver apolipoprotein A-I, apolipoprotein A-II and acylcoenzyme A oxidase gene expression by fibrates and dietary fatty acids, Eur. J. Biochem. 232 (1995) 179-187.

[34] T.T.Lu, J.J.Repa, and D.J.Mangelsdorf, Orphan nuclear receptors as eLiXiRs and FiXeRs of sterol metabolism, J. Biol. Chem. 276 (2001) 37735-37738.

[35] T.S.Worgall, S.L.Sturley, T.Seo, T.F.Osborne, and R.J.Deckelbaum, Polyunsaturated fatty acids decrease expression of promoters with sterol regulatory elements by decreasing levels of mature sterol regulatory element-binding protein, J. Biol. Chem. 273 (1998) 25537-25540.

[36] G.P.Hayhurst, Y.H.Lee, G.Lambert, J.M.Ward, and F.J.Gonzalez, Hepatocyte nuclear factor 4alpha (nuclear receptor 2A1) is essential for maintenance of hepatic gene expression and lipid homeostasis, Mol. Cell Biol. 21 (2001) 1393-1403.

[37] Y.Zhao, S.Joshi-Barve, S.Barve, and L.H.Chen, Eicosapentaenoic acid prevents LPS-induced TNF-alpha expression by preventing NF-kappaB activation, J. Am. Coll. Nutr. 23 (2004) 7178. 
[38] D.B.Jump, S.D.Clarke, A.Thelen, and M.Liimatta, Coordinate regulation of glycolytic and lipogenic gene expression by polyunsaturated fatty acids, J. Lipid Res. 35 (1994) 1076-1084.

[39] H.P.Cho, M.Nakamura, and S.D.Clarke, Cloning, expression, and fatty acid regulation of the human delta-5 desaturase, J. Biol. Chem. 274 (1999) 37335-37339.

[40] H.P.Cho, M.Nakamura, and S.D.Clarke, Cloning, expression, and fatty acid regulation of the human delta-6 desaturase, J. Biol. Chem. 274 (1999) 471-477.

[41] D.B.Jump and S.D.Clarke, Regulation of gene expression by dietary fat, Annu. Rev. Nutr. 19 (1999) 63-90.

[42] A.M.Sessler and J.M.Ntambi, Polyunsaturated fatty acid regulation of gene expression, J. Nutr. 128 (1998) 923-926.

[43] P.W.Tebbey, K.M.McGowan, J.M.Stephens, T.M.Buttke, and P.H.Pekala, Arachidonic acid down-regulates the insulin-dependent glucose transporter gene (GLUT4) in 3T3-L1 adipocytes by inhibiting transcription and enhancing mRNA turnover, J. Biol. Chem. 269 (1994) 639-644.

[44] K.W.Wahle, D.Rotondo, and S.D.Heys, Polyunsaturated fatty acids and gene expression in mammalian systems, Proc. Nutr. Soc. 62 (2003) 349-360.

[45] E.Duplus, M.Glorian, and C.Forest, Fatty acid regulation of gene transcription, J. Biol. Chem. 275 (2000) 30749-30752.

[46] B.Desvergne and W.Wahli, Peroxisome proliferator-activated receptors: nuclear control of metabolism, Endocr. Rev. 20 (1999) 649-688. 
[47] M.S.Brown and J.L.Goldstein, The SREBP pathway: regulation of cholesterol metabolism by proteolysis of a membrane-bound transcription factor, Cell 89 (1997) 331-340.

[48] T.F.Osborne, Sterol regulatory element-binding proteins (SREBPs): key regulators of nutritional homeostasis and insulin action, J. Biol. Chem. 275 (2000) 32379-32382.

[49] A.Takahashi, H.Shimano, Y.Nakagawa, T.Yamamoto, K.Motomura, T.Matsuzaka, H.Sone, H.Suzuki, H.Toyoshima, and N.Yamada, Transgenic mice overexpressing SREBP-1a under the control of the PEPCK promoter exhibit insulin resistance, but not diabetes, Biochim. Biophys. Acta 1740 (2005) 427-433.

[50] J.I.Toth, S.Datta, J.N.Athanikar, L.P.Freedman, and T.F.Osborne, Selective coactivator interactions in gene activation by SREBP-1a and -1c, Mol. Cell Biol. 24 (2004) 8288-8300.

[51] L.M.Salati, W.Szeszel-Fedorowicz, H.Tao, M.A.Gibson, B.mir-Ahmady, L.P.Stabile, and D.L.Hodge, Nutritional regulation of mRNA processing, J. Nutr. 134 (2004) 2437S-2443S.

[52] W.L.Blake and S.D.Clarke, Suppression of rat hepatic fatty acid synthase and S14 gene transcription by dietary polyunsaturated fat, J. Nutr. 120 (1990) 1727-1729.

[53] P.Ferre, Regulation of gene expression by glucose, Proc. Nutr. Soc. 58 (1999) 621-623.

[54] A.G.Goodridge, Regulation of the gene for fatty acid synthase, Fed. Proc. 45 (1986) 23992405.

[55] D.B.Jump, S.D.Clarke, O.MacDougald, and A.Thelen, Polyunsaturated fatty acids inhibit S14 gene transcription in rat liver and cultured hepatocytes, Proc. Natl. Acad. Sci. U. S. A 90 (1993) 8454-8458. 
[56] A.Katsurada, N.Iritani, H.Fukuda, Y.Matsumura, N.Nishimoto, T.Noguchi, and T.Tanaka, Effects of nutrients and hormones on transcriptional and post-transcriptional regulation of fatty acid synthase in rat liver, Eur. J. Biochem. 190 (1990) 427-433.

[57] K.S.Kim, S.W.Park, and Y.S.Kim, Regulation of ATP-citrate lyase at transcriptional and post-transcriptional levels in rat liver, Biochem. Biophys. Res. Commun. 189 (1992) 264-271.

[58] K.S.Kim, S.W.Park, and Y.S.Kim, Regulation of fatty acid synthase at transcriptional and post-transcriptional levels in rat liver, Yonsei Med. J. 33 (1992) 199-208.

[59] J.D.Paulauskis and H.S.Sul, Hormonal regulation of mouse fatty acid synthase gene transcription in liver, J. Biol. Chem. 264 (1989) 574-577.

[60] B.Amir-Ahmady and L.M.Salati, Regulation of the processing of glucose-6-phosphate dehydrogenase mRNA by nutritional status, J. Biol. Chem. 276 (2001) 10514-10523.

[61] L.P.Stabile, S.A.Klautky, S.M.Minor, and L.M.Salati, Polyunsaturated fatty acids inhibit the expression of the glucose-6-phosphate dehydrogenase gene in primary rat hepatocytes by a nuclear posttranscriptional mechanism, J. Lipid Res. 39 (1998) 1951-1963.

[62] B.Dozin, J.E.Rall, and V.M.Nikodem, Tissue-specific control of rat malic enzyme activity and messenger RNA levels by a high carbohydrate diet, Proc. Natl. Acad. Sci. U. S. A 83 (1986) 4705-4709.

[63] C.I.Gonzalez and C.E.Martin, Fatty acid-responsive control of mRNA stability. Unsaturated fatty acid-induced degradation of the Saccharomyces OLE1 transcript, J. Biol. Chem. 271 (1996) 25801-25809. 
[64] A.M.Sessler, N.Kaur, J.P.Palta, and J.M.Ntambi, Regulation of stearoyl-CoA desaturase 1 mRNA stability by polyunsaturated fatty acids in 3T3-L1 adipocytes, J. Biol. Chem. 271 (1996) 29854-29858.

[65] L.A.Burmeister and C.N.Mariash, Dietary sucrose enhances processing of mRNA-S14 nuclear precursor, J. Biol. Chem. 266 (1991) 22905-22911.

[66] G.Martini, D.Toniolo, T.Vulliamy, L.Luzzatto, R.Dono, G.Viglietto, G.Paonessa, M.D'Urso, and M.G.Persico, Structural analysis of the X-linked gene encoding human glucose 6phosphate dehydrogenase, EMBO J. 5 (1986) 1849-1855.

[67] D.Toniolo, M.Filippi, R.Dono, T.Lettieri, and G.Martini, The CpG island in the 5' region of the G6PD gene of man and mouse, Gene 102 (1991) 197-203.

[68] G.S.Pai, J.A.Sprenkle, T.T.Do, C.E.Mareni, and B.R.Migeon, Localization of loci for hypoxanthine phosphoribosyltransferase and glucose-6-phosphate dehydrogenase and biochemical evidence of nonrandom $\mathrm{X}$ chromosome expression from studies of a human $\mathrm{X}$ autosome translocation, Proc. Natl. Acad. Sci. U. S. A 77 (1980) 2810-2813.

[69] M.Philippe, Y.Larondelle, F.Lemaigre, B.Mariame, H.Delhez, P.Mason, L.Luzzatto, and G.G.Rousseau, Promoter function of the human glucose-6-phosphate dehydrogenase gene depends on two GC boxes that are cell specifically controlled, Eur. J. Biochem. 226 (1994) $377-384$.

[70] K.B.Rank, P.K.Harris, L.C.Ginsberg, and S.R.Stapleton, Isolation and sequence of a rat glucose-6-phosphate dehydrogenase promoter, Biochim. Biophys. Acta 1217 (1994) 90-92. 
[71] A.Franze, M.I.Ferrante, F.Fusco, A.Santoro, E.Sanzari, G.Martini, and M.V.Ursini, Molecular anatomy of the human glucose 6-phosphate dehydrogenase core promoter, FEBS Lett. 437 (1998) 313-318.

[72] Y.S.Ho, A.J.Howard, and J.D.Crapo, Cloning and sequence of a cDNA encoding rat glucose6-phosphate dehydrogenase, Nucleic Acids Res. 16 (1988) 7746.

[73] T.Takizawa, I.Y.Huang, T.Ikuta, and A.Yoshida, Human glucose-6-phosphate dehydrogenase: primary structure and cDNA cloning, Proc. Natl. Acad. Sci. U. S. A 83 (1986) 4157-4161.

[74] E.Beutler, Glucose-6-phosphate dehydrogenase deficiency, N. Engl. J. Med. 324 (1991) 169174.

[75] S.Tuttle, T.Stamato, M.L.Perez, and J.Biaglow, Glucose-6-phosphate dehydrogenase and the oxidative pentose phosphate cycle protect cells against apoptosis induced by low doses of ionizing radiation, Radiat. Res. 153 (2000) 781-787.

[76] C.R.Scriver, Glucose-6-Phosphate Dehydrogenase Deficiency, The metabolic and molecular bases of inherited disease, McGraw- Hill, 1995, pp.3367-3398.

[77] T.Takizawa, [Gene analysis and genetic diagnosis of hereditary erythrocyte abnormalities. Glucose-6-phosphate dehydrogenase deficiency], Nippon Rinsho 45 (1987) 2905-2910.

[78] A.Mehta, P.J.Mason, and T.J.Vulliamy, Glucose-6-phosphate dehydrogenase deficiency, Baillieres Best. Pract. Res. Clin. Haematol. 13 (2000) 21-38. 
[79] S.Dessi, B.Batetta, O.Spano, D.Pulisci, M.F.Mulas, S.Muntoni, M.Armeni, C.Sanna, R.Antonucci, and P.Pani, Serum lipoprotein pattern as modified in G6PD-deficient children during haemolytic anaemia induced by fava bean ingestion, Int. J. Exp. Pathol. 73 (1992) 157160.

[80] J.W.Kurtz and W.W.Wells, Induction of glucose-6-phosphate dehydrogenase in primary cultures of adult rat hepatocytes. Requirement for insulin and dexamethasone, J. Biol. Chem. 256 (1981) 10870-10875.

[81] K.Yoshimoto, T.Nakamura, S.Niimi, and A.Ichihara, Hormonal regulation of translatable mRNA of glucose-6-phosphate dehydrogenase in primary cultures of adult rat hepatocytes, Biochim. Biophys. Acta 741 (1983) 143-149.

[82] J.W.Anderson, Glucose metabolism in jejunal mucosa of fed, fasted, and streptozotocindiabetic rats, Am. J. Physiol 226 (1974) 226-229.

[83] E.A.Berg, J.Y.Wu, L.Campbell, M.Kagey, and S.R.Stapleton, Insulin-like effects of vanadate and selenate on the expression of glucose-6-phosphate dehydrogenase and fatty acid synthase in diabetic rats, Biochimie 77 (1995) 919-924.

[84] R.W.Geisler, A.E.Roggeveen, and R.J.Hansen, The effects of insulin on the turnover of glucose-6-phosphate dehydrogenase in epididymal adipose tissue of the rat, Biochim. Biophys. Acta 544 (1978) 284-293.

[85] G.E.Glock and P.McLean, Levels of enzymes of the direct oxidative pathway of carbohydrate metabolism in mammalian tissues and tumours, Biochem. J. 56 (1954) 171-175. 
[86] D.R.Garcia and D.Holten, Inhibition of rat liver glucose-6-phosphate dehydrogenase synthesis by glucagon, J. Biol. Chem. 250 (1975) 3960-3965.

[87] R.J.Miksicek and H.C.Towle, Changes in the rates of synthesis and messenger RNA levels of hepatic glucose-6-phosphate and 6-phosphogluconate dehydrogenases following induction by diet or thyroid hormone, J. Biol. Chem. 257 (1982) 11829-11835.

[88] J.Tepperman and H.M.Tepperman, Effects of antecedent food intake pattern on hepatic lipogenesis, Am. J. Physiol 193 (1958) 55-64.

[89] H.Fukuda and N.Iritani, Diurnal variations of lipogenic enzyme mRNA quantities in rat liver, Biochim. Biophys. Acta 1086 (1991) 261-264.

[90] L.M.Salati, B.dkins-Finke, and S.D.Clarke, Free fatty acid inhibition of the insulin induction of glucose-6-phosphate dehydrogenase in rat hepatocyte monolayers, Lipids 23 (1988) 36-41.

[91] P.Manos, R.Nakayama, and D.Holten, Regulation of glucose-6-phosphate dehydrogenase synthesis and mRNA abundance in cultured rat hepatocytes, Biochem. J. 276 ( Pt 1) (1991) 245-250.

[92] D.J.Stumpo and R.F.Kletzien, Regulation of glucose-6-phosphate dehydrogenase mRNA by insulin and the glucocorticoids in primary cultures of rat hepatocytes, Eur. J. Biochem. 144 (1984) 497-502.

[93] T.Nakamura, K.Yoshimoto, K.Aoyama, and A.Ichihara, Hormonal regulations of glucose-6phosphate dehydrogenase and lipogenesis in primary cultures of rat hepatocytes, J. Biochem. (Tokyo) 91 (1982) 681-693. 
[94] C.D.Berdanier and D.Shubeck, Interaction of glucocorticoid and insulin in the responses of rats to starvation-refeeding, J. Nutr. 109 (1979) 1766-1771.

[95] C.R.Prostko, R.S.Fritz, and R.F.Kletzien, Nutritional regulation of hepatic glucose-6phosphate dehydrogenase. Transient activation of transcription, Biochem. J. 258 (1989) 295299.

[96] R.A.Freedland, S.Murad, and A.I.Hurvitz, Relationship of nutritional and hormonal influences on liver enzyme activity, Fed. Proc. 27 (1968) 1217-1222.

[97] E.Kastrouni, T.Pegiou, P.Gardiki, and A.Trakatellis, Activity changes of glucose-6-phosphate dehydrogenase in response to diet and insulin, Int. J. Biochem. 16 (1984) 1353-1358.

[98] S.D.Clarke, D.R.Romsos, and G.A.Leveille, Specific inhibition of hepatic fatty acid synthesis exerted by dietary linoleate and linolenate in essential fatty acid adequate rats, Lipids 11 (1976) 485-490.

[99] S.D.Clarke, D.R.Romsos, and G.A.Leveille, Differential effects of dietary methyl esters of long-chain saturated and polyunsaturated fatty acids on rat liver and adipose tissue lipogenesis, J. Nutr. 107 (1977) 1170-1181.

[100] D.E.Peavy and R.J.Hansen, Immunological titration of rat liver glucose-6-phosphate dehydrogenase from animals fed high and low carbohydrate diets, Biochem. Biophys. Res. Commun. 66 (1975) 1106-1111.

[101] L.Winberry and D.Holten, Rat liver glucose-6-p dehydrogenase. Dietary regulation of the rate of synthesis, J. Biol. Chem. 252 (1977) 7796-7801. 
[102] E.M.Gozukara, M.Frolich, and D.Holten, The effect of unsaturated fatty acids on the rate of synthesis of rat liver glucose-6-phosphate dehydrogenase, Biochim. Biophys. Acta 286 (1972) 155-163.

[103] N.Morikawa, R.Nakayama, and D.Holten, Dietary induction of glucose-6-phosphate dehydrogenase synthesis, Biochem. Biophys. Res. Commun. 120 (1984) 1022-1029.

[104] D.Rudack, B.Davie, and D.Holten, Regulation of rat liver glucose 6- phosphate dehydrogenase levels by adenosine 3', 5' -monophosphate, J. Biol. Chem. 246 (1971) 78237824.

[105] H.C.Towle, C.N.Mariash, H.L.Schwartz, and J.H.Oppenheimer, Quantitation of rat liver messenger ribonucleic acid for malic enzyme during induction by thyroid hormone, Biochemistry 20 (1981) 3486-3492.

[106] R.F.Kletzien, C.R.Prostko, D.J.Stumpo, J.K.McClung, and K.L.Dreher, Molecular cloning of DNA sequences complementary to rat liver glucose-6-phosphate dehydrogenase mRNA. Nutritional regulation of mRNA levels, J. Biol. Chem. 260 (1985) 5621-5624.

[107] R.J.Miksicek and H.C.Towle, Use of a cloned cDNA sequence to measure changes in 6phosphogluconate dehydrogenase mRNA levels caused by thyroid hormone and dietary carbohydrate, J. Biol. Chem. 258 (1983) 9575-9579.

[108] J.E.Tomlinson, R.Nakayama, and D.Holten, Repression of pentose phosphate pathway dehydrogenase synthesis and mRNA by dietary fat in rats, J. Nutr. 118 (1988) 408-415. 
[109] D.Bentley, Coupling RNA polymerase II transcription with pre-mRNA processing, Curr. Opin. Cell Biol. 11 (1999) 347-351.

[110] J.W.Stiller and M.S.Cook, Functional unit of the RNA polymerase II C-terminal domain lies within heptapeptide pairs, Eukaryot. Cell 3 (2004) 735-740.

[111] B.Palancade and O.Bensaude, Investigating RNA polymerase II carboxyl-terminal domain (CTD) phosphorylation, Eur. J. Biochem. 270 (2003) 3859-3870.

[112] B.Palancade, N.F.Marshall, A.Tremeau-Bravard, O.Bensaude, M.E.Dahmus, and M.F.Dubois, Dephosphorylation of RNA polymerase II by CTD-phosphatase FCP1 is inhibited by phospho-CTD associating proteins, J. Mol. Biol. 335 (2004) 415-424.

[113] A.Yuryev, M.Patturajan, Y.Litingtung, R.V.Joshi, C.Gentile, M.Gebara, and J.L.Corden, The C-terminal domain of the largest subunit of RNA polymerase II interacts with a novel set of serine/arginine-rich proteins, Proc. Natl. Acad. Sci. U. S. A 93 (1996) 6975-6980.

[114] M.A.Verdecia, M.E.Bowman, K.P.Lu, T.Hunter, and J.P.Noel, Structural basis for phosphoserine-proline recognition by group IV WW domains, Nat. Struct. Biol. 7 (2000) 639643.

[115] M.J.Smith, S.Kulkarni, and T.Pawson, FF domains of CA150 bind transcription and splicing factors through multiple weak interactions, Mol. Cell Biol. 24 (2004) 9274-9285.

[116] P.Komarnitsky, E.J.Cho, and S.Buratowski, Different phosphorylated forms of RNA polymerase II and associated mRNA processing factors during transcription, Genes Dev. 14 (2000) 2452-2460. 
[117] S.C.Schroeder, B.Schwer, S.Shuman, and D.Bentley, Dynamic association of capping enzymes with transcribing RNA polymerase II, Genes Dev. 14 (2000) 2435-2440.

[118] E.J.Cho, T.Takagi, C.R.Moore, and S.Buratowski, mRNA capping enzyme is recruited to the transcription complex by phosphorylation of the RNA polymerase II carboxy-terminal domain, Genes Dev. 11 (1997) 3319-3326.

[119] E.J.Cho, C.R.Rodriguez, T.Takagi, and S.Buratowski, Allosteric interactions between capping enzyme subunits and the RNA polymerase II carboxy-terminal domain, Genes Dev. 12 (1998) 3482-3487.

[120] C.A.Beelman and R.Parker, Degradation of mRNA in eukaryotes, Cell 81 (1995) 179-183.

[121] K.F.Wilson, P.Fortes, U.S.Singh, M.Ohno, I.W.Mattaj, and R.A.Cerione, The nuclear capbinding complex is a novel target of growth factor receptor-coupled signal transduction, J. Biol. Chem. 274 (1999) 4166-4173.

[122] E.Wahle and W.Keller, The biochemistry of polyadenylation, Trends Biochem. Sci. 21 (1996) $247-250$.

[123] N.Proudfoot, New perspectives on connecting messenger RNA 3' end formation to transcription, Curr. Opin. Cell Biol. 16 (2004) 272-278.

[124] M.Kim, N.J.Krogan, L.Vasiljeva, O.J.Rando, E.Nedea, J.F.Greenblatt, and S.Buratowski, The yeast Rat1 exonuclease promotes transcription termination by RNA polymerase II, Nature 432 (2004) 517-522. 
[125] S.West, N.Gromak, and N.J.Proudfoot, Human 5' --> 3' exonuclease Xrn2 promotes transcription termination at co-transcriptional cleavage sites, Nature 432 (2004) 522-525.

[126] J.Ross, mRNA stability in mammalian cells, Microbiol. Rev. 59 (1995) 423-450.

[127] D.Murphy, K.Pardy, V.Seah, and D.Carter, Posttranscriptional regulation of rat growth hormone gene expression: increased message stability and nuclear polyadenylation accompany thyroid hormone depletion, Mol. Cell Biol. 12 (1992) 2624-2632.

[128] E.Pauws, A.H.van Kampen, S.A.van de Graaf, J.J.de Vijlder, and C.Ris-Stalpers, Heterogeneity in polyadenylation cleavage sites in mammalian mRNA sequences: implications for SAGE analysis, Nucleic Acids Res. 29 (2001) 1690-1694.

[129] T.Maniatis and R.Reed, An extensive network of coupling among gene expression machines, Nature 416 (2002) 499-506.

[130] I.Wetterberg, J.Zhao, S.Masich, L.Wieslander, and U.Skoglund, In situ transcription and splicing in the Balbiani ring 3 gene, EMBO J. 20 (2001) 2564-2574.

[131] H.P.Phatnani, J.C.Jones, and A.L.Greenleaf, Expanding the functional repertoire of CTD kinase I and RNA polymerase II: novel phosphoCTD-associating proteins in the yeast proteome, Biochemistry 43 (2004) 15702-15719.

[132] K.C.Abruzzi, S.Lacadie, and M.Rosbash, Biochemical analysis of TREX complex recruitment to intronless and intron-containing yeast genes, EMBO J. 23 (2004) 2620-2631.

[133] J.L.Manley and R.Tacke, SR proteins and splicing control, Genes Dev. 10 (1996) 1569-1579.

[134] X.D.Fu, The superfamily of arginine/serine-rich splicing factors, RNA. 1 (1995) 663-680. 
[135] B.J.Blencowe, R.Issner, J.A.Nickerson, and P.A.Sharp, A coactivator of pre-mRNA splicing, Genes Dev. 12 (1998) 996-1009.

[136] X.D.Fu, Towards a splicing code, Cell 119 (2004) 736-738.

[137] B.R.Graveley, Sorting out the complexity of SR protein functions, RNA. 6 (2000) 11971211.

[138] R.Tacke and J.L.Manley, Functions of SR and Tra2 proteins in pre-mRNA splicing regulation, Proc. Soc. Exp. Biol. Med. 220 (1999) 59-63.

[139] T.Misteli, Cell biology of transcription and pre-mRNA splicing: nuclear architecture meets nuclear function, J. Cell Sci. 113 ( Pt 11) (2000) 1841-1849.

[140] T.Misteli, J.F.Caceres, and D.L.Spector, The dynamics of a pre-mRNA splicing factor in living cells, Nature 387 (1997) 523-527.

[141] T.Misteli and D.L.Spector, Serine/threonine phosphatase 1 modulates the subnuclear distribution of pre-mRNA splicing factors, Mol. Biol. Cell 7 (1996) 1559-1572.

[142] T.Misteli and D.L.Spector, RNA polymerase II targets pre-mRNA splicing factors to transcription sites in vivo, Mol. Cell 3 (1999) 697-705.

[143] B.J.Lam and K.J.Hertel, A general role for splicing enhancers in exon definition, RNA. 8 (2002) 1233-1241.

[144] D.F.Stojdl and J.C.Bell, SR protein kinases: the splice of life, Biochem. Cell Biol. 77 (1999) 293-298. 
[145] B.L.Robberson, G.J.Cote, and S.M.Berget, Exon definition may facilitate splice site selection in RNAs with multiple exons, Mol. Cell Biol. 10 (1990) 84-94.

[146] S.R.Lim and K.J.Hertel, Modulation of survival motor neuron pre-mRNA splicing by inhibition of alternative 3' splice site pairing, J. Biol. Chem. 276 (2001) 45476-45483.

[147] A.C.Black, J.Luo, C.Watanabe, S.Chun, A.Bakker, J.K.Fraser, J.P.Morgan, and J.D.Rosenblatt, Polypyrimidine tract-binding protein and heterogeneous nuclear ribonucleoprotein A1 bind to human T-cell leukemia virus type 2 RNA regulatory elements, J. Virol. 69 (1995) 6852-6858.

[148] K.K.Nelson and M.R.Green, Splice site selection and ribonucleoprotein complex assembly during in vitro pre-mRNA splicing, Genes Dev. 2 (1988) 319-329.

[149] R.Reed and T.Maniatis, A role for exon sequences and splice-site proximity in splice-site selection, Cell 46 (1986) 681-690.

[150] Z.M.Zheng, Regulation of alternative RNA splicing by exon definition and exon sequences in viral and mammalian gene expression, J. Biomed. Sci. 11 (2004) 278-294.

[151] J.D.Kohtz, S.F.Jamison, C.L.Will, P.Zuo, R.Luhrmann, M.A.Garcia-Blanco, and J.L.Manley, Protein-protein interactions and 5'-splice-site recognition in mammalian mRNA precursors, Nature 368 (1994) 119-124.

[152] D.Staknis and R.Reed, SR proteins promote the first specific recognition of Pre-mRNA and are present together with the $\mathrm{U} 1$ small nuclear ribonucleoprotein particle in a general splicing enhancer complex, Mol. Cell Biol. 14 (1994) 7670-7682. 
[153] D.Staknis and R.Reed, Direct interactions between pre-mRNA and six U2 small nuclear ribonucleoproteins during spliceosome assembly, Mol. Cell Biol. 14 (1994) 2994-3005.

[154] J.Y.Wu and T.Maniatis, Specific interactions between proteins implicated in splice site selection and regulated alternative splicing, Cell 75 (1993) 1061-1070.

[155] U.Pozzoli and M.Sironi, Silencers regulate both constitutive and alternative splicing events in mammals, Cell Mol. Life Sci. 62 (2005) 1579-1604.

[156] A.Lavigueur, La Branch, A.R.Kornblihtt, and B.Chabot, A splicing enhancer in the human fibronectin alternate ED1 exon interacts with SR proteins and stimulates U2 snRNP binding, Genes Dev. 7 (1993) 2405-2417.

[157] Q.Sun, A.Mayeda, R.K.Hampson, A.R.Krainer, and F.M.Rottman, General splicing factor SF2/ASF promotes alternative splicing by binding to an exonic splicing enhancer, Genes Dev. 7 (1993) 2598-2608.

[158] A.Watakabe, K.Tanaka, and Y.Shimura, The role of exon sequences in splice site selection, Genes Dev. 7 (1993) 407-418.

[159] R.Xu, J.Teng, and T.A.Cooper, The cardiac troponin T alternative exon contains a novel purine-rich positive splicing element, Mol. Cell Biol. 13 (1993) 3660-3674.

[160] E.Stickeler, S.D.Fraser, A.Honig, A.L.Chen, S.M.Berget, and T.A.Cooper, The RNA binding protein YB-1 binds A/C-rich exon enhancers and stimulates splicing of the CD44 alternative exon v4, EMBO J. 20 (2001) 3821-3830. 
[161] T.D.Schaal and T.Maniatis, Multiple distinct splicing enhancers in the protein-coding sequences of a constitutively spliced pre-mRNA, Mol. Cell Biol. 19 (1999) 261-273.

[162] W.P.Dirksen, S.A.Mohamed, and S.A.Fisher, Splicing of a myosin phosphatase targeting subunit 1 alternative exon is regulated by intronic cis-elements and a novel bipartite exonic enhancer/silencer element, J. Biol. Chem. 278 (2003) 9722-9732.

[163] A.Staffa, N.H.Acheson, and A.Cochrane, Novel exonic elements that modulate splicing of the human fibronectin EDA exon, J. Biol. Chem. 272 (1997) 33394-33401.

[164] B.A.Amendt, D.Hesslein, L.J.Chang, and C.M.Stoltzfus, Presence of negative and positive cis-acting RNA splicing elements within and flanking the first tat coding exon of human immunodeficiency virus type 1, Mol. Cell Biol. 14 (1994) 3960-3970.

[165] G.F.Del and R.Breathnach, Exon and intron sequences, respectively, repress and activate splicing of a fibroblast growth factor receptor 2 alternative exon, Mol. Cell Biol. 15 (1995) $4825-4834$.

[166] A.Staffa and A.Cochrane, Identification of positive and negative splicing regulatory elements within the terminal tat-rev exon of human immunodeficiency virus type 1, Mol. Cell Biol. 15 (1995) 4597-4605.

[167] M.P.Wentz, B.E.Moore, M.W.Cloyd, S.M.Berget, and L.A.Donehower, A naturally arising mutation of a potential silencer of exon splicing in human immunodeficiency virus type 1 induces dominant aberrant splicing and arrests virus production, J. Virol. 71 (1997) 85428551. 
[168] C.G.Burd and G.Dreyfuss, RNA binding specificity of hnRNP A1: significance of hnRNP A1 high-affinity binding sites in pre-mRNA splicing, EMBO J. 13 (1994) 1197-1204.

[169] R.C.Chan and D.L.Black, The polypyrimidine tract binding protein binds upstream of neural cell-specific c-src exon N1 to repress the splicing of the intron downstream, Mol. Cell Biol. 17 (1997) 4667-4676.

[170] C.R.Rothrock, A.E.House, and K.W.Lynch, HnRNP L represses exon splicing via a regulated exonic splicing silencer, EMBO J. 24 (2005) 2792-2802.

[171] A.N.Ladd and T.A.Cooper, Finding signals that regulate alternative splicing in the postgenomic era, Genome Biol. 3 (2002) reviews0008.

[172] R.Sorek and G.Ast, Intronic sequences flanking alternatively spliced exons are conserved between human and mouse, Genome Res. 13 (2003) 1631-1637.

[173] G.W.Yeo, N.E.Van, D.Holste, T.Poggio, and C.B.Burge, Identification and analysis of alternative splicing events conserved in human and mouse, Proc. Natl. Acad. Sci. U. S. A 102 (2005) 2850-2855 .

[174] R.H.Hovhannisyan and R.P.Carstens, A novel intronic cis element, ISE/ISS-3, regulates rat fibroblast growth factor receptor 2 splicing through activation of an upstream exon and repression of a downstream exon containing a noncanonical branch point sequence, Mol. Cell Biol. 25 (2005) 250-263. 
[175] R.H.Hovhannisyan, C.C.Warzecha, and R.P.Carstens, Characterization of sequences and mechanisms through which ISE/ISS-3 regulates FGFR2 splicing, Nucleic Acids Res. 34 (2006) 373-385.

[176] G.Dreyfuss, M.J.Matunis, S.Pinol-Roma, and C.G.Burd, hnRNP proteins and the biogenesis of mRNA, Annu. Rev. Biochem. 62 (1993) 289-321.

[177] S.Nakielny and G.Dreyfuss, Transport of proteins and RNAs in and out of the nucleus, Cell 99 (1999) 677-690.

[178] K.Bomsztyk, O.Denisenko, and J.Ostrowski, hnRNP K: one protein multiple processes, Bioessays 26 (2004) 629-638.

[179] J.Ostrowski, D.S.Schullery, O.N.Denisenko, Y.Higaki, J.Watts, R.Aebersold, L.Stempka, M.Gschwendt, and K.Bomsztyk, Role of tyrosine phosphorylation in the regulation of the interaction of heterogenous nuclear ribonucleoprotein $\mathrm{K}$ protein with its protein and RNA partners, J. Biol. Chem. 275 (2000) 3619-3628.

[180] J.Ostrowski, Y.Kawata, D.S.Schullery, O.N.Denisenko, Y.Higaki, C.K.Abrass, and K.Bomsztyk, Insulin alters heterogeneous nuclear ribonucleoprotein K protein binding to DNA and RNA, Proc. Natl. Acad. Sci. U. S. A 98 (2001) 9044-9049.

[181] J.Ostrowski, Y.Kawata, D.S.Schullery, O.N.Denisenko, and K.Bomsztyk, Transient recruitment of the hnRNP K protein to inducibly transcribed gene loci, Nucleic Acids Res. 31 (2003) 3954-3962. 
[182] D.T.Braddock, J.L.Baber, D.Levens, and G.M.Clore, Molecular basis of sequence-specific single-stranded DNA recognition by KH domains: solution structure of a complex between hnRNP K KH3 and single-stranded DNA, EMBO J. 21 (2002) 3476-3485.

[183] K.Klimek-Tomczak, L.S.Wyrwicz, S.Jain, K.Bomsztyk, and J.Ostrowski, Characterization of hnRNP K protein-RNA interactions, J. Mol. Biol. 342 (2004) 1131-1141.

[184] J.Ostrowski, K.Klimek-Tomczak, L.S.Wyrwicz, M.Mikula, D.S.Schullery, and K.Bomsztyk, Heterogeneous nuclear ribonucleoprotein K enhances insulin-induced expression of mitochondrial UCP2 protein, J. Biol. Chem. 279 (2004) 54599-54609.

[185] J.Ostrowski, D.S.Schullery, O.N.Denisenko, Y.Higaki, J.Watts, R.Aebersold, L.Stempka, M.Gschwendt, and K.Bomsztyk, Role of tyrosine phosphorylation in the regulation of the interaction of heterogenous nuclear ribonucleoprotein $\mathrm{K}$ protein with its protein and RNA partners, J. Biol. Chem. 275 (2000) 3619-3628.

[186] J.Ostrowski, Y.Kawata, D.S.Schullery, O.N.Denisenko, Y.Higaki, C.K.Abrass, and K.Bomsztyk, Insulin alters heterogeneous nuclear ribonucleoprotein K protein binding to DNA and RNA, Proc. Natl. Acad. Sci. U. S. A 98 (2001) 9044-9049.

[187] D.S.Schullery, J.Ostrowski, O.N.Denisenko, L.Stempka, M.Shnyreva, H.Suzuki, M.Gschwendt, and K.Bomsztyk, Regulated interaction of protein kinase Cdelta with the heterogeneous nuclear ribonucleoprotein K protein, J. Biol. Chem. 274 (1999) 15101-15109.

[188] S.Pinol-Roma, M.S.Swanson, J.G.Gall, and G.Dreyfuss, A novel heterogeneous nuclear RNP protein with a unique distribution on nascent transcripts, J. Cell Biol. 109 (1989) 2575-2587. 
[189] B.Hahm, Y.K.Kim, J.H.Kim, T.Y.Kim, and S.K.Jang, Heterogeneous nuclear ribonucleoprotein $\mathrm{L}$ interacts with the 3 ' border of the internal ribosomal entry site of hepatitis C virus, J. Virol. 72 (1998) 8782-8788.

[190] B.J.Hamilton, R.C.Nichols, H.Tsukamoto, R.J.Boado, W.M.Pardridge, and W.F.Rigby, hnRNP A2 and hnRNP L bind the 3'UTR of glucose transporter 1 mRNA and exist as a complex in vivo, Biochem. Biophys. Res. Commun. 261 (1999) 646-651.

[191] S.C.Shih and K.P.Claffey, Regulation of human vascular endothelial growth factor mRNA stability in hypoxia by heterogeneous nuclear ribonucleoprotein L, J. Biol. Chem. 274 (1999) $1359-1365$.

[192] J.Hui, G.Reither, and A.Bindereif, Novel functional role of CA repeats and hnRNP L in RNA stability, RNA. 9 (2003) 931-936.

[193] J.Hui, K.Stangl, W.S.Lane, and A.Bindereif, HnRNP L stimulates splicing of the eNOS gene by binding to variable-length CA repeats, Nat. Struct. Biol. 10 (2003) 33-37.

[194] A.Mayeda, S.H.Munroe, J.F.Caceres, and A.R.Krainer, Function of conserved domains of hnRNP A1 and other hnRNP A/B proteins, EMBO J. 13 (1994) 5483-5495.

[195] T.Kozu, B.Henrich, and K.P.Schafer, Structure and expression of the gene (HNRPA2B1) encoding the human hnRNP protein A2/B1, Genomics 25 (1995) 365-371.

[196] C.G.Burd, M.S.Swanson, M.Gorlach, and G.Dreyfuss, Primary structures of the heterogeneous nuclear ribonucleoprotein $\mathrm{A} 2, \mathrm{~B} 1$, and $\mathrm{C} 2$ proteins: a diversity of RNA binding 
proteins is generated by small peptide inserts, Proc. Natl. Acad. Sci. U. S. A 86 (1989) 97889792.

[197] E.J.Wagner and M.A.Garcia-Blanco, Polypyrimidine tract binding protein antagonizes exon definition, Mol. Cell Biol. 21 (2001) 3281-3288.

[198] I.Perez, C.H.Lin, J.G.McAfee, and J.G.Patton, Mutation of PTB binding sites causes misregulation of alternative 3' splice site selection in vivo, RNA. 3 (1997) 764-778.

[199] I.Perez, J.G.McAfee, and J.G.Patton, Multiple RRMs contribute to RNA binding specificity and affinity for polypyrimidine tract binding protein, Biochemistry 36 (1997) 11881-11890.

[200] B.Charlet, P.Logan, G.Singh, and T.A.Cooper, Dynamic antagonism between ETR-3 and PTB regulates cell type-specific alternative splicing, Mol. Cell 9 (2002) 649-658.

[201] N.Rooke, V.Markovtsov, E.Cagavi, and D.L.Black, Roles for SR proteins and hnRNP A1 in the regulation of c-src exon N1, Mol. Cell Biol. 23 (2003) 1874-1884.

[202] H.Shen, J.L.Kan, C.Ghigna, G.Biamonti, and M.R.Green, A single polypyrimidine tract binding protein (PTB) binding site mediates splicing inhibition at mouse IgM exons M1 and M2, RNA. 10 (2004) 787-794.

[203] B.Honore, H.H.Rasmussen, H.Vorum, K.Dejgaard, X.Liu, P.Gromov, P.Madsen, B.Gesser, N.Tommerup, and J.E.Celis, Heterogeneous nuclear ribonucleoproteins $\mathrm{H}, \mathrm{H}$ ', and $\mathrm{F}$ are members of a ubiquitously expressed subfamily of related but distinct proteins encoded by genes mapping to different chromosomes, J. Biol. Chem. 270 (1995) 28780-28789. 
[204] M.Caputi and A.M.Zahler, Determination of the RNA binding specificity of the heterogeneous nuclear ribonucleoprotein (hnRNP) H/H'/F/2H9 family, J. Biol. Chem. 276 (2001) 43850-43859.

[205] C.D.Chen, R.Kobayashi, and D.M.Helfman, Binding of hnRNP H to an exonic splicing silencer is involved in the regulation of alternative splicing of the rat beta-tropomyosin gene, Genes Dev. 13 (1999) 593-606.

[206] D.J.Elliott, K.Oghene, G.Makarov, O.Makarova, T.B.Hargreave, A.C.Chandley, I.C.Eperon, and H.J.Cooke, Dynamic changes in the subnuclear organisation of pre-mRNA splicing proteins and RBM during human germ cell development, J. Cell Sci. 111 ( Pt 9) (1998) 12551265.

[207] M.T.Nasim, T.K.Chernova, H.M.Chowdhury, B.G.Yue, and I.C.Eperon, HnRNP G and Tra2beta: opposite effects on splicing matched by antagonism in RNA binding, Hum. Mol. Genet. 12 (2003) 1337-1348.

[208] B.R.Graveley, K.J.Hertel, and T.Maniatis, The role of U2AF35 and U2AF65 in enhancerdependent splicing, RNA. 7 (2001) 806-818.

[209] P.Zuo and T.Maniatis, The splicing factor U2AF35 mediates critical protein-protein interactions in constitutive and enhancer-dependent splicing, Genes Dev. 10 (1996) 13561368.

[210] J.L.Kan and M.R.Green, Pre-mRNA splicing of IgM exons M1 and M2 is directed by a juxtaposed splicing enhancer and inhibitor, Genes Dev. 13 (1999) 462-471. 
[211] A.M.Zahler, C.K.Damgaard, J.Kjems, and M.Caputi, SC35 and heterogeneous nuclear ribonucleoprotein $\mathrm{A} / \mathrm{B}$ proteins bind to a juxtaposed exonic splicing enhancer/exonic splicing silencer element to regulate HIV-1 tat exon 2 splicing, J. Biol. Chem. 279 (2004) 1007710084.

[212] R.Lemaire, A.Winne, M.Sarkissian, and R.Lafyatis, SF2 and SRp55 regulation of CD45 exon 4 skipping during T cell activation, Eur. J. Immunol. 29 (1999) 823-837.

[213] G.B.ten Dam, C.F.Zilch, D.Wallace, B.Wieringa, P.C.Beverley, L.G.Poels, and G.R.Screaton, Regulation of alternative splicing of CD45 by antagonistic effects of SR protein splicing factors, J. Immunol. 164 (2000) 5287-5295.

[214] B.J.Blencowe, G.Bauren, A.G.Eldridge, R.Issner, J.A.Nickerson, E.Rosonina, and P.A.Sharp, The SRm160/300 splicing coactivator subunits, RNA. 6 (2000) 111-120.

[215] N.A.Patel, C.E.Chalfant, J.E.Watson, J.R.Wyatt, N.M.Dean, D.C.Eichler, and D.R.Cooper, Insulin regulates alternative splicing of protein kinase $\mathrm{C}$ beta II through a phosphatidylinositol 3-kinase-dependent pathway involving the nuclear serine/arginine-rich splicing factor, SRp40, in skeletal muscle cells, J. Biol. Chem. 276 (2001) 22648-22654.

[216] N.A.Patel, D.C.Eichler, D.S.Chappell, P.A.Illingworth, C.E.Chalfant, M.Yamamoto, N.M.Dean, J.R.Wyatt, K.Mebert, J.E.Watson, and D.R.Cooper, The protein kinase C beta II exon confers mRNA instability in the presence of high glucose concentrations, J. Biol. Chem. 278 (2003) 1149-1157.

[217] N.A.Patel, S.Kaneko, H.S.Apostolatos, S.S.Bae, J.E.Watson, K.Davidowitz, D.S.Chappell, M.J.Birnbaum, J.Q.Cheng, and D.R.Cooper, Molecular and genetic studies imply Akt- 
mediated signaling promotes protein kinase CbetaII alternative splicing via phosphorylation of serine/arginine-rich splicing factor SRp40, J. Biol. Chem. 280 (2005) 14302-14309.

[218] Y.Ke, J.Ash, and L.F.Johnson, Splicing signals are required for S-phase regulation of the mouse thymidylate synthase gene, Mol. Cell Biol. 16 (1996) 376-383.

[219] K.E.Baker and R.Parker, Nonsense-mediated mRNA decay: terminating erroneous gene expression, Curr. Opin. Cell Biol. 16 (2004) 293-299.

[220] M.Antoniou, F.Geraghty, J.Hurst, and F.Grosveld, Efficient 3'-end formation of human betaglobin mRNA in vivo requires sequences within the last intron but occurs independently of the splicing reaction, Nucleic Acids Res. 26 (1998) 721-729.

[221] N.Custodio, M.Carmo-Fonseca, F.Geraghty, H.S.Pereira, F.Grosveld, and M.Antoniou, Inefficient processing impairs release of RNA from the site of transcription, EMBO J. 18 (1999) 2855-2866.

[222] L.E.Maquat, A.J.Kinniburgh, L.R.Beach, G.R.Honig, J.Lazerson, W.B.Ershler, and J.Ross, Processing of human beta-globin mRNA precursor to mRNA is defective in three patients with beta+-thalassemia, Proc. Natl. Acad. Sci. U. S. A 77 (1980) 4287-4291.

[223] L.E.Maquat, When cells stop making sense: effects of nonsense codons on RNA metabolism in vertebrate cells, RNA. 1 (1995) 453-465.

[224] Z.Wang, M.E.Rolish, G.Yeo, V.Tung, M.Mawson, and C.B.Burge, Systematic identification and analysis of exonic splicing silencers, Cell 119 (2004) 831-845. 
[225] M.J.Moore and M.Rosbash, Cell biology. TAPping into mRNA export, Science 294 (2001) 1841-1842.

[226] P.Hilleren, T.McCarthy, M.Rosbash, R.Parker, and T.H.Jensen, Quality control of mRNA 3'end processing is linked to the nuclear exosome, Nature 413 (2001) 538-542.

[227] D.Muhlrad and R.Parker, Premature translational termination triggers mRNA decapping, Nature 370 (1994) 578-581.

[228] S.W.Peltz and A.Jacobson, mRNA stability: in trans-it, Curr. Opin. Cell Biol. 4 (1992) 979983.

[229] S.W.Peltz, A.H.Brown, and A.Jacobson, mRNA destabilization triggered by premature translational termination depends on at least three cis-acting sequence elements and one transacting factor, Genes Dev. 7 (1993) 1737-1754.

[230] L.E.Maquat, A.J.Kinniburgh, E.A.Rachmilewitz, and J.Ross, Unstable beta-globin mRNA in mRNA-deficient beta o thalassemia, Cell 27 (1981) 543-553.

[231] M.R.Culbertson, RNA surveillance. Unforeseen consequences for gene expression, inherited genetic disorders and cancer, Trends Genet. 15 (1999) 74-80.

[232] P.A.Frischmeyer and H.C.Dietz, Nonsense-mediated mRNA decay in health and disease, Hum. Mol. Genet. 8 (1999) 1893-1900.

[233] M.W.Hentze and A.E.Kulozik, A perfect message: RNA surveillance and nonsense-mediated decay, Cell 96 (1999) 307-310. 
[234] J.Cheng and L.E.Maquat, Nonsense codons can reduce the abundance of nuclear mRNA without affecting the abundance of pre-mRNA or the half-life of cytoplasmic mRNA, Mol. Cell Biol. 13 (1993) 1892-1902.

[235] I.O.Daar and L.E.Maquat, Premature translation termination mediates triosephosphate isomerase mRNA degradation, Mol. Cell Biol. 8 (1988) 802-813.

[236] M.S.Carter, J.Doskow, P.Morris, S.Li, R.P.Nhim, S.Sandstedt, and M.F.Wilkinson, A regulatory mechanism that detects premature nonsense codons in T-cell receptor transcripts in vivo is reversed by protein synthesis inhibitors in vitro, J. Biol. Chem. 270 (1995) 2899529003.

[237] M.S.Carter, S.Li, and M.F.Wilkinson, A splicing-dependent regulatory mechanism that detects translation signals, EMBO J. 15 (1996) 5965-5975.

[238] J.Zhang, X.Sun, Y.Qian, J.P.LaDuca, and L.E.Maquat, At least one intron is required for the nonsense-mediated decay of triosephosphate isomerase mRNA: a possible link between nuclear splicing and cytoplasmic translation, Mol. Cell Biol. 18 (1998) 5272-5283.

[239] O.Muhlemann, C.S.Mock-Casagrande, J.Wang, S.Li, N.Custodio, M.Carmo-Fonseca, M.F.Wilkinson, and M.J.Moore, Precursor RNAs harboring nonsense codons accumulate near the site of transcription, Mol. Cell 8 (2001) 33-43.

[240] S.Strudwick and K.L.Borden, The emerging roles of translation factor eIF4E in the nucleus, Differentiation 70 (2002) 10-22. 
[241] G.Mangiarotti, Coupling of transcription and translation in Dictyostelium discoideum nuclei, Biochemistry 38 (1999) 3996-4000.

[242] J.Wang, Y.F.Chang, J.I.Hamilton, and M.F.Wilkinson, Nonsense-associated altered splicing: a frame-dependent response distinct from nonsense-mediated decay, Mol. Cell 10 (2002) 951957.

[243] J.S.Butler, The yin and yang of the exosome, Trends Cell Biol. 12 (2002) 90-96.

[244] C.Y.Chen, R.Gherzi, S.E.Ong, E.L.Chan, R.Raijmakers, G.J.Pruijn, G.Stoecklin, C.Moroni, M.Mann, and M.Karin, AU binding proteins recruit the exosome to degrade ARE-containing mRNAs, Cell 107 (2001) 451-464.

[245] C.Allmang, J.Kufel, G.Chanfreau, P.Mitchell, E.Petfalski, and D.Tollervey, Functions of the exosome in rRNA, snoRNA and snRNA synthesis, EMBO J. 18 (1999) 5399-5410.

[246] M.W.Briggs, K.T.Burkard, and J.S.Butler, Rrp6p, the yeast homologue of the human PM-Scl 100-kDa autoantigen, is essential for efficient 5.8 S rRNA 3' end formation, J. Biol. Chem. 273 (1998) 13255-13263. 


\section{Chapter 2}

\section{Development of Techniques to Identify RNA Binding Proteins}

The following data in this chapter (Figures 1, 3, 4, and Table 1) were incorporated into a manuscript recently published in the Journal of Biological Chemistry. Szeszel-Fedorowicz W, Talukdar I, Griffith BN, Walsh CM, Salati LM. An exonic splicing silencer is involved in the regulated splicing of glucose 6-phosphate dehydrogenase mRNA. J Biol Chem. 2006 Nov 10;281(45):34146-58. Epub 2006 Sep 15. 


\section{Development of Techniques to Identify RNA Binding Proteins}

\section{SUMMARY}

Isolation of proteins that specifically interact with a given RNA regulatory element is essential for studies on the molecular mechanisms of gene expression. RNA affinity purification protocol that consists of an RNA oligo bound to adipic-acid agarose beads. The RNA oligo is covalently bound via the free 3' hydroxyl group to sodium periodate treated adipic acid dihydrazide-agarose beads. The bound proteins are run on SDS-PAGE and colloidal Coomassie stained protein bands are cut out and subjected to trypsin digestion prior to mass spectrometry (MS) analysis. Using this method, hnRNP K, L, I, E1, and A2/B1 proteins were found to be associated with the glucose-6-phosphate dehdyrogenase (G6PD) mRNA exon splicing silencer sequence (ESS) located within nucleotides 43 to 72 of exon 12 . The ability of this assay to differentiate such small RNA sequences will help define RNA regulatory sequences and their respective protein binding partners. RNA affinity purifications schemes have often used long RNA sequences; however, we have used 15 nucleotide RNA oligos to purify essential proteins. RNA oligos were used in a RNA affinity assay to purify specific proteins bound to RNA oligos.

The RNA oligos were able to successfully purify several HeLa cell nuclear extract proteins, heterogeneous nuclear ribonuclear protein (hnRNP) K, L, I, E1 and A2/B1, bound to the conserved exon splicing sequence within exon 12 of G6PD mRNA. 


\section{INTRODUCTION}

The interaction of RNA binding proteins with their RNA targets plays a critical role in RNA processing [1], polyadenylation [2], nuclear exit [3], RNA interference [4-6], and cytoplasmic RNA degradation [7-9]. Qualitative methods for initial identification of RNAprotein interactions such as immunoprecipitation, and tag-based methods, such as tandem affinity purification have undergone significant evolution in the past few years $[10,11]$. However, a method that provides accurate identification of proteins bound to 15 nucleotide oligonucleotides (oligos) will facilitate the purification and identification of only a subset of proteins bound to RNA sequences. This method facilitates the covalently binding of short RNA oligos to adipic acid dihydrazide-agarose beads prior to purification and identification with Liquid Chromatography-Tandem Mass Spectrometry (LC-MS/MS) Analysis, Matrix-Assisted Laser Desorption/Ionization-Time of Flight (MALDI-TOF) Mass Spectrometry Analysis and Western analysis. In order to validate this method we will perform protein purification and identification by evaluating the proteins bound to an exonic splicing silencer sequence (ESS) found within exon 12 of G6PD mRNA. G6PD is posttranscriptionally regulated by an exon splicing silencer located within exon 12 and identification of proteins bound via this ESS will be fundamental in characterization of a novel gene regulatory pathway $[12,13]$.

In this report, we present evidence that hnRNP $\mathrm{K}, \mathrm{L}, \mathrm{I}$ and $\mathrm{A} 2 / \mathrm{B} 1$ proteins are bound to the ESS1 site within exon 12. Using the modified approach we have identified a region of G6PD exon 12 mRNA from nucleotides 65-79 essential for hnRNP K, L, I, A2/B1 binding; however, purification of these proteins required a 30 nucleotide RNA element corresponding to nucleotides 50-79 of exon 12. These data are consistent with a role for these proteins in 
silencing the splicing of G6PD pre-mRNA. The identification of these regulatory proteins provides new information on the breadth of mechanisms by which hnRNP proteins are involved in constitutive splicing of G6PD mRNA.

\section{$\underline{\text { METHODS }}$}

\section{Cell growth and nuclear extract preparation}

HeLa cells (American Type Culture Collection, Rockville, MD) were grown in MEM medium containing $10 \%$ heat inactivated fetal bovine serum. Nuclear extracts from HeLa cells were isolated by a modification of the Dignam protocol $[14,15]$. All buffers contained $0.1 \mathrm{mM}$ phenylmethylsulfonyl fluoride (PMSF) and $0.5 \mathrm{mM}$ dithiothreitol (DTT). Nuclei were extracted in $350 \mathrm{mM} \mathrm{KCl}$ in the presence of protease inhibitor cocktail COMPLETE (Roche). Aliquots of the extracts were frozen and stored at $-80^{\circ} \mathrm{C}$. Protein concentrations were determined using the Bradford assay (Bio-Rad) and were typically in the range of $1-2 \mu \mathrm{g} / \mu \mathrm{l}$. HeLa cell nuclear extracts were also purchased from Promega and ProteinOne.

In vitro transcription of $R N A$ substrates

Plasmid E12 contained the 93 nucleotide exon 12 of G6PD mRNA and was generated by the PCR using the 5' primer AATAAGCTTTGATGAACTCAGGGA and the 3' primer ATTTCTAGACTGCCATATACATAG. The 5' primer contained a HindIII restriction site and the 3' primer contained an Xba1 site. The PCR amplified insert was subcloned in $\mathrm{pKS}^{+}$vector (Stratagene) using the corresponding restriction sites. Probes were either gel purified or purified using sephadex G50 spin columns (Amersham). Exon 12 $\Delta^{1}$ probe (nucleotides 56-93 of exon 12) was created using the PCR with the following 5' primer 
ATAAAGCTTCTGCTGCACAAGATTGAT and the 3' primer ATTTCTAGACTGCCAT

ATACATAG to generate an insert that was subcloned into the pKS + plasmid. Exon $12 \Delta^{2}$ probe (nucleotides 66-93 of exon 12) was generated with the same 3' primer and the following 5' primer TGAAAGCTTATTGATCGAGAAAAGCC and the amplified fragment was inserted into $\mathrm{pKS}^{+}$plasmid. All PCR purified inserts were produced from a HindIII/HindIII insert of G6PD genomic DNA. The purified products were sequenced and the sequence was verified with the NCBI database sequence of G6PD (BCOOO337).

The RNA probes were synthesized with T3 polymerase to generate the RNA strand as described [16]. Briefly, plasmids were linearized with appropriate restriction enzymes, RNA templates were transcribed with T3 RNA polymerase in the presence of $500 \mathrm{mM}$ (each) ATP, UTP, and GTP; $50 \mathrm{mM} \mathrm{CTP;} \mathrm{and} 50 \mu \mathrm{Ci}$ of $\alpha^{32} \mathrm{P}-\mathrm{CTP}$ (MP Biomedicals). RNAs were gel purified by separating them on a 5\% denaturing polyacrylamide gel. RNA was visualized by autoradiography and probes were cut from the gel and purified by crushing and extracting them in RNA extraction buffer (Ambion). RNAs were purified with 1/10 volume of $5 \mathrm{M}$ sodium acetate and 2.5 volumes of $100 \%$ ethanol at $-20^{\circ} \mathrm{C}$ for $1 \mathrm{~h}$ followed by centrifugation at $10,000 \mathrm{~g}$ for $30 \mathrm{~min}$ at $37^{\circ} \mathrm{C}$. The purified RNA was dissolved in EB buffer (Qiagen) and the activity of the RNA probe was measured using a scintillation counter.

\section{RNA Oligos}

The RNA oligos (IDT) correspond to 15 nucleotide regions of exon 12 G6PD mRNA. The RNA oligos corresponded to nucleotides 50-64, 65-79 and 79-93. Two RNA oligos were designed as positive and negative controls. RNA oligo, hnRNPA1 was designed to contain the following sequence UAGGGACUUAGGGUG based upon known data of hnRNPA1 high 
affinity binding sites [17]. The negative control oligo was a non-specific oligo that was predicted by the ESE database http://exon.cshl.edu/ESE [18] and the ESS data bases, http://genes.mit.edu/fas-ess [19], and http://cubweb.biology.columbia.edu/pesx [20], to have limited protein binding sites and the sequence of the non-specific oligo was CAAAAGCAUGCAAAA. An additional 30 nucleotide oligo was designed to nucleotides 50-79 of exon 12 to increase the quantity of protein bound by decreasing steric hindrance between the protein and the adipic acid beads. RNA oligos were labeled with $\gamma-\mathrm{P}^{32}$-ATP using a kinase Max kit (Ambion). Briefly, RNA oligos were incubated with $1 \mathrm{X}$ kinase buffer (Ambion) with $\gamma-\mathrm{P}^{32}$ ATP $(7,000 \mathrm{Ci} / \mathrm{mmol})$ (MP Biomedicals) for $1 \mathrm{hr}$ at $37^{\circ} \mathrm{C}$. Unincorpated nucleotides were removed using a Sephadex G50 spin column [17] (Amersham BioScience) according to the manufacturer's protocol.

\section{UV crosslinking}

UV cross-linking reaction mixtures contained 5 to $10 \mu \mathrm{g}$ of nuclear extract, 10 to $20 \mathrm{fmol}$ of substrate RNA (50,000 to $100,000 \mathrm{cpm}), 1 \mathrm{mM} \mathrm{ATP}, 0.7 \mathrm{mM} \mathrm{MgCl}_{2}$, and $40 \mathrm{ng}$ of carrier tRNA, brought to a $25-\mathrm{ml}$ final volume with nuclear extract dialysis buffer [15]. Reaction mixtures were incubated for 5 to $10 \mathrm{~min}$ at $30^{\circ} \mathrm{C}$ and then subjected to $\mathrm{UV}$ cross-linking on ice for $10 \mathrm{~min}$ in a Stratalinker $\left(1.8 \times 10^{6} \mathrm{~mJ} / \mathrm{cm}^{2}\right)$. In vitro transcribed RNA probes were treated with RNase A ( $1 \mathrm{mg} / \mathrm{ml})$ for $15 \mathrm{~min}$ at $37^{\circ} \mathrm{C}$. Reactions with RNA oligos were not treated with RNase A. Proteins were boiled for $5 \mathrm{~min}$ in cracking buffer $(80 \mathrm{mM}$ Tris-HCl, $\mathrm{pH}$ 6.8, $0.1 \mathrm{M}$ dithiothreitol, $2 \%$ sodium dodecyl sulfate (SDS), $10 \%$ glycerol, $0.2 \%$ bromphenolblue) and separated by SDS-10\% polyacrylamide gel electrophoresis (PAGE) [15]. 


\section{LC-MS/MS analysis}

Proteins binding to the RNA coated beads were separated by size in a $10 \%$ SDSpolyacrylamide gel. The proteins bands of interest were visualized by colloidal Coomassie blue and excised from the gels. The gel slices were digested with trypsin $(2 \mu \mathrm{g} / \mathrm{ml})$ overnight at $37^{\circ} \mathrm{C}$. The digested peptides were dried and reconstituted in 5\% acetonitrile, $0.1 \%$ formic acid and then loaded onto a $\mathrm{C}_{18}$ column using a helium pressure cell. Peptides were eluted from the column using a linear acetonitrile gradient of 5-50\% over $60 \mathrm{~min}$ with a flow rate $300 \mathrm{nl} / \mathrm{min}$. The iontrap mass spectrometer (ThermoFinnigan LCQ Deca PLUS) was programmed to perform a full MS scan followed by MS/MS scans of the five most abundant ions present. Raw data files were compared to the Swiss-Pro database using SEQUEST software to identify proteins that match the peptide fragments. Protein identification used very rigorous criteria to determine protein identification. Peptides sequenced by LC MS/MS have three charged states $(+1,+2$, and +3$)$ and each charge state produces a unique spectrum. Only those peptides with a $\Delta \mathrm{Cn}$ greater then 0.1 regardless of the charge state were accepted except in those peptides with very strong XCorr values. Peptides were accepted only if they meet the minimal XCorr scores of 1.9, 2.2, and 3.7 for the $+1,+2$, and +3 charge state peptides. Protein identifications were manually confirmed [21].

\section{Purification of RNA binding proteins}

RNAs were covalently linked to adipic acid dihydrazide-agarose beads by a modification of a published procedure [22,23]. Briefly, 1000 pmol of RNA were placed in a $400 \mu 1$ reaction mixture containing $100 \mathrm{mM}$ sodium acetate, $\mathrm{pH} 5.0$, and $5 \mathrm{mM}$ sodium m-periodate (Sigma). Reaction mixtures were incubated for $1 \mathrm{~h}$ in the dark at room temperature. The RNA was then 
ethanol-precipitated and resuspended in $500 \mu \mathrm{l}$ of $0.1 \mathrm{M}$ sodium acetate, $\mathrm{pH}$ 5.0. Adipic acid dihydrazide-agarose beads ( $400 \mu \mathrm{l})($ Sigma) were washed four times in $10 \mathrm{ml}$ of $0.1 \mathrm{M}$ sodium acetate, $\mathrm{pH} 5.0$, and pelleted after each wash at $300 \mathrm{rpm}$ for $2 \mathrm{~min}$ in a clinical centrifuge. After the final wash, $1000 \mu \mathrm{l}$ of $0.1 \mathrm{M}$ sodium acetate, $\mathrm{pH}$ 5.0, was added to the beads, and the slurry was then mixed with the periodate-treated RNA and rotated for $12 \mathrm{~h}$ at $4{ }^{\circ} \mathrm{C}$. The beads with the bound RNA were pelleted and washed three times in $1 \mathrm{ml}$ of $2 \mathrm{M} \mathrm{NaCl}$ and three times in $1 \mathrm{ml}$ of buffer (20 mM HEPES-KOH, pH 7.6, 10\% v/v glycerol, 150mM M KCl, $0.2 \mathrm{mM}$ EDTA) and $200 \mu \mathrm{g}$ tRNA to block nonspecific protein binding to the beads. The beads containing immobilized RNA were incubated in a reaction mixture containing 100-250 $\mu \mathrm{g}$ of HeLa cell nuclear extract with $300 \mu \mathrm{l}$ of, ATP $(2.5 \mathrm{mM}), \mathrm{MgCl}_{2}(2.0 \mathrm{mM})$, tRNA (500 ng) and buffer for $30 \mathrm{~min}$ at $30^{\circ} \mathrm{C}$. Beads were pelleted by centrifugation at $1000 \mathrm{rpm}$ for $2 \mathrm{~min}$ and washed four times with $1 \mathrm{ml}$ of buffer. After the final centrifugation to sediment the beads at 13,000 g the proteins bound to the immobilized RNA were eluted by $75 \mu 1$ of $80 \mathrm{mM}$ Tris-Cl, $\mathrm{pH} 6.8,0.1 \mathrm{M}$ dithiothrieitol, $2 \%$ SDS, $10 \%$ glycerol and $0.2 \%$ bromophenol blue by heating for $5 \mathrm{~min}$ at $95^{\circ} \mathrm{C}$.

\section{Western Blot Analysis}

Eluted proteins from the adipic acid dihydrazide-agarose beads bound to RNA oligonucleotides were separated on an 10\% SDS-polyacrylamide gel. Western blot analysis was as previously described [24]. The primary antibodies against hnRNP K, L, I and A2/B1 were obtained from ImmuQuest. Anti-mouse IgG2b (Zymed) and IgG (Bio-Rad) conjugated to horseradish peroxidase were used as secondary antibodies to detect hnRNP K, I and L, A2/B1, respectively. The immunocomplexes were detected by enhanced chemiluminescence (Pierce). 
Images were visualized with film (Pierce) and quantified by densitometry using ImageQuant (Molecular Dynamics).

\section{$\underline{\text { RESULTS }}$}

The nuclear extracts are commercially available from several sources and has provided a good quality extract to analyze in vitro transcription reactions [14], DNA/protein interactions [25], RNA-protein interactions [22], and protein-protein interactions [26]. In addition, HeLa cell nuclear extracts have been found to support in vitro splicing assays [27]. HeLa cells are a very well characterized cell line that seems to have the ability of producing high-quality nuclear extracts. HeLa cells produce a very high quality nuclear extract that is capable of recapitulating transcription, translation, splicing, and poly adenylation. In addition, HeLa cell nuclear extracts are also commercially available and methods for using these nuclear extracts are worked out. These nuclear extracts provide a good starting point for the characterization of proteins bound to the exonic RNA regulatory sequence found within exon 12 of G6PD mRNA.

In order to characterize the binding of RNA binding proteins to the exon splicing silencer sequence within exon 12 of G6PD, we performed UV crosslinking analysis with full-length exon 12 and HeLa cell nuclear extract (Figure 1A). Protein bands of approximately 37, 45, 50, 60, and $75 \mathrm{kDa}$ were observed (Figure 1B). The RNA-crosslinked proteins were digested with proteinase $\mathrm{K}$ to determine if these bands were RNA-RNA or RNA-protein complexes and as

shown in Figure 1B, lane 5, and all protein bands were abolished in the presence of proteinase $\mathrm{K}$ indicating that these bands were protein-RNA complexes and not RNA-RNA complexes. In addition, protein bands observed at 75-100 $\mathrm{kDa}$ indicated by the asterisk seem to be artifacts of the UV crosslinking assay, because they were not observed consistently throughout all 
experiments and were observed in an RNA probe containing regions of the $\mathrm{KS}^{+}$vector (Figure $1 \mathrm{C}$, lane 1). In addition, the binding of proteins to exon 12 was independent of ATP $(1 \mathrm{mM})$ as shown by the same pattern of proteins observed in the presence or absence of ATP (Figure 1C, lane 2 vs. lane 3).

To further map the region of exon 12 involved in protein binding the first 37 and 47 nucleotides of exon 12 were deleted (Figure 1A). The exon $12 \Delta^{1}$ RNA was a deletion of the first 37 nucleotides of exon 12 and there was no observable difference in protein binding with this RNA (Figure 1D). In addition, deletion of the first 47 nucleotides of exon 12, exon $12 \Delta^{2}$, showed a similar pattern as compared to full-length exon 12 RNA. Therefore, the first 47 nucleotides were not involved in the RNA binding of proteins (Figure 1D).

Further mapping studies were required to precisely map the RNA element and therefore RNA oligos were used. Non-overlapping oligos from nucleotides 50-93 were UV crosslinked with HeLa cell nuclear extract (Figure 2A). A positive control oligo to an hnRNP A1 binding site was designed [17]. This hnRNP A1 RNA oligo contains nucleotide 6 through 20 of an hnRNP A1 consensus sequence (Figure 2A). In addition, to being a high affinity site for hnRNP A1 other hnRNPs will also bind this sequence. Incubation of RNA oligos 5' labeled with $\gamma$ - $\mathrm{P}^{32}$ ATP with or without HeLa cell nuclear extract results in the appearance of several unique proteins bound for each oligo (Figure 2B). The ability of each RNA oligo to bind a unique set of protein bands indicates the specificity of this assay using short RNA oligos. Across multiple experiments several bands were consistently observed. The 50-64 nucleotide oligo bound several proteins at 75,55,50,45, and $40 \mathrm{kDa}$ (Figure 2B) and all of these protein were decreased in the presence of 100X unlabelled nucleotide 50-64 RNA oligo (lane 3, Figure 2B). The nucleotide 65-79 RNA oligo binds several proteins at 100, 60, 37, and $30 \mathrm{kDa}$ as shown in lane 5 
(Figure 2B). These proteins decrease in intensity in the presence of 100x unlabelled nucleotide 65-79 RNA oligo as shown in lane 6. The nucleotide 79-93 RNA oligo binds a series of bands at 75,50 , and $37 \mathrm{kDa}$ (lane 8 , Figure $2 \mathrm{~B}$ ). The most prominent band bound to this oligo is the 50 $\mathrm{kDa}$ band. All protein bands including the $50 \mathrm{kDa}$ band decreased in intensity with $100 \mathrm{x}$ unlabelled 79-93 nucleotide RNA oligo.

Recent findings have shown that a region from nucleotides 43-72 contain an exonic RNA regulatory sequence [12]. In addition exon 12 was shown to inhibit splicing suggesting that this region from nucleotides 43-72 contains an exonic splicing silencer sequence. Protein identification studies were performed in intact animals and these studies showed the differential binding of three hnRNP proteins to nucleotides 50-79. The identification of hnRNP L, K, and A2/B1 to this region suggests that these three proteins are involved in the constitutive splicing of G6PD mRNA by an exonic splicing silencer element [28]. These three proteins were identified by the differential binding of a 60 and a $37 \mathrm{kDa}$ band that was referred to as $\mathrm{A}$ and $\mathrm{B}$ for simplicity [28]. The binding of two similar size proteins is also observed in HeLa cell nuclear extracts (Figure 1B, lane 4; 1D, lane 1; and 2B). At this point these two bands will be identified and from now on as the 60 and $37 \mathrm{kDa}$ band.

The proteins in the 60 and $37 \mathrm{kDa}$ bands were purified using RNA-affinity purification and identified by LC-MS/MS analysis. RNA oligos 50-64, 65-79, 79-93, non-specific oligo, and an oligo containing 50-79 nucleotides were used in an RNA affinity assay (Figure 3). Each RNA oligo was covalently bound to adipic acid beads and incubated with HeLa cell nuclear extract (Figure 3). Proteins were separated with 10\% SDS-PAGE analysis and protein bands were visualized by SRYPO Ruby because of the sensitivity and compatibility with MS/MS analysis. The first observation is the ability of the adipic-acid bead purification to recapitulate the pattern 
of protein binding observed in the UV crosslinking. The longer RNA oligo containing 30 nucleotides was used in order to decrease possible steric hindrance of proteins bound in close proximity to the bead (Figure 3, lane 5). The nucleotide 50-79 oligo did increase protein binding, and the pattern was similar to the 65-79 nucleotide RNA oligo, but the band intensity was increased several fold as shown in three different experiments (Figure 3, lane 5 vs. lane 2). The boxes show the region that was cut from the SDS gel and sequenced by LC MS/MS analysis.

LC-MS/MS analysis determined that the $60 \mathrm{kDa}$ band contained three positive protein matches. The first protein identified was hnRNP K and hnRNP K was sequenced with greater then $40 \%$ sequence coverage and over 20 unique peptides were identified in the MS/MS run (Table 1). The second major protein was hnRNP I, also known as polyprimidine tract binding protein. This protein was sequenced with greater then $20 \%$ sequence coverage and six unique peptides were sequenced during the MS/MS run (Table 1). The final constituent was identified as hnRNP L, however the MS/MS data was weak with only $10 \%$ sequence coverage and only 3 unique peptides were identified by the LC-MS/MS. However, each peptide score was greater then the minimal scores needed for accurate protein determination. The $\Delta \mathrm{Cn}$ scores were greater then 0.1 and the XCorr values were greater then $1.9,2.2$, or 3.7, with a charged state of $+1,+2$, and +3 .

The identification of the $37 \mathrm{kDa}$ band revealed two hnRNP proteins referred to as hnRNP A2/B1 and hnRNP E1. The hnRNP A2/B1 was sequenced by greater than $20 \%$ and eight unique peptides were sequenced with high validity (Table 1). The hnRNP E1 protein was sequenced by $17 \%$ and four unique peptides were sequenced with high enough scores to consider this protein a positive match (Table 1). Each peptide was screened rigorously to ensure proper protein 
identification and all peptide scores were within the desired range of 0.1 and 1.9, 2.2, or 3.7 for $+1,+2$, or +3 charged state peptides for $\Delta \mathrm{Cn}$ and XCorr scores, respectively.

The RNA-affinity approach was used to purify those protein bands bound to the exonic RNA regulatory element found within exon 12 . To provide additional evidence on protein binding, Western blot analysis using antibodies to detect hnRNP K, L, I, A2/B1 and a nonspecific hnRNP M protein bound to the entire regulatory sequence from nucleotides 43-72. The protein identification from nucleotides 50-79 was carried out by LC MS/MS analysis and at this same time we further characterized a small region from nucleotides 43-50 was involved in G6PD mRNA splicing in an in vivo animal study. Therefore we validated that the proteins bound to nucleotides 50-79 were identical to the proteins bound to nucleotides 43-72 of exon 12 (Figure 4). As hypothesized identical patterns of protein binding was observed with nucleotides 50-79 and 43-72 confirming the identity of hnRNP K, L, I, and A2/B1 to an exon sequence within exon 12. The negative control in these experiments was the 79-93 oligo. The RNA sequences from nucleotides 43-72 and 79-93 were used in the RNA affinity purification of proteins prior to Western analysis with antibodies directed against hnRNP K, L, I, A2/B1, and hnRNP M. HnRNP K, L, I, and A2/B1 were only detected bound to nucleotides 43-72 and were not detected bound to nucleotides 79-93 (Figure 4). In addition, an additional negative control was used to determine the selectivity of this RNA affinity approach to purify non-specific proteins. An additional hnRNP family member, hnRNP M, was used to show selectivity within the assay. The protein hnRNP M consist of a subfamily of four isoforms (M1, M2, M3, and M4) that are known to bind to poly $\mathrm{G}$ and poly $\mathrm{U}$ rich regions with high affinity and are known to affect RNA transport [29] and RNA alternative splicing [30]. However, hnRNP M was not detected in 
Western analysis or in LC-MS/MS analysis confirming the specificity of this RNA-affinity approach to purifying authentic RNA binding proteins.

In this report we have presented evidence that a modified approach to the adipic-acid bead RNA affinity purification will allow the use of short RNA oligos to purify high affinity RNA binding proteins. In addition, the proteins at 60 and $37 \mathrm{kDa}$ bound to nucleotides $65-79$ were similar to those proteins observed in the full-length exon 12. One major disadvantage of this approach is the minimal length of the RNA oligos used in the assay. However, the ability of this assay to differentiate between sequences confirms the usefulness of this assay to characterize the molecular mechanisms of gene expression.

\section{DISCUSSION}

These experiments describe a technique to covalently link oxidized 15 nucleotide oligos to adipic acid agarose beads for the purification of RNA binding proteins. Purification of RNA binding proteins is fundamental in defining and characterizing molecular biological events. Therefore, the development of a purification scheme using short RNA oligos will allow the fundamental purification and characterization of RNA binding proteins important for RNA processing. Compared to reports using sequences greater then 100 nucleotides, the short oligo approach has the advantage of only purifying those specific proteins bound to the regulatory element. Because most RNA elements, ESEs and ESS, are six to ten nucleotides in length [31,32], the 15 nucleotide oligos are more likely to encompass the entire RNA regulatory sequence. This approach is not without disadvantages. The major disadvantage of the 15 nucleotide approach is the low recovery of proteins as compared to larger oligos, for example the 30 nucleotide oligos. 
In higher eukaryotes, pre-mRNA splicing is under the control of both positive and negative regulatory elements, located within exon or intron sequences. These sequences are usually small sequence specific sequences (4-20 nucleotides in length). These sequences are referred to as intronic or exonic splicing enhancers or silencers [33]. The exonic splicing enhancer sequences are most commonly bound by the SR family of splicing activator proteins $[19,34,35]$. The SR family of splicing activators is thought to enhance the interaction with U2AF35/65 and U1snRNP. In addition SR proteins recruit splicing co-activators like the Srm160 protein to the spliceosome [36-38]. Our study did not identify any potential SR proteins because of our methodology. In our experiments we used trypsin as a site specific protease to cleave our proteins into peptides. SR proteins are arginine rich and would have been digested to very small fragments by trypsin and therefore eluding detection via LC MS/MS. Other methods including different proteases like Trypsin C which cleaves only at lysine residues could be used in LC-MS/MS analysis. A recent published paper from Szeszel-Fedorowicz et al. has shown the binding of SRp75 and potentially ASF/SF2 and/or SC35 to nucleotides 43-72 of exon 12 G6PD mRNA by Western analysis [12].

Exon splicing silencer sequences (ESS) are known to function through binding of the hnRNP proteins $[33,39]$. HnRNP proteins are a structurally diverse family of proteins originally identified through their interaction with pre-mRNA $[33,39]$. Individual members of the hnRNP family are known to have specific effects on RNA processing and function, including both alternative and constitutive splicing $[8,40]$. The most common associated proteins to RNA are the hnRNP A/B, hnRNP I (PTB), hnRNP K and the hnRNP H protein. These proteins are known to repress splicing of many exons by binding to UAGG, UCUC, C-rich patches, and poly G motifs, respectively. The identification of hnRNP K bound to region 43-72 nucleotides of exon 
12 revealed a strong C-rich patch consisting of two C-rich patches within 65-72 nucleotides of exon 12. Further analysis of the sequence did not reveal any UAGG, UCUC, or poly G motifs within the region of 43-72 nucleotides of exon 12. The interaction of hnRNP proteins with ESS elements are thought to inhibit the spliceosome assembly complex [17,41,42]. Identification of these proteins and many more unidentified proteins will increase the depth of knowledge about splicing and their role in constitutive and alternative splicing events. Originally it was thought that ESE sequences were more important but recent discoveries have concluded that ESS sequences are more important. Once we have identified specific proteins bound to specific sequences we can begin to understand the genomic and proteomic diversity within different cell types. The identification of hnRNP K, L, I, A2/B1 bound to a region from 43-72 nucleotides of exon 12 confirms our original hypothesis that exon 12 contains a cis-acting regulatory element that we will now call an ESS. Further identification and characterization of this element and its respective protein binding partners will be further characterized in HeLa cell nuclear extracts. 


\section{FOOTNOTES}

*This work was supported by National Institutes of Health Grant DK46897 (to L.M.S) and by American heart Association Mid-Ohio Valley 0315129B (to B.N.G.)

* G6PD, glucose-6-phosphate dehydrogenase; LC-MS/MS, liquid chromatography mass spectrometry/mass spectrometry; hnRNP, heterogeneous nuclear ribonucleoprotein; SR protein, serine-arginine protein; ESE, exonic splicing enhancer; ESS, Exonic splicing silencer; PCR, polymerase chain reaction, HEPES, N-2-hydroxyethyliperazine-N'-2ethanesulfonic acid; SDS, sodium dodecyl sulfate.

\section{ACKNOWLEDGMENTS}

We would like to thank Dr. Timothy Vincent and the proteomics facility for protein

identification and critically reviewing our data. We would also like to thank Dr. Massimo Caputi for help on the development of our bead protocol system. 
Table 1: The identification of hnRNP K, L, I, A2/B1 and E2 is bound to the RNA element within 50-79 nucleotides of exon 12. The 60 and $37 \mathrm{kDa}$ bands were excised from the gel digested with trypsin $(2 \mu \mathrm{g} / \mathrm{ml})$, prior to peptide purification. Peptides were eluted from a $\mathrm{C}_{18}$ column using a 5-50\% acetonitrile gradient. Each peptide with strong cross-correlation scores of greater then $1.9,2.7$, and 3.7 for $+1,+2$, and +3 peptides, respectively and $\Delta \mathrm{Cn}$ scores greater then 0.1 was considered a positive peptide match. Each peptide was then scanned using the SEQUEST software analysis tool in order to determine protein IDs.

\begin{tabular}{|c|c|c|c|c|c|c|}
\hline & Protein & Orgenism & $\begin{array}{c}\text { Accession } \\
\#\end{array}$ & $\begin{array}{c}\text { Mese } \\
\text { kDa }\end{array}$ & $\begin{array}{c}\% \\
\text { Sequence } \\
\text { covered }\end{array}$ & $\begin{array}{c}\text { Number of } \\
\text { Unique } \\
\text { Peptidee }\end{array}$ \\
\hline & ( hnRNP K & Human & 12230546 & 50.9 & 44.3 & 21 \\
\hline \multirow[t]{2}{*}{$60 \mathrm{kDa}$} & hnRNP I & Human & 131528 & 57.1 & 20.7 & 6 \\
\hline & hnRNP L & Human & 133274 & 60.1 & 10.9 & 3 \\
\hline \multirow{2}{*}{$37 \mathrm{kDa}$} & $\int \begin{array}{c}\text { hnRNP } \\
\text { A2/B1 }\end{array}$ & Human & 133257 & 37.4 & 26.3 & 8 \\
\hline & hnRNP E1 & Human & 12230408 & 37.4 & 17.1 & 4 \\
\hline
\end{tabular}


Figure 1: Exon 12 binds several proteins from HeLa cells as detected with UV crosslinking (a) The G6PD gene contains 13 exons and 12 introns. A series of RNAs was made to map the cisacting element responsible for protein binding. The full-length exon 12 contains 93 nucleotides of exon 12 , the exon $12 \Delta^{1}$ contains region 37-93 nucleotides of exon 12 and exon $12 \Delta^{2}$ contains region 47-93 nucleotides of exon 12. (b) Exon 12 RNA was incubated with or without HeLa cell nuclear extracts and UV crosslinked as described in the materials and methods. Proteins bound to the Exon 12 RNA element were abolished by the presence of proteinase $\mathrm{K}$. This figure is representative of six different nuclear extract experiments. (c) Protein binding was observed in the presence of ATP (lane 2) compared to the absence of ATP (lane 3). (d) Full-length exon 12 and the two deletion probes were used to identify sequence specific protein binding. All proteins were visualized by phosphor imager analysis. The series of protein bands bound to the exon 12 RNA elements were consistently observed in two separate nuclear extract preparations.

Figure 2: The fine mapping of the exon 12 protein binding siteusing RNA oligonucleotides. (a) The 15 nucleotides RNA oligos were designed to regions 50-93 nucleotides within exon 12 . A longer oligo was designed to nucleotides 50-79 of exon 12. The positive control RNA oligo is referred to as the hnRNP A1 consensus oligo. The non-specific oligo was a random 15 nucleotide oligo. (b) Each RNA oligo was mixed with HeLa cell nuclear extract and UV crosslinked as described in Materials and Methods. Competitor was the same oligo, unlabeled, and present at $100 \mathrm{X}$ concentration. The blots are representative of three different nuclear extract preparations. 
Figure 3: RNA affinity purification of the 60 and $37 \mathrm{kDa}$ protein bands bound to the RNA element located within 65-79 nucleotides of exon 12. A series of RNA oligos were covalently bound to adipic acid dihydrazide-agarose beads and used to purify the RNA bound proteins using the bead pull-down approach. An additional RNA oligo was designed to represent nucleotides 50-79 of exon 12. The asterisks represent non-specific proteins observed in varying intensities in all RNA oligos. The dotted boxes represent those bands that were manually excised from the gel for LC-MS/MS analysis. Only the bands in the 50-79 nucleotide oligo were excised from the gel. The bands labeled as A and B were 60 and $37 \mathrm{kDa}$, respectively and were consistently observed in all experiments.

Figure 4: Confirmation of hnRNP K, L, I, and A2/B1 binding to a region of G6PD mRNA from nucleotides 43-72 within exon 12. Two RNA oligos (nucleotides 43-72 and 79-93) were covalently bound to the adipic acid dihydrazide-agarose beads and incubated with $100 \mu \mathrm{g}$ of HeLa cell nuclear extract in the presence of splicing conditions. The proteins were purified using the bead pull-down approach and all proteins were separated on a 10\%-SDS polyacrylamide gel prior to western blotting. The input reflects $10 \%$ of the total HeLa cell nuclear extract used in the assay. 


\section{Reference List}

[1] M.S.Jurica and M.J.Moore, Pre-mRNA splicing: awash in a sea of proteins, Mol. Cell 12 (2003) $5-14$.

[2] U.Kuhn and E.Wahle, Structure and function of poly(A) binding proteins, Biochim. Biophys. Acta 1678 (2004) 67-84.

[3] J.A.Erkmann and U.Kutay, Nuclear export of mRNA: from the site of transcription to the cytoplasm, Exp. Cell Res. 296 (2004) 12-20.

[4] N.Agrawal, P.V.Dasaradhi, A.Mohmmed, P.Malhotra, R.K.Bhatnagar, and S.K.Mukherjee, RNA interference: biology, mechanism, and applications, Microbiol. Mol. Biol. Rev. 67 (2003) 657685.

[5] C.D.Novina and P.A.Sharp, The RNAi revolution, Nature 430 (2004) 161-164.

[6] M.Tijsterman and R.H.Plasterk, Dicers at RISC; the mechanism of RNAi, Cell 117 (2004) 1-3.

[7] R.E.Dodson and D.J.Shapiro, Regulation of pathways of mRNA destabilization and stabilization, Prog. Nucleic Acid Res. Mol. Biol. 72 (2002) 129-164.

[8] G.Dreyfuss, V.N.Kim, and N.Kataoka, Messenger-RNA-binding proteins and the messages they carry, Nat. Rev. Mol. Cell Biol. 3 (2002) 195-205.

[9] R.Parker and H.Song, The enzymes and control of eukaryotic mRNA turnover, Nat. Struct. Mol. Biol. 11 (2004) 121-127. 
[10] G.Rigaut, A.Shevchenko, B.Rutz, M.Wilm, M.Mann, and B.Seraphin, A generic protein purification method for protein complex characterization and proteome exploration, Nat. Biotechnol. 17 (1999) 1030-1032.

[11] S.A.Tenenbaum, P.J.Lager, C.C.Carson, and J.D.Keene, Ribonomics: identifying mRNA subsets in mRNP complexes using antibodies to RNA-binding proteins and genomic arrays, Methods 26 (2002) 191-198.

[12] W.Szeszel-Fedorowicz, I.Talukdar, B.N.Griffith, C.M.Walsh, and L.M.Salati, An exonic splicing silencer is involved in the regulated splicing of glucose 6-phosphate dehydrogenase mRNA, J. Biol. Chem. 281 (2006) 34146-34158.

[13] H.Tao, W.Szeszel-Fedorowicz, B.mir-Ahmady, M.A.Gibson, L.P.Stabile, and L.M.Salati, Inhibition of the splicing of glucose-6-phosphate dehydrogenase precursor mRNA by polyunsaturated fatty acids, J. Biol. Chem. 277 (2002) 31270-31278.

[14] J.D.Dignam, R.M.Lebovitz, and R.G.Roeder, Accurate transcription initiation by RNA polymerase II in a soluble extract from isolated mammalian nuclei, Nucleic Acids Res. 11 (1983) 1475-1489.

[15] G.Edwalds-Gilbert and C.Milcarek, Regulation of poly(A) site use during mouse B-cell development involves a change in the binding of a general polyadenylation factor in a B-cell stage-specific manner, Mol. Cell Biol. 15 (1995) 6420-6429.

[16] B.Amir-Ahmady and L.M.Salati, Regulation of the processing of glucose-6-phosphate dehydrogenase mRNA by nutritional status, J. Biol. Chem. 276 (2001) 10514-10523. 
[17] C.G.Burd and G.Dreyfuss, RNA binding specificity of hnRNP A1: significance of hnRNP A1 high-affinity binding sites in pre-mRNA splicing, EMBO J. 13 (1994) 1197-1204.

[18] L.Cartegni, S.L.Chew, and A.R.Krainer, Listening to silence and understanding nonsense: exonic mutations that affect splicing, Nat. Rev. Genet. 3 (2002) 285-298.

[19] Z.Wang, M.E.Rolish, G.Yeo, V.Tung, M.Mawson, and C.B.Burge, Systematic identification and analysis of exonic splicing silencers, Cell 119 (2004) 831-845.

[20] X.H.Zhang and L.A.Chasin, Computational definition of sequence motifs governing constitutive exon splicing, Genes Dev. 18 (2004) 1241-1250.

[21] A.J.Link, J.Eng, D.M.Schieltz, E.Carmack, G.J.Mize, D.R.Morris, B.M.Garvik, and J.R.Yates, III, Direct analysis of protein complexes using mass spectrometry, Nat. Biotechnol. 17 (1999) 676-682.

[22] M.Caputi, A.Mayeda, A.R.Krainer, and A.M.Zahler, hnRNP A/B proteins are required for inhibition of HIV-1 pre-mRNA splicing, EMBO J. 18 (1999) 4060-4067.

[23] J.O.Langland, S.M.Pettiford, and B.L.Jacobs, Nucleic acid affinity chromatography: preparation and characterization of double-stranded RNA agarose, Protein Expr. Purif. 6 (1995) 25-32.

[24] I.Talukdar, W.Szeszel-Fedorowicz, and L.M.Salati, Arachidonic acid inhibits the insulin induction of glucose-6-phosphate dehydrogenase via p38 MAP kinase, J. Biol. Chem. 280 (2005) 40660-40667.

[25] T.M.Kristie, J.H.LeBowitz, and P.A.Sharp, The octamer-binding proteins form multi-protein-DNA complexes with the HSV alpha TIF regulatory protein, EMBO J. 8 (1989) 4229-4238. 
[26] A.Ostareck-Lederer, D.H.Ostareck, K.P.Rucknagel, A.Schierhorn, B.Moritz, S.Huttelmaier, N.Flach, L.Handoko, and E.Wahle, Asymmetric arginine dimethylation of heterogeneous nuclear ribonucleoprotein $\mathrm{K}$ by protein-arginine methyltransferase 1 inhibits its interaction with c-Src, J. Biol. Chem. 281 (2006) 11115-11125.

[27] A.R.Krainer, T.Maniatis, B.Ruskin, and M.R.Green, Normal and mutant human beta-globin premRNAs are faithfully and efficiently spliced in vitro, Cell 36 (1984) 993-1005.

[28] B.N.Griffith, C.M.Walsh, W.Szeszel-Fedorowicz, A.T.Timperman, and L.M.Salati, Identification of hnRNPs $\mathrm{K}, \mathrm{L}$ and $\mathrm{A} 2 / \mathrm{B} 1$ as candidate proteins involved in the nutritional regulation of mRNA splicing, Biochim. Biophys. Acta (2006).

[29] E.Kiesler, M.E.Hase, D.Brodin, and N.Visa, Hrp59, an hnRNP M protein in Chironomus and Drosophila, binds to exonic splicing enhancers and is required for expression of a subset of mRNAs, J. Cell Biol. 168 (2005) 1013-1025.

[30] P.Kafasla, M.Patrinou-Georgoula, J.D.Lewis, and A.Guialis, Association of the 72/74-kDa proteins, members of the heterogeneous nuclear ribonucleoprotein M group, with the pre-mRNA at early stages of spliceosome assembly, Biochem. J. 363 (2002) 793-799.

[31] A.Goren, O.Ram, M.Amit, H.Keren, G.Lev-Maor, I.Vig, T.Pupko, and G.Ast, Comparative analysis identifies exonic splicing regulatory sequences--The complex definition of enhancers and silencers, Mol. Cell 22 (2006) 769-781.

[32] H.X.Liu, M.Zhang, and A.R.Krainer, Identification of functional exonic splicing enhancer motifs recognized by individual SR proteins, Genes Dev. 12 (1998) 1998-2012. 
[33] D.L.Black, Mechanisms of alternative pre-messenger RNA splicing, Annu. Rev. Biochem. 72 (2003) 291-336.

[34] W.G.Fairbrother and L.A.Chasin, Human genomic sequences that inhibit splicing, Mol. Cell Biol. 20 (2000) 6816-6825.

[35] X.D.Fu, Towards a splicing code, Cell 119 (2004) 736-738.

[36] B.J.Blencowe, R.Issner, J.A.Nickerson, and P.A.Sharp, A coactivator of pre-mRNA splicing, Genes Dev. 12 (1998) 996-1009.

[37] B.J.Blencowe, G.Bauren, A.G.Eldridge, R.Issner, J.A.Nickerson, E.Rosonina, and P.A.Sharp, The SRm160/300 splicing coactivator subunits, RNA. 6 (2000) 111-120.

[38] A.G.Eldridge, Y.Li, P.A.Sharp, and B.J.Blencowe, The SRm160/300 splicing coactivator is required for exon-enhancer function, Proc. Natl. Acad. Sci. U. S. A 96 (1999) 6125-6130.

[39] Z.M.Zheng, Regulation of alternative RNA splicing by exon definition and exon sequences in viral and mammalian gene expression, J. Biomed. Sci. 11 (2004) 278-294.

[40] A.M.Krecic and M.S.Swanson, hnRNP complexes: composition, structure, and function, Curr. Opin. Cell Biol. 11 (1999) 363-371.

[41] R.C.Chan and D.L.Black, The polypyrimidine tract binding protein binds upstream of neural cellspecific c-src exon N1 to repress the splicing of the intron downstream, Mol. Cell Biol. 17 (1997) 4667-4676.

[42] C.R.Rothrock, A.E.House, and K.W.Lynch, HnRNP L represses exon splicing via a regulated exonic splicing silencer, EMBO J. 24 (2005) 2792-2802. 


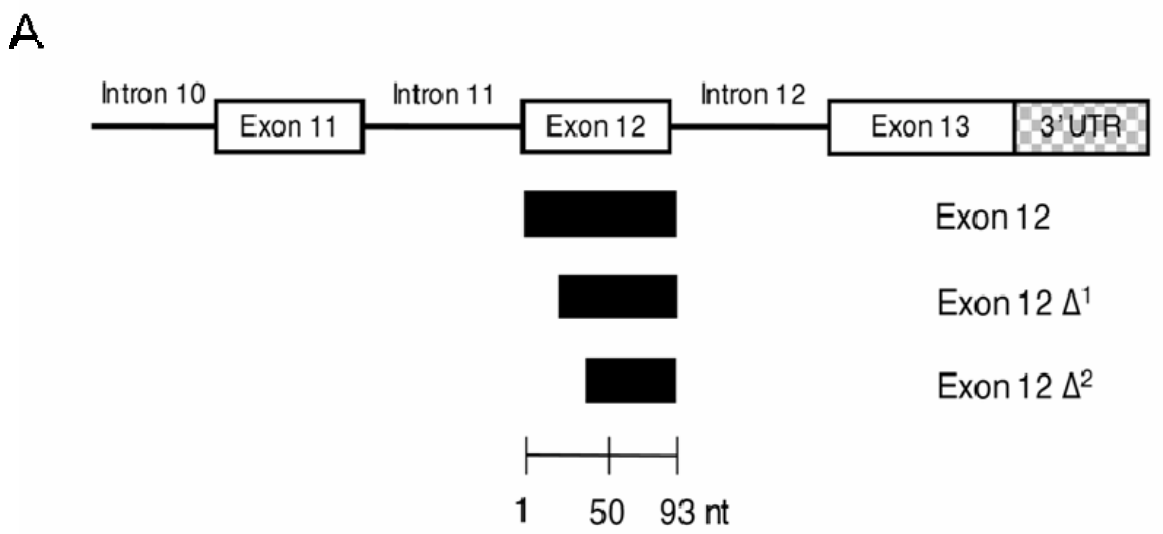

Figure 1 
B

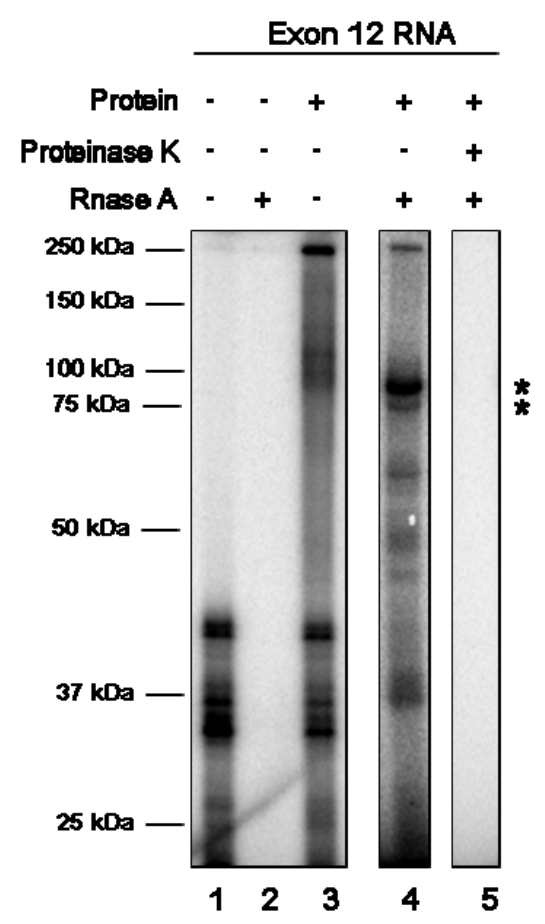

Figure 1 


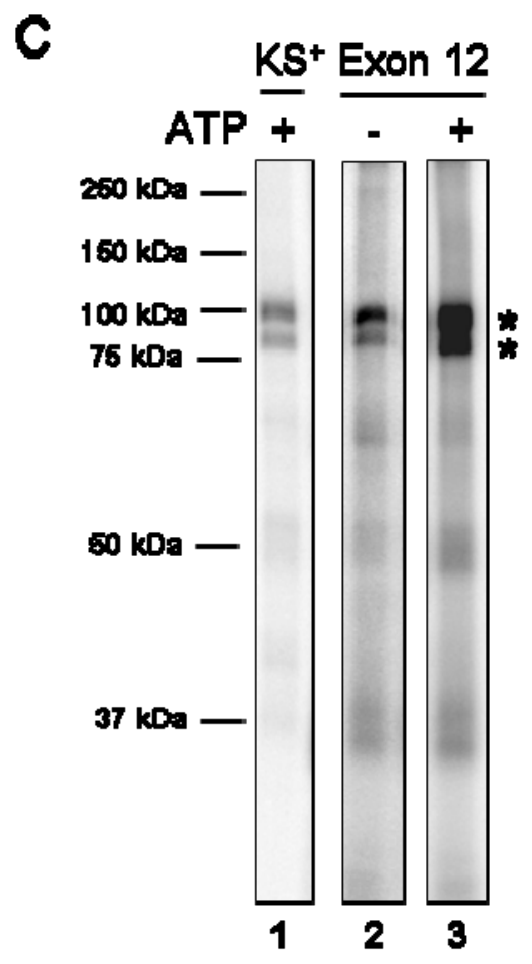

Figure 1 


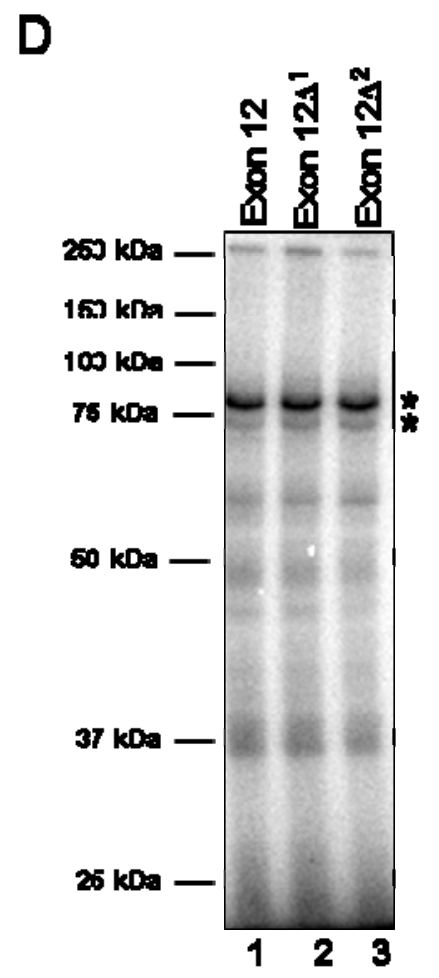

Flgure 1 


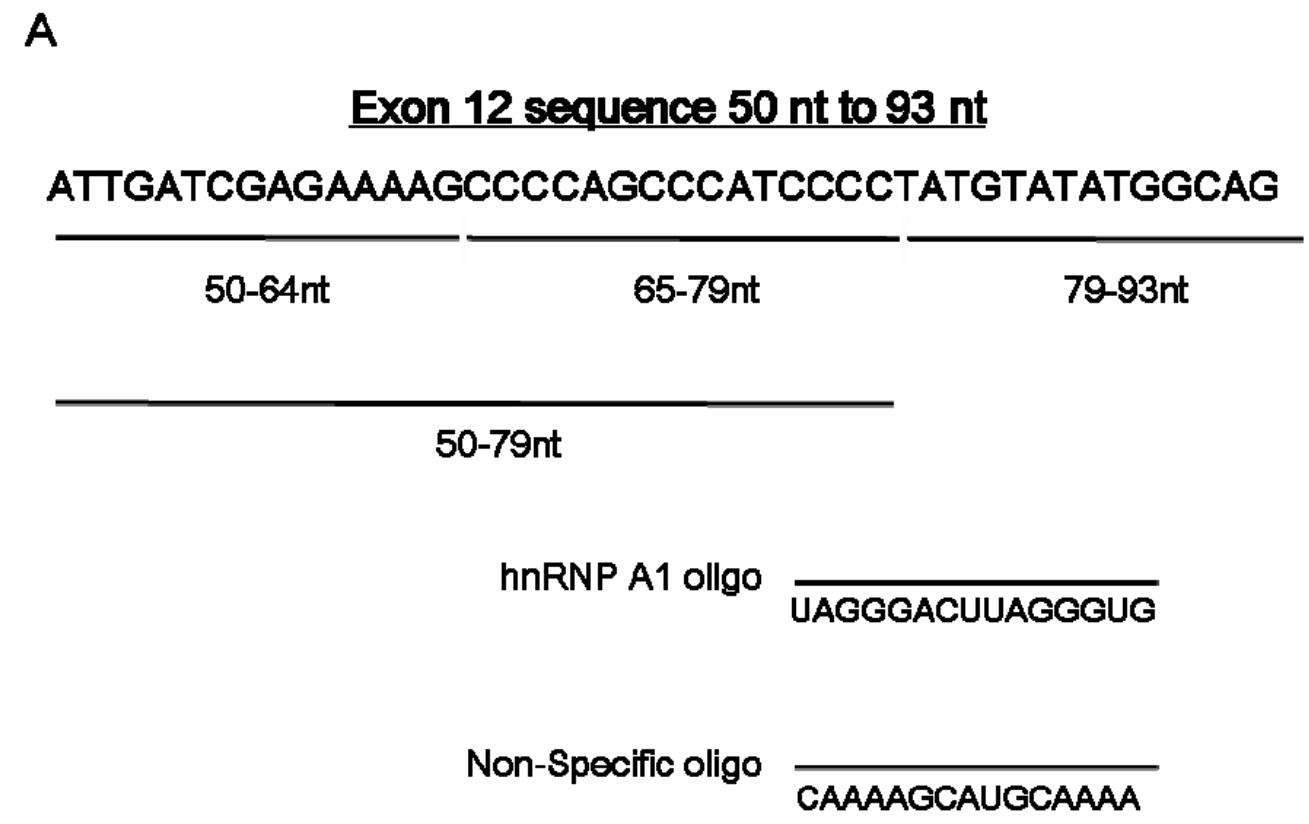

Figure 2 
B

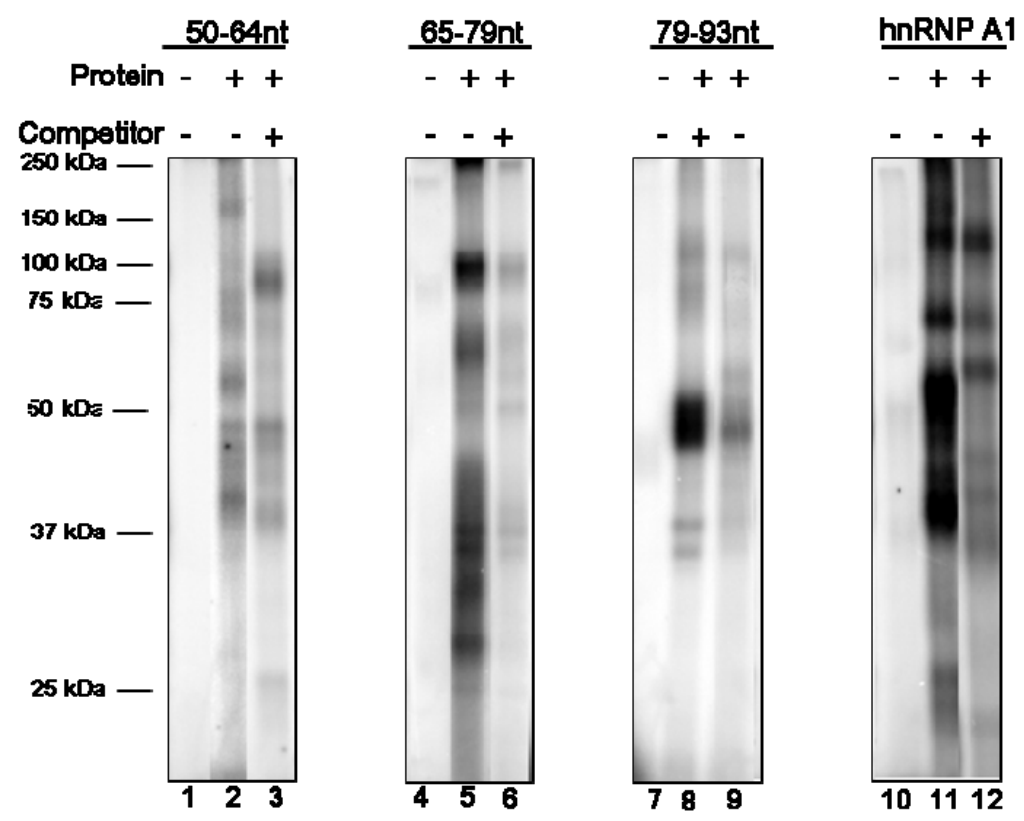

Figure 2 


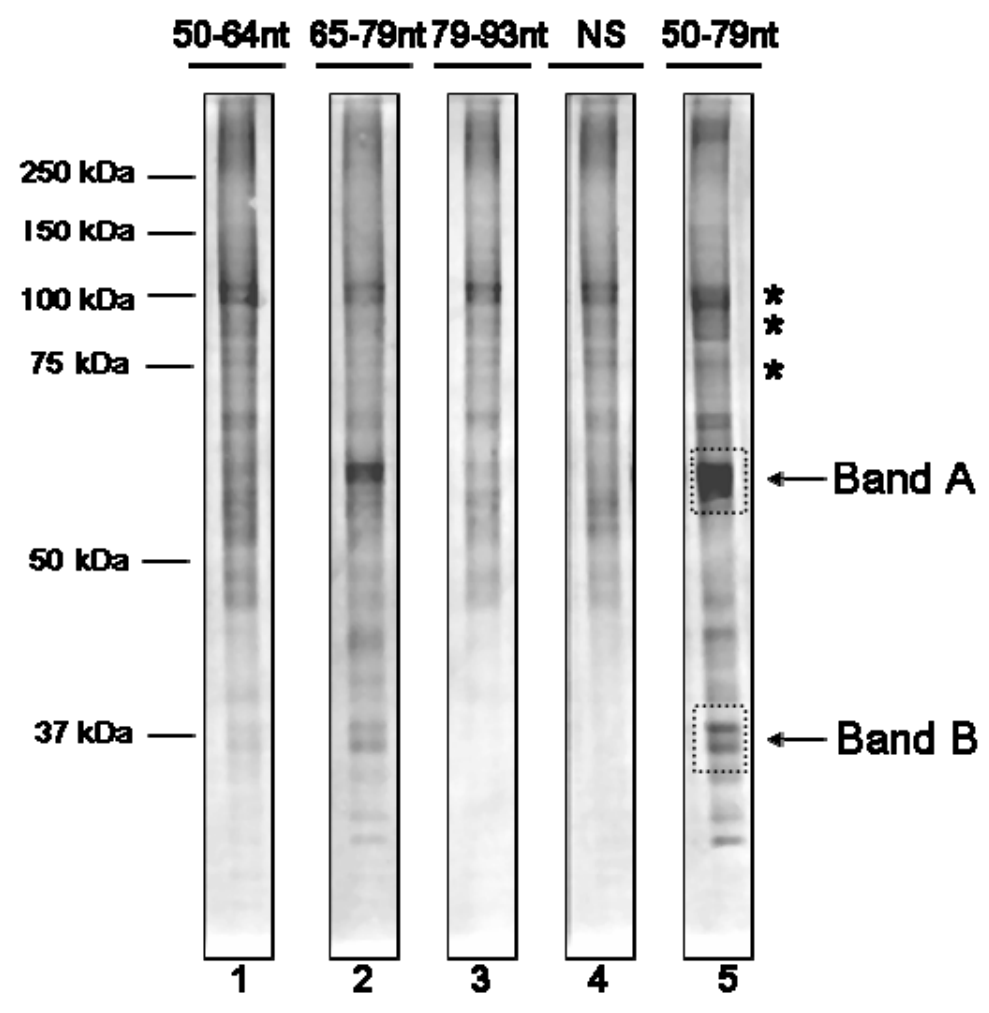

Figure 3 


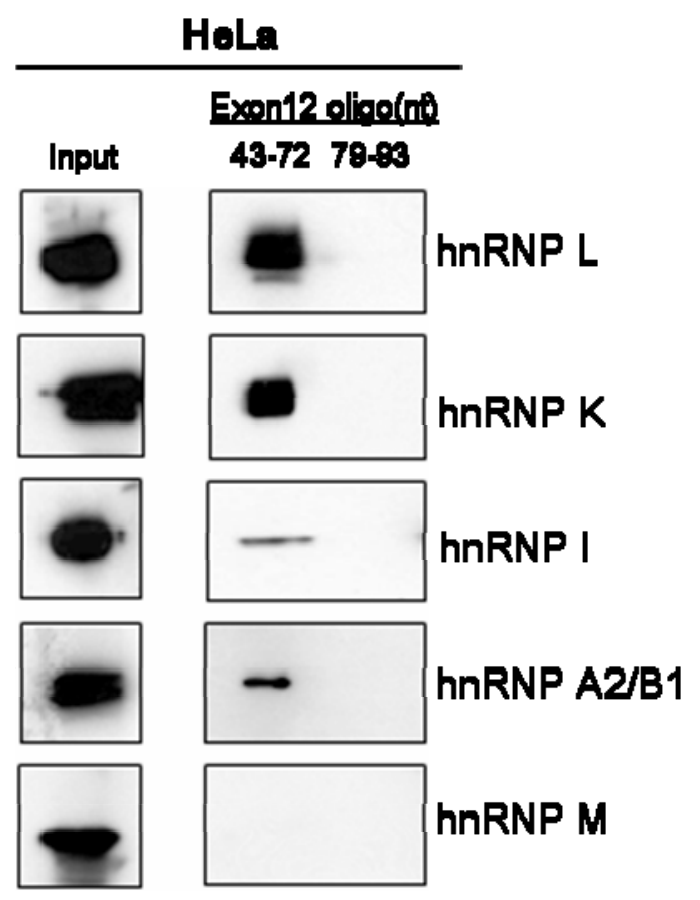

Figure 4 


\title{
$\underline{\text { Chapter } 3}$
}

\section{Identification of hnRNPs $K, L$ and $A 2 / B 1$ as candidate proteins involved in the nutritional regulation of mRNA splicing}

\author{
Brian N. Griffith ${ }^{a}$, Callee M. Walsh ${ }^{a}$, Wioletta Szeszel-Fedorowicz ${ }^{a}$, Aaron T. Timperman ${ }^{b}$ \\ and Lisa M. Salati ${ }^{\mathbf{a}^{*}}$ \\ ${ }^{a}$ Department of Biochemistry and Molecular Pharmacology, West Virginia University, \\ Morgantown, $W V 26506$ \\ ${ }^{b}$ Department of Chemistry, West Virginia University, Morgantown, WV 24901
}

"To whom correspondence should be addressed:

Department of Biochemistry and Molecular Pharmacology

WVU Health Sciences Center, PO Box 9142

Morgantown, WV 26506

Phone: (304) 293-7759, e-mail

Lsalati@hsc.wvu.edu

Keywords: RNA splicing, hnRNP, nutritional regulation, posttranscriptional gene regulation, lipogenesis, liver

This manuscript was published in BBA-Gene Structure and Expression

Griffith BN, Walsh CM, Szeszel-Fedorowicz W, Timperman AT, Salati LM. Identification of hnRNPs $\mathrm{K}, \mathrm{L}$ and $\mathrm{A} 2 / \mathrm{B} 1$ as candidate proteins involved in the nutritional regulation of mRNA splicing. Biochim Biophys Acta. 2006 Oct 6; [Epub ahead of print] 


\section{Summary}

Nutrient regulation of glucose-6-phosphate dehydrogenase (G6PD) expression occurs through changes in the rate of splicing of G6PD pre-mRNA. This posttranscriptional mechanism accounts for the 12- to 15-fold increase in G6PD expression in livers of mice that were starved and then refed a high-carbohydrate diet. Regulation of G6PD pre-mRNA splicing requires a cis-acting element in exon 12 of the pre-mRNA. Using RNA probes to exon 12 and nuclear extracts from livers of mice that were starved or refed, proteins of $60 \mathrm{kDa}$ and $37 \mathrm{kDa}$ were detected bound to nucleotides $65-79$ of exon 12 and this binding was decreased by $50 \%$ with nuclear extracts from refed mice. The proteins were identified as hnRNP K, and L, and hnRNP A2/B1 by LC-MS/MS. The decrease in binding of these proteins to exon 12 during refeeding was not accompanied by a decrease in the total amount of these proteins in total nuclear extract. HnRNPs K, L and A2/B1 have known roles in the regulation of mRNA splicing. The decrease in binding of these proteins during treatments that increase G6PD expression is consistent with a role for these proteins in the inhibition of G6PD mRNA splicing. 


\section{Introduction}

The conversion of excess dietary energy to stored fuel via de novo fatty acid synthesis is essential to energy homeostasis. Excess carbohydrate and protein in the diet are the primary substrates for this pathway, which is most active in liver and adipose tissue. Fatty acid synthesis involves a family of enzymes commonly referred to as lipogenic enzymes [1]. Lipogenic enzymes include glucose-6-phosphate dehydrogenase (G6PD), ATP-citrate lyase, malic enzyme, acetyl-CoA carboxylase, and fatty acid synthase. Consistent with their role in energy metabolism, the activities of these enzymes are induced when animals are fed a highcarbohydrate diet and decreased during starvation or by the addition of polyunsaturated fat to the diet. The unique aspect of this dietary regulation is that the nutrients per se play a significant role in the molecular mechanisms regulating the synthesis of these enzymes and in the signal transduction pathways that mediate the change in nutritional status. While ATPcitrate lyase, acetyl-CoA carboxylase, fatty acid synthase, and malic enzyme are regulated by changes in the transcriptional rate, G6PD is regulated solely by posttranscriptional mechanisms $[1,2]$. Posttranscriptional regulation has been proposed for malic enzyme and fatty acid synthase [3-5], as well, indicating that nutrients regulate via multiple mechanism even for the same gene.

Posttranscriptional regulation of mRNA abundance can occur at multiple steps during RNA processing or through changes in the stability of the mature mRNA. The processing of a nascent transcript includes addition of the 7-methylguanosine cap, 3'-end formation, and splicing of all introns. Accurate processing is essential for the release of the mRNA from its transcription site and for export of the mRNA to the cytoplasm [6]. Thus, efficient and 
complete maturation of mRNA is a potential control point in gene expression. Splicing of mRNA requires distinguishing exons from introns. Within introns several sequences bind components of the spliceosome; these include the $5^{\prime}$ and 3 ' splice site, the branch point, and the polypyrimidine tract [7]. Additional sequences in both the exons and introns function to regulate the efficiency of splicing. Within exons, the splicing regulatory sequences are referred to exonic splicing enhancers (ESE) and exonic splicing silencers (ESS) and these sequences affect the recruitment of components of the spliceosome [7-9]. Introns contain analogous regulatory sequences and these function to either enhance or block splice site recognition [10]. Families of serine-arginine rich proteins (SR proteins) and heterogeneous nuclear ribonucleoproteins (hnRNPs) bind to these regulatory sequences. In general, SR proteins bind ESEs and enhance splicing, while ESSs or their intronic counterparts are bound by hnRNPs and splicing is silenced [8,11-14]. Examples also exist of SR proteins inhibiting splicing and hnRNPs enhancing splicing $[15,16]$. Thus considerable research remains in order to understand how cis-acting RNA elements and their binding proteins regulate splicing.

We characterized the posttranscriptional regulation of G6PD by dietary factors. Refeeding mice after starvation causes a 12- to 15-fold increase in G6PD mRNA abundance in the liver, while addition of polyunsaturated fatty acids to the diet or to the medium of primary rat hepatocytes caused an 80\% decrease in G6PD mRNA [17]. Despite this large change in mRNA accumulation, the rate of transcription of the G6PD gene does not change. Rather, the changes in G6PD mRNA abundance during refeeding of starved mice or by fatty acids are caused by an in the rate of splicing of the primary transcript [18]. In this regard, changes in the accumulation of the mature mRNA are preceded by changes in the rate of accumulation of partially spliced mRNA in the absence of changes in polyadenylation or length of the poly (A) 
tail. If splicing is the regulated step, then sequences within G6PD RNA should be required for this regulation. This hypothesis was tested by transfection of RNA reporter constructs into primary rat hepatocytes. These constructs contained portions of the G6PD gene encoding the pre-mRNA ligated to the CMV promoter, which is not regulated by nutrients. Expression of RNA from this reporter was inhibited by treatment of the hepatocytes with fatty acids. Using deletion mutagenesis of the reporter DNA a cis-acting element required for the control of G6PD mRNA accumulation was localized to exon 12 of the G6PD pre-mRNA. Inclusion of exon 12 and its surrounding introns was required for the inhibition of reporter RNA expression by polyunsaturated fatty acids. Furthermore, this exon when ligated to a heterologous RNA confers regulation by nutrients to this RNA [19]. These characteristics are consistent with exon 12 containing an enhancer or a silencer element. Unique to this regulation is that it is the rate of exon splicing that is regulated; G6PD mRNA is not alternatively spliced to form different isoforms.

Constitutive exons are those always present in the mature mRNA. The regulated splicing of G6PD mRNA involves a constitutive exon in this mRNA and a decrease in splicing of this exon diminishes expression of this mRNA. This is a primary mechanism by which G6PD expression is regulated [2]. Molecular mechanisms involved in the exclusion and inclusion of alternatively spliced exons have been characterized. Little is known about the mechanism regulating the rate of constitutive exon splicing particularly in response to hormonal or nutritional factors.. The proteins involved in regulation of inclusion of alternatively spliced exons may also be involved in the splicing of constitutive exons particularly those with weak splice sites. To understand the molecular mechanisms involved in regulation of G65PD splicing, we sought to identify the proteins that bind to exon 12 of G6PD mRNA. The large 
change in the accumulation of G6PD mRNA during the starvation to refeeding transition makes this dietary paradigm ideal for the identification of regulatory proteins particularly those whose binding might change in response to nutritional status. In this report, we present evidence that hnRNPs $\mathrm{K}, \mathrm{L}$ and A2/B1 bind to the exon 12 splicing regulatory element. A region of G6PD exon 12 from nt 65-79 is sufficient to bind these proteins. The binding of these proteins is enhanced by starvation and correlates with the decrease in G6PD mRNA abundance in the livers of starved mice. These data are consistent with a role for these proteins silencing the splicing of G6PD pre-mRNA. The identification of these regulatory proteins provides new insight into the mechanisms by which nutrients control gene expression.

\section{Materials and Methods}

\subsection{Animal Care}

Four to six week old, male, C57BL/6 mice (Hill Top) were maintained on a highcarbohydrate diet with glucose as the carbohydrate source (Purina Mill) and supplemented with 1\% (by weight) safflower oil (Sigma) as a source of essential fatty acids for seven days. On day eight, the food was removed for a $24 \mathrm{~h}$ starvation period. At the end of the starvation period, 10 mice were sacrificed and 10 were refed the high-carbohydrate diet for $24 \mathrm{~h}$.

\subsection{Plasmids and In vitro Transcription of RNA}


The plasmid containing exon 12 of G6PD mRNA was generated by PCR using the 5' primer AATAAGCTTTGATGAACTCAGGGA and the 3' primer ATTTCTAGACTGCCATATACATAG. The exon 11-13 plasmid was generated by subcloning from a genomic clone following restriction digestion using Pst1 and Kpn1. Exon $12 \Delta^{1}$ probe (nt 37-93 of exon 12) was generated using PCR with the 5' primer ATAAAGCTTCTGCTGCACAAGATTGAT and the 3' primer above. Exon $12 \Delta^{2}$ probe (nt 47-93 of exon 12) was generated with the same 3' primer and the 5' primer TGAAAGCTTATTGATCGAGAAAAGCC. All DNA inserts were subcloned into pKS+ plasmid using Hind III and Xba I sites created with the primers (Fig. 1A). RNA probes were made using an in vitro transcription reaction with T3 RNA polymerase (Ambion) as previously described [20].

\subsection{RNA Oligonucleotides}

RNA oligonucleotides corresponding to 15 or $30 \mathrm{nt}$ regions of exon 12 (Fig. 1B) were purchased from IDT (Coralville, IA). An RNA oligonucleotide, UAGGGACUUAGGGUG (positions 6 to 20nt of a consensus sequence for hnRNP A1) was used as a positive control [21]. As a negative control, an oligonucleotide, CAAAAGCAUGCAAAA, was designed to lack known RNA regulatory elements as screened by the ESE and ESS finder databases: http://exon.cshl.edu/ESE [22], http://genes.mit.edu/fas-ess [23], and http://cubweb.biology.columbia.edu/pesx [24]. RNA oligonucleotides were end-labeled with $\left(\gamma-\mathrm{P}^{32}\right)$ ATP using a kinase Max kit (Ambion). 


\subsection{UV Crosslinking}

Nuclear extracts were prepared by the Dignam protocol [25]. Protein concentration was measured by the Bradford assay. UV crosslinking reactions contained 5 to $10 \mu \mathrm{g}$ of nuclear extract protein, 10 to $20 \mathrm{fmol}$ of substrate RNA (50,000 to $100,000 \mathrm{cpm}), 1 \mathrm{mM} \mathrm{ATP}, 0.7 \mathrm{mM}$ $\mathrm{MgCl}_{2}$, and $40 \mathrm{ng}$ of carrier tRNA in a $25 \mu \mathrm{l}$ final volume of buffer $(20 \mathrm{mM} \mathrm{N}-2-$ hydroxyethylpiperazine-N'-2-ethanesulfonic acid (HEPES) pH 7.9, 0.2 mM EDTA, 10\% glycerol, and $150 \mathrm{mM} \mathrm{KCl}$ ) [26]. Reaction mixtures were incubated for 5 to $10 \mathrm{~min}$ at $30^{\circ} \mathrm{C}$

and then subjected to UV crosslinking on ice for $10 \mathrm{~min}$ in a Stratalinker $\left(1.8 \times 10^{6} \mu \mathrm{J} / \mathrm{cm}^{2}\right)$. Samples were treated with $(1 \mathrm{mg} / \mathrm{ml})$ at $37^{\circ} \mathrm{C}$ for $30 \mathrm{~min}$. Proteins were boiled for $5 \mathrm{~min}$ in cracking buffer (80 mM Tris-Cl, $\mathrm{pH}$ 6.8, 0,1 M dithiothreitol, 2\% sodium dodecyl sulfate (SDS), 10\% glycerol, and $0.2 \%$ bromophenol blue) and separated in 10\% SDS-polyacrylamide gels [26]. Binding of proteins to the RNA was visualized using storage phosphor imaging and quantified using ImageQuaNT software.

\subsection{RNA Affinity Purification of Binding Proteins}

RNAs were covalently linked to adipic acid dihydrazide-agarose beads by a modification of a published procedure [27, 28]. Briefly, 1000 pmol of RNA were placed in a $400 \mu 1$ reaction mixture (100 $\mathrm{mM}$ sodium acetate, $\mathrm{pH} 5.0$, and $5 \mathrm{mM}$ sodium m-periodate)and incubated for $1 \mathrm{~h}$ in the dark at room temperature. Following ethanol-precipitated, the RNA was resuspended in $500 \mu \mathrm{l}$ of $0.1 \mathrm{M}$ sodium acetate, $\mathrm{pH}$ 5.0. Adipic acid dihydrazide-agarose beads $(400 \mu \mathrm{l})($ Sigma) were washed four times in $10 \mathrm{ml}$ of $0.1 \mathrm{M}$ sodium acetate, $\mathrm{pH}$ 5.0, 
resuspended in $1 \mathrm{ml}$ of $0.1 \mathrm{M}$ sodium acetate, $\mathrm{pH} 5.0$ and mixed with the periodate-treated RNA by rotation for $12 \mathrm{~h}$ at $4^{\circ} \mathrm{C}$. The beads with the bound RNA were washed three times in $2 \mathrm{M} \mathrm{NaCl}$ and three times in $20 \mathrm{mM}$ HEPES-KOH, $\mathrm{pH} 7.6,10 \% \mathrm{v} / \mathrm{v}$ glycerol, $150 \mathrm{mM} \mathrm{KCl}$, $0.2 \mathrm{mM}$ EDTA and $200 \mu \mathrm{g} / \mathrm{ml}$ tRNA to block nonspecific protein binding to the beads. The beads containing immobilized RNA were incubated with mouse liver nuclear extracts (100-500 $\mu \mathrm{g}$ protein) in $300 \mu \mathrm{l}$ of $20 \mathrm{mM}$ HEPES-KOH, $\mathrm{pH} 7.6,10 \% \mathrm{v} / \mathrm{v}$ glycerol, $150 \mathrm{mM} \mathrm{KCl}, 0.2$ mM EDTA plus $2.5 \mathrm{mM} \mathrm{ATP,} 2.0 \mathrm{mM} \mathrm{MgCl} 2,1000 \mathrm{ng} / \mathrm{ml} \mathrm{tRNA} \mathrm{for} 30 \mathrm{~min}$ at $30^{\circ} \mathrm{C}$. Beads were pelleted by centrifugation and washed four times with $1 \mathrm{ml}$ of buffer without ATP, $\mathrm{MgCl}_{2}$ or tRNA. For one dimensional gels and Western analysis, the protein were eluted in $75 \mu 1$ of 80 $\mathrm{mM}$ Tris-Cl, pH 6.8, 0.1 M dithiothreitol, 2\% SDS, 10\% glycerol, and $0.2 \%$ bromophenol blue by heating for $5 \mathrm{~min}$ at $95^{\circ} \mathrm{C}$. For two-dimensional gel electrophoresis, the proteins were eluted in $250 \mu 1$ of $8 \mathrm{M}$ Urea, $2 \%$ Triton X-100, 1\% dithiothreitol, $0.5 \%$ Pharmalyte, and $0.002 \%$ bromophenol blue for $2-3 \mathrm{~h}$ at room temperature.

\subsection{Two-Dimensional Gel Electrophoresis}

Proteins eluted from the beads were separated by isoelectric focusing (13 cm strips; Amersham) with a pH range of 3.0 to 10.0 in the first dimension. The gels were hydrated by incubation with the elution buffer containing the purified proteins for $12 \mathrm{~h}$ followed by separation at 50 volts for $5 \mathrm{~h}, 100$ volts for $2 \mathrm{~h}, 1000$ volts for $2 \mathrm{~h}, 5000$ volts for $2 \mathrm{~h}, 8000$ volts for $6 \mathrm{~h}$ and maintained at 1000 volts for $4 \mathrm{~h}$. The gels were then incubated in equilibration buffer (50 mM Tris-Cl, pH 6.8, 6 M Urea, 20\% glycerol, 2\% SDS, 0.002\% bromophenol blue) plus $15 \mathrm{mg} / \mathrm{ml}$ of dithiothreitol for $15 \mathrm{~min}$ plus an additional $15 \mathrm{~min}$ in 
equilibration buffer plus iodoacetamide $(18 \mathrm{mg} / \mathrm{ml})$. The gels were placed horizontally onto an SDS- $10 \%$ polyacrylamide gel and run at $100 \mathrm{~V}$ for $6-8 \mathrm{~h}$. For quantitation of the proteins, the gels were stained with SYPRO Ruby using the manufacture's protocol and visualized using an excitation of $450 \mathrm{~nm}$ and emission of $610 \mathrm{~nm}$ on a Typhoon Scanner (GE Healthcare). For visualization of proteins prior to excision of protein spots, the gels were stained with colloidal Coomassie blue (Invitrogen) and visualized under a light box. The visualized spots were excised from the gel and stored at $-80^{\circ} \mathrm{C}$.

\subsection{Liquid Chromatography-Tandem Mass Spectrometry (LC-MS/MS) Analysis}

Proteins binding to the RNA coated beads were separated by size in a $10 \%$ SDSpolyacrylamide gel. The proteins bands of interest were visualized by colloidal Coomassie blue and excised from the gels. The gel slices were digested with trypsin $(2 \mu \mathrm{g} / \mathrm{ml})$ overnight at $37^{\circ} \mathrm{C}$. The digested peptides were dried and reconstituted in $5 \%$ acetonitrile, $0.1 \%$ formic acid and then loaded onto a $\mathrm{C}_{18}$ column (ZipTip) using a helium pressure cell. Peptides were eluted from the column using a linear acetonitrile gradient of 5-50\% over 60 min with a flow rate $300 \mathrm{nl} / \mathrm{min}$. The ion-trap mass spectrometer (ThermoFinnigan LCQ Deca Plus) was programmed to perform a full MS scan followed by MS/MS scans of the five most abundant ions present. Raw data files were compared to the Swiss-Prot database (Version 47) using SEQUEST software (Turbo) to identify proteins that match the sequence of the peptide fragments. The criteria we used to determine the protein identity were a $C_{n}$ score of less than 0.1 , regardless of the charge state and a cross correlation $\left(\mathrm{X}_{\text {corr }}\right)$ score of at least 1.9, 2.2, or 3.7 for the $+1,+2$, or +3 charge states, respectively [29]. In a few cases, peptides with an $C_{n}$ 
score of greater than 0.1 were accepted if the $\mathrm{X}_{\text {corr }}$ was strong. Protein identifications were manually confirmed [30].

\subsection{Matrix-Assisted Laser Desorption/Ionization-Time of Flight (MALDI-TOF)}

Mass Spectrometry Analysis

Following separation in the two-dimensional gels, the colloidal Coomassie blue stained gel pieces containing proteins were destained using a 1:1 ratio of $100 \mathrm{mM}$ ammonium bicarbonate and methanol for 30 min followed by 30 min with $100 \mathrm{mM}$ ammonium bicarbonate and acetonitrile for $10 \mathrm{~min}$. The samples were dried under a vacuum and rehydrated overnight in $2 \mu \mathrm{g} / \mathrm{ml}$ of trypsin in $25 \mathrm{mM}$ ammonium bicarbonate at $37^{\circ} \mathrm{C}$. The samples were sonicated for $15 \mathrm{~min}$ in 2 volumes of acetonitrile. The peptides were purified using a ZipTip $\mathrm{C}_{18}$ (Millipore) pre-equilibrated with $10 \%$ acetonitrile and $0.1 \%$ trifluoroacetic acid. The samples were eluted from the ZipTip using 2\% acetic acid and 50\% acetonitrile solution. The resulting sample was mixed with matrix $(50 \mathrm{mM}$-cyano-cinnamic acid in $49.5 \%$ ethanol, $49.5 \%$ acetonitrile and $0.0001 \%$ trifluoroacetic acid solution. The MALDI 96 well plate was spotted with $1 \mu 1$ in each well and air-dried. The MALDI-TOF (Proteomics Workflow) data was evaluated using the MASCOT software (2.1).

\subsection{Western Blot Analysis}

Eluted proteins from the adipic acid dihydrazide-agarose beads bound to RNA oligonucleotides were separated on 10\% SDS-polyacrylamide gel. Western analysis was as 
previously described [31]. The primary antibodies against hnRNP K, L and A2/B1 were obtained from ImmuQuest. Anti-mouse IgG2b (Zymed) and IgG (Bio-Rad) conjugated to horseradish peroxidase were used as secondary antibodies to detect hnRNP K, and L and A2/B1, respectively. The immunocomplexes were detected by enhanced chemiluminescence (Pierce). Images were visualized with film (Pierce) and quantified by densitometry using ImageQuant (Molecular Dynamics).

\section{Results}

\subsection{Starvation enhances binding of proteins to exon 12 RNA}

Regulation of G6PD expression both in mouse liver and primary rat hepatocytes occurs by changes in the rate of pre-mRNA splicing $[18,32]$. Exon 12 contains a regulatory element involved in regulated splicing of G6PD pre-mRNA [19]. Therefore, we used exon 12 as a probe (Fig. 1A) in UV crosslinking assays with mouse liver nuclear extracts to identify RNA binding proteins that may be involved in regulated splicing. Multiple proteins bound to exon 12 RNA. Unique bands were consistently observed at approximately $60 \mathrm{kDa}, 50 \mathrm{kDa}$ and 37 $\mathrm{kDa}$ (Fig. 2A, lane 1). Additional protein bands at $75 \mathrm{kDa}$ and $150 \mathrm{kDa}$ were not observed in all experiments, and a $100 \mathrm{kDa}$ band was observed with multiple RNA probes including the transcribed multiple cloning site of pKS+ (data not shown). Thus, the 75, 100 and $150 \mathrm{kDa}$ bands were interpreted to be non-specific binding caused by UV crosslinking and such band are not atypical of this assay (cf., Fig. 2A versus Fig. 5, first lane each panel). Multiple controls were used to verify that the observed bands represented protein bound to the RNA 
(data not shown). Competition experiments with unlabelled exon 12 RNA probe were performed. The bands at $60 \mathrm{kDa}, 50 \mathrm{kDa}$, and $37 \mathrm{kDa}$ were decreased by unlabelled RNA probe in a concentration dependent manner. UV crosslinking of the RNA probe in the absence of nuclear extract did not result in any bands. Furthermore, digestion of the RNA/protein complex with proteinase $\mathrm{K}$ eliminated all bands verifying that they are bound protein and not double stranded RNA molecules. Thus, the pattern of bands observed in this assay represents proteins binding to the RNA probe.

The amount of protein binding to exon 12 varied with nutritional status of the mice. Refeeding with a high-carbohydrate diet resulted in a decrease in the intensities of the protein bands at 60 and $37 \mathrm{kDa}$. These bands designated as A and B, respectively, were decreased by almost 50\% (Fig. 2A compare lanes 1 and 5), and this decrease in protein binding exceeded the minor differences in intensity observed with the non-specific band at $100 \mathrm{kDa}$. Furthermore, the inhibition of binding was consistent across multiple nuclear extract preparations (Fig. 2B). These nuclear extracts were prepared from intact livers. During refeeding, the amount of glycogen in liver increases dramatically (25\% increase in liver weight, [33]); glycogen can contaminant cellular fractions. A remote possibility is that these differences in band intensity reflect differences in the concentration of glycogen in the nuclear extract that artificially affected protein binding. Purified glycogen ( 1 to $5 \mu \mathrm{g}$ ) was added to the UV crosslinking reactions using the starved nuclear extracts. The pattern and intensity of protein binding was not altered by the addition of glycogen (data not shown). In addition, silver staining of nuclear extracts separated on polyacrylamide gels further confirmed that overall protein content was similar between starved and refed extracts (data not shown). Thus these differences in protein 
binding between dietary states are consistent with the idea that these proteins at 60 and $37 \mathrm{kDa}$ are involved in the regulated splicing of G6PD mRNA.

We next asked if additional differences in protein binding or intensity would be observed if we included the introns surrounding exon 12 in the RNA probe. Using a construct containing exon 11 through 13 with surrounding introns, a similar pattern of protein bands was observed as with exon 12 alone (Fig. 2A, lanes 2 and 6). A band at $55 \mathrm{kDa}$ was unique to the exon 11-13 RNA probe. Importantly, the decrease in protein binding at bands A and B during refeeding was retained with this longer construct (Fig. 2B). The intensity of the band at 55 $\mathrm{kDa}$ did not vary across multiple experiments. Thus, starvation and refeeding cause major differences in the binding of proteins to an exon involved in regulated splicing of G6PD premRNA.

\subsection{The $60 \mathrm{kDa}$ and $37 \mathrm{kDa}$ proteins bind to $\mathrm{nt}$ 65-79 of exon 12 .}

To further localize the binding sites for the $60 \mathrm{kDa}$ and $37 \mathrm{kDa}$ proteins in bands $\mathrm{A}$ and B, two RNA probes containing 5' deletions of exon 12 sequences were synthesized. These probes had deletions of the first 37 and $47 \mathrm{nt}$ from exon 12, respectively (Exon $12 \Delta^{1}$ and Exon $12 \Delta^{2}$; Fig. 1A). The pattern of protein binding to these probes was the same as to the fulllength exon 12 (Fig. 2A, lanes 3 and 4). In addition, the decrease in binding at bands A and B during refeeding was maintained in these shorter RNA probes (Fig. 2A, lanes 3 and 4 versus 7 and 8 , and Fig. 2B). The first 37 nt of exon 12 are not required for regulated splicing of G6PD mRNA in rat hepatocytes [19]. 
An RNA oligonucleotide approach was used to further localize the region of exon 12 that binds the 60 and $37 \mathrm{kDa}$ proteins. RNA oligonucleotides, $15 \mathrm{nt}$ in length were synthesized across sequence from 35-93 of exon 12 and were used in the UV crosslinking assay (Fig. 1B). An oligonucleotide from 35-49 that overlaps with the $47 \mathrm{nt}$ deletion above, functioned as a negative control. Unique proteins bound to each RNA oligonucleotide (Fig. 3). Bands A and B associated with full-length exon 12 were only observed with the oligonucleotide, nt 65-79 (Fig. 3). The intensity of bands A and B decreased in the nuclear extracts from livers of refed mice, similar to the decrease observed with the full-length exon 12 RNA probe. Apparent differences in protein binding observed with the other oligonucleotides (bands 1-6) were not consistently observed in five separate crosslinking assays and with different preparations of nuclear extracts. A positive control was designed to detect overall differences in protein amounts between starved and refed nuclear extracts. Burd and Dreyfuss identified a $20 \mathrm{nt}$ sequence that is bound by hnRNP A1 as well as other members of the hnRNP family [21]. The hnRNP A1 oligonucleotide was designed to contain nucleotides 6-20 of the Burd and Dreyfuss sequence including the consensus UAGGGA sequence for hnRNP A1 binding [21]. In the UV crosslinking assay, multiple bands were detected with the hnRNP A1 oligonucleotide including an intense doublet at $37 \mathrm{kDa}$, corresponding in size to hnRNP A1 (Fig. 3). The intensity of the bands did not differ between starved and refed nuclear extracts ( $\mathrm{n}=12$ nuclear extracts; data not shown). An additional control was a non-specific oligonucleotide representing a random RNA sequence that did not contain known binding sites for splicing regulatory proteins, as determined using the databases indicated in Material and Methods. Binding of proteins to this oligonucleotide was not detected (Fig. 3). These data further verify that the differences in 
protein binding between nuclear extracts from starved and refed mice are due to differences in the interaction of the $60 \mathrm{kDa}$ and $37 \mathrm{kDa}$ proteins with $\mathrm{nt} 65-79$.

\subsection{RNA affinity purification of proteins binding to nt 65-79 of exon 12.}

To determine the identity of the proteins in bands A and B, RNA oligonucleotides were linked to adipic acid beads and used to purify proteins from the nuclear extract without covalently linking them to the RNA. We first asked if this assay resulted in a similar pattern of protein binding as the UV crosslinking assay. Proteins binding in the 60 and $37 \mathrm{kDa}$ regions (bands A and B, respectively) were detected with nt 65-79 (Fig. 4). The $60 \mathrm{kDa}$ band was not detected with nt $35-49$, nt 50-64, nt 70-93 or the non-specific oligonucleotide. The $37 \mathrm{kDa}$ band was detected with nt 50-64, but not with nt 35-49, nt 79-93 or the non-specific oligonucleotide. Proteins were not detected co-purifying with the beads alone (Fig. 4). As observed with the UV crosslinking assay, the amount of proteins bound in bands A and B were $60 \%$ and $53 \%$ less, respectively in the nuclear extracts from refed mice. Thus, the assay recapitulated the differences in protein binding at bands $\mathrm{A}$ and $\mathrm{B}$ observed with $\mathrm{UV}$ crosslinking.

Steric hindrance between the short RNA oligonucleotides and the large beads could have decreased overall protein binding. To facilitate maximum protein pull-down for identification of the proteins with LC-MS/MS, a larger oligonucleotide spanning nt 50-79 of exon 12 was used in the RNA affinity assay (Fig. 4). An identical pattern of proteins was observed with this oligonucleotide as with nt 65-79; however, more protein per band bound to nt 50-79 and the inhibition of protein binding in nuclear extracts from refed mice $(51 \%$ and $44 \%$ for bands A 
and $\mathrm{B}$, respectively) was maintained. The proteins bound to exon 12 were the same size as the proteins bound to nt 50-79. To test if the bound proteins were the same, competition analysis was used. The RNA oligonucleotide, nt 50-79 was used as a competitor in the UV crosslinking assay with the full-length exon 12 as the probe (Fig. 5). Increasing amounts of unlabeled nt 50-79 were added to the reaction. This oligonucleotide effectively competed with the labeled exon 12 probe for binding of the proteins in bands of A and B (Fig. 5, lane 1 versus lanes 2-4). In contrast, the non-specific oligonucleotide was unable to compete with exon 12 for these proteins (Fig. 5, lane 1 versus lanes 5-7). Thus, the region from nt 50-79 of exon 12 accounts for the binding of the $60 \mathrm{kDa}$ and $37 \mathrm{kDa}$ proteins to the full-length exon.

3.4. HnRNPs $K, L$ and $A 2 / B 1$ bind to exon 12 , and the binding is regulated by nutritional status.

The RNA affinity assay was used to purify the proteins in band A and band B in order to determine their identity using LC-MS/MS. Only starved nuclear extract was used and the reaction was increased five-fold to provide sufficient protein for the LC-MS/MS analysis. Despite the increase in protein, the specificity of binding of the $60 \mathrm{kDa}$ and $37 \mathrm{kDa}$ proteins (bands A and B) to nt 65-79 and nt 50-79 was retained (Fig. 6, lanes 3 and 6). Bands A and B were excised from the gel and an in-gel digestion with trypsin was performed prior to LCMS/MS analysis (Fig. 6). Band A contained two proteins, hnRNP K and hnRNP L. The percent sequence coverage of hnRNP K was $35.7 \%$ and 14 unique peptides were sequenced. The coverage for hnRNP L was 33.2\% with 16 unique peptides (Table 1). Band B contained hnRNP A2/B1, which was identified based on sequence coverage of greater than $60 \%$ and with 21 unique peptides (Table 1). HnRNPs A2 and B1 are isoforms generated by alternative 
splicing and differ by 12 amino acids that are present in exon 2 of hnRNP B1 but not in hnRNP A2 [34]. A manual search for a peptide containing this amino acid sequence yielded the peptide, TLETVPL, with an $\mathrm{X}_{\text {corr }}$ of 2.9 for a +2 charge-state peptide and a $\Delta \mathrm{C}_{\mathrm{n}}$ value of greater than 0.5. This peptide was from amino acids $4-12$ of exon 2 and confirmed that hnRNP B1 is in band B. Because both proteins share all other peptides, the occurrence of a peptide unique to hnRNP B1 does not exclude hnRNP A2 from also being present in band B. The molecular weight of the three identified proteins matched their mass predicted from the SDSpolyacrylamide gels. HnRNP C1/C2 was also identified in band B. Seven peptides of this protein were sequenced and the percent sequence coverage was less then $20 \%$ making identification of this protein inconclusive.

To verify these protein identifications and to determine if additional proteins bound to nt 50-79, the proteins eluted from the adipic-acid beads were resolved in two-dimensional gels and identification of protein spots was performed by MALDI-TOF. Once again, the hnRNP proteins $\mathrm{K}, \mathrm{L}$, and $\mathrm{A} 2 / \mathrm{B} 1$ were detected bound to this sequence. Multiple spots corresponding to hnRNP A2/B1 were observed. HnRNP A2 migrates at a more acid $\mathrm{pH}$ in 2 dimensional gels [35]. Thus, this is consistent with both isoforms binding to the RNA element but the existence of one isoforms versus the other cannot be determined by MALDI-TOF analysis. The identifications of hnRNPs K, L and A2/B1 were based on sequence coverage of $45 \%, 24 \%$ and $55 \%$, respectively. HnRNP C1/C2 was not detected in the two-dimensional analysis. Three additional proteins, dematin, p47 and SAP 114 were also detected bound to nt 50-79 (Fig. 7; asterisk). These proteins are not directly involved in regulation of RNA splicing. They may have bound non-specifically to one of the proteins pulled-down by the RNA-linked beads, and thus, their intensity was decreased in the refed samples because the amount of their interacting 
partner, possibly hnRNP K was also decreased. Additional proteins in the 2D gels were not sequenced because their concentration was too low to permit positive protein identification. Proteins of greater intensity in the refed nuclear extracts were not observed consistent with the previous data using UV crosslinking and one-dimensional gel analysis after affinity purification.

The identification of hnRNPs K, L, and A2/B1 was confirmed using Western blot analysis. Antibodies against hnRNPs $\mathrm{K}$ and $\mathrm{L}$ detected bands at $65 \mathrm{kDa}$ binding to oligonucleotides 65-79 and 50-79 (Fig. 8). Although the predicted molecular mass of hnRNP $\mathrm{K}$ is $50.9 \mathrm{kDa}$, it migrates in polyacrylamide gels at $65 \mathrm{kDa}[36$ and Immunoquest product literature]. Little or no protein bound to either the beads alone, to the non-specific oligonucleotide (Fig. 8), or to the oligonucleotide, nt 79-93 (data not shown). Furthermore, refeeding decreased the binding of hnRNPs K and L to nt $50-79$ by $70 \pm 8 \%$ and $62 \pm 3 \%$, respectively, for three separate pull-down assays. HnRNP A2/B1 was detected as a broad band at $37 \mathrm{kDa}$. The antibody detects both isoforms of this protein. The amount of hnRNP A2/B1 bound was decreased by $70.1 \%$ ( $\mathrm{n}=2$ pull-down assays) in extracts from refed mice. The amount of these proteins in the total nuclear extracts (Fig. 8, input) did not vary with nutritional status. Thus, nutritional status regulates the binding of hnRNP K, L, and A2/B1 to a region of exon 12 from nt 65-79 in the absence of a change in their nuclear concentration.

\section{Discussion}

Over half of all genes undergo alternative splicing either in response to hormonal, developmental signals or in a tissue-specific manner. This process is highly regulated. An 
increasing number of genes have been identified whose expression is regulated by changes in the rate of splicing of constitutive exons; G6PD is one such gene [2, 37-39]. Unique to the regulated splicing of G6PD is that it occurs in response to nutritional cues [2]. In this regard, the 12- to 15-fold increase in G6PD mRNA accumulation during the starvation to refeeding transition is caused by comparable changes in the rate of RNA splicing [18]. This large change in mRNA accumulation makes this an excellent dietary paradigm in which to study the molecular details involved in regulated splicing. Our work has identified a cis-acting regulatory element in exon 12 of the G6PD mRNA that is required for regulated splicing of this RNA [19]. In this report, we present evidence that hnRNP K, L, and A2/B1 differentially bind to exon 12 in response to starvation and refeeding.

The inverse correlation between increased binding of hnRNP K, L and A2/B1 to G6PD mRNA and a decrease in the abundance of G6PD mRNA during starvation suggests that these proteins function to inhibit G6PD splicing. Only a few regulatory proteins have been described that function to inhibit RNA splicing and among these are hnRNP L and A2/B1. HnRNP L binds to an ESS in the CD45 mRNA and silences inclusion of three alternatively spliced exons within this RNA $[14,40]$. In each alternatively spliced exon of CD45 pre-mRNA, hnRNP L functions within a composite RNA regulatory element that also contains an ESE and a regulatory sequence that facilitates splicing regulation in response to external stimuli. In contrast to this splicing silencing activity of hnRNP L, this protein also functions to enhance splicing of the nitric oxide synthase pre-mRNA [15]. HnRNPs of the A and B group function in the inhibition of tat exon 1 splicing in the HIV-1 pre-mRNA [27, 41]. The different isoforms within this group are equally effective in causing this inhibition. Because hnRNP A2 and B1 cross-reacted with the antibody used in the Western analysis (Fig. 8), the presence of 
both hnRNPs or just hnRNP B1 cannot be determined. None-the-less, the binding of this group of hnRNPs to G6PD exon 12 is consistent with it functioning in the inhibition of G6PD expression during starvation. A potential role for hnRNP K in inhibiting G6PD splicing is less clear. HnRNP K has ubiquitous functions in RNA metabolism; its roles in RNA translation and mRNA stability are the best-characterized [42]. The ability of hnRNP K to interact with other proteins involved in RNA processing [43] suggests that it may have a permissive function, recruiting proteins that directly interact with components of the spliceosome.

Sequence specific details by which these proteins bind to their RNA elements are not clear. The sequence between nt 65 and 79 of exon 12 is the minimal sequence required for binding of these proteins, while binding is enhanced by inclusion of the upstream $15 \mathrm{nt}$. HnRNP L binds to CA repeats in the nitric oxide synthetase mRNA but this binding enhances mRNA splicing [15]. HnRNP L binds to an ESS in the CD45 mRNA [14]. The G6PD regulatory element does not resemble this sequence and neither of these elements scores highly using software designed to search for splicing silencing elements. HnRNPs of the A/B family are predicted to bind tandem UAG repeats [21, 44]. This sequence is not present in the G6PD regulatory element. The G6PD regulatory sequence does score highly as a potential exonic regulatory sequence using a new algorithm developed using computational analysis of 46,103 exons [45]. This is consistent with our most recent data demonstrating that the region from nt 43-72 of exon 12 is an ESS [46].

The nt 65-79 sequence in exon 12 of G6PD mRNA does contain two C-rich stretches, predictive of hnRNP K binding sites [42]. Mutation of the three C's from nt 65-67 markedly decreases the binding of all proteins to the RNA (Griffith, B.N. and Salati, L.M., unpublished data) and corroborates the finding that hnRNP K binds to this element. HnRNP K interacts 
with a large number of nuclear proteins involved in splicing including hnRNPs L and A2/B1 [43]. The observation that elimination of a potential hnRNP K binding site also decreased the binding of hnRNPs $\mathrm{L}$ and A2/B1 is consistent with the idea that the binding of hnRNP $\mathrm{K}$ facilitates the interaction of hnRNPs $L$ and A2/B1. Because these in vitro assays eliminate regulatory functions of nuclear structure on RNA/protein interactions, conclusions regarding their role in regulated splicing cannot be made. The physiological relevance of the interaction of these hnRNPs with the G6PD regulatory element must be tested directly; these experiments are on-going in the laboratory.

Regulatory elements found within exons can act as splicing enhancers or silencers depending on the proteins that bind these sequences. Most enhancers bind members of the SR family of proteins, while silencers bind members of the hnRNP family [8, 11-14]. In general, the binding of SR proteins to ESEs enhances the recruitment of spliceosome components to the exon 12. SR protein binding might have been expected using nuclear extracts from refed mice. Bands increasing in intensity were not observed nor were these proteins detected in the 2dimensional gels. Thus, these proteins either do not bind within this sequence or the amount bound was below the limits of detection. Because hnRNPs L and A2/B1 are known to bind ESSs and act as splicing silencers, the binding of these proteins to G6PD pre-mRNA is consistent withthis element being an ESS [46].

Three additional proteins were also identified by MALDI-TOF analysis. Dematin is a known actin filament bundling protein that is not known to play a role in splicing [47]. The protein, p47 is similar to a zinc finger protein (Zfp462), but the function of this protein is not known (Swiss-prot database). SAP 114 protein, is a subunit of the spliceosome referred to as the spliceosome associated protein, but the molecular weight of this protein is $30 \mathrm{kDa}$ and does 
not match the $60 \mathrm{kDa}$ molecular weight observed in the gel and perhaps co-purified with another protein [48]. Therefore, the significance of these three proteins is not clear at this point.

The changes in binding of hnRNPs K, L and A2/B1 to exon 12 occurred in the absence of changes in the total amount of these proteins in the nuclear extracts (Fig. 8). HnRNPs are known to undergo posttranslational modifications such as phosphorylation $[49,50]$, methylation [51, 52], and sumoylation [53]. In the case of hnRNP K, phosphorylation can regulate RNA binding [49]. It is likely that posttranslational modifications control the binding of hnRNP K, L, and A2/B1 to the RNA regulatory element within G6PD mRNA. Phosphorylation can cause a shift in the mobility of proteins in two-dimensional gels [54]. A shift was not observed suggesting that this is not the case. Determining the mechanism for these changes in protein binding and how they regulate mRNA splicing is the subject of ongoing research in our laboratory. Determination of how hnRNP K, L and A2/B1 differentially bind to the RNA regulatory element within exon 12 will be fundamental in the elucidation of novel regulation mechanisms involved in the nutritional regulation of gene expression. 


\section{Acknowledgments}

*We thank Dr. Timothy Vincent and the proteomics facility for protein identifications and for helpful discussions, and Dr. Massimo Caputi for advice with the adipic acid bead protocol. We acknowledge the contribution of Ms. Xiaohui Hou for constructing the exon 11-13 probe. This work was supported by National Institutes of Health Grant DK46897 (to L.M.S.), by a predoctoral fellowship from the American Heart Association Mid 0315129B (to B.N.G), and by the COBRE for Signal Transduction and Cancer (5P20RR016440-05) and the WVU Proteomics Facility

\section{Table 1:}

Assigned identities of Proteins bound to the 50-79nt region of exon 12. The band A identification determined two proteins hnRNP $\mathrm{K}$ and $\mathrm{L}$ as two key proteins within band $\mathrm{A}$. The identification of the proteins in band B identified hnRNP A2/B1 protein. The table represents the molecular weight of each protein, the percent sequence coverage as well as the number of unique peptides sequenced for each protein.

\begin{tabular}{llccccc}
\hline & Protein & Organism & $\begin{array}{c}\text { Accession } \\
\#\end{array}$ & $\begin{array}{c}\text { Mass } \\
(\mathrm{kDa})\end{array}$ & $\begin{array}{c}\text { Sequence } \\
\text { coverage }\end{array}$ & $\begin{array}{c}\text { Unique } \\
\text { peptides }\end{array}$ \\
\hline Band A & hnRNP L & Mouse & 796275 & 60.4 & $33.2 \%$ & 16 \\
& hnRNP K & Mouse & 079555 & 50.9 & $35.7 \%$ & 14 \\
\hline Band B & hnRNP A2/B1 Mouse & 872591 & 37.4 & $60.1 \%$ & 21 \\
\hline
\end{tabular}




\section{References}

[1] F.B. Hillgartner, L.M. Salati and A.G. Goodridge, Physiological and molecular mechanisms involved in nutritional regulation of fatty acid synthesis, Physiol. Rev. 75 (1995) $47-76$.

[2] L.M. Salati, W. Szeszel-Fedorowicz, H. Tao, M.A. Gibson, B. Amir-Ahmady, L.P. Stabile and D.L. Hodge, Nutritional regulation of mRNA processing, J. Nutr. 134 (2004) $2437 \mathrm{~S}-2443 \mathrm{~S}$.

[3] B. Dozin, J.E. Rall and V.M. Nikodem, Tissue-specific control of rat malic enzyme activity and messenger RNA levels by a high carbohydrate diet, Proc. Natl. Acad. Sci. U. S. A. 83 (1986) 4705-9.

[4] A. Katsurada, N. Iritani, H. Fukuda, Y. Matsumura, N. Nishimoto, T. Noguchi and T. Tanaka, Effects of nutrients and hormones on transcriptional and post-transcriptional regulation of acetyl-CoA carboxylase in rat liver, Eur. J. Biochem. 190 (1990) 435-41.

[5] C.F. Semenkovich, T. Coleman and R. Goforth, Physiologic concentrations of glucose regulate fatty acid synthase activity in HepG2 cells by mediating fatty acid synthase mRNA stability, J. Biol. Chem. 268 (1993) 6961-70.

[6] N. Custodio, M. Carmo-Fonseca, F. Geraghty, H.S. Pereira, F. Grosveld and M. Antoniou, Inefficient processing impairs release of RNA from the site of transcription, EMBO J. 18 (1999) 2855-66.

[7] D.L. Black, Mechanisms of alternative pre-messenger RNA splicing, Annu. Rev. Biochem. 72 (2003) 291-336.

[8] S.M. Berget, Exon recognition in vertebrate splicing, J. Biol. Chem. 270 (1995) 2411-4. 
[9] W.G. Fairbrother and L.A. Chasin, Human genomic sequences that inhibit splicing, Mol. Cell. Biol. 20 (2000) 6816-25.

[10] R.C. Chan and D.L. Black, The polypyrimidine tract binding protein binds upstream of neural cell-specific c-src exon N1 to repress the splicing of the intron downstream, Mol. Cell. Biol. 17 (1997) 4667-76.

[11] B.J. Blencowe, Exonic splicing enhancers: mechanism of action, diversity and role in human genetic diseases, Trends Biochem. Sci. 25 (2000) 106-10.

[12] G. Dreyfuss, M.J. Matunis, S. Pinol-Roma and C.G. Burd, hnRNP proteins and the biogenesis of mRNA, Annu. Rev. Biochem. 62 (1993) 289-321.

[13] H.X. Liu, M. Zhang and A.R. Krainer, Identification of functional exonic splicing enhancer motifs recognized by individual SR proteins, Genes Dev. 12 (1998) 1998-2012. [14] C.R. Rothrock, A.E. House and K.W. Lynch, HnRNP L represses exon splicing via a regulated exonic splicing silencer, EMBO J. 24 (2005) 2792-802.

[15] J. Hui, K. Stangl, W.S. Lane and A. Bindereif, HnRNP L stimulates splicing of the eNOS gene by binding to variable-length CA repeats, Nat. Struct. Biol. 10 (2003) 33-7.

[16] C. Ibrahim el, T.D. Schaal, K.J. Hertel, R. Reed and T. Maniatis, Serine/arginine-rich protein-dependent suppression of exon skipping by exonic splicing enhancers, Proc. Natl. Acad. Sci. U. S. A. 102 (2005) 5002-7.

[17] L.P. Stabile, D.L. Hodge, S.A. Klautky and L.M. Salati, Posttranscriptional regulation of glucose-6-phosphate dehydrogenase by dietary polyunsaturated fat, Arch. Biochem. Biophys. 332 (1996) 269-79.

[18] B. Amir-Ahmady and L.M. Salati, Regulation of the processing of glucose-6-phosphate dehydrogenase mRNA by nutritional status, J. Biol. Chem. 276 (2001) 10514-23. 
[19] H. Tao, W. Szeszel-Fedorowicz, B. Amir-Ahmady, M.A. Gibson, L.P. Stabile and L.M. Salati, Inhibition of the splicing of glucose-6-phosphate dehydrogenase precursor mRNA by polyunsaturated fatty acids, J. Biol. Chem. 277 (2002) 31270-8.

[20] D.L. Hodge and L.M. Salati, Nutritional regulation of the glucose-6-phosphate dehydrogenase gene is mediated by a nuclear posttranscriptional mechanism, Arch. Biochem. Biophys. 348 (1997) 303-12.

[21] C.G. Burd and G. Dreyfuss, RNA binding specificity of hnRNP A1: significance of hnRNP A1 high-affinity binding sites in pre-mRNA splicing, EMBO J. 13 (1994) 1197-204.

[22] L. Cartegni, J. Wang, Z. Zhu, M.Q. Zhang and A.R. Krainer, ESEfinder: A web resource to identify exonic splicing enhancers, Nucleic Acids Res. 31 (2003) 3568-71.

[23] Z. Wang, M.E. Rolish, G. Yeo, V. Tung, M. Mawson and C.B. Burge, Systematic identification and analysis of exonic splicing silencers, Cell 119 (2004) 831-45.

[24] X.H. Zhang and L.A. Chasin, Computational definition of sequence motifs governing constitutive exon splicing, Genes Dev. 18 (2004) 1241-50.

[25] J.D. Dignam, R.M. Lebovitz and R.G. Roeder, Accurate transcription initiation by RNA polymerase II in a soluble extract from isolated mammalian nuclei, Nucleic Acids Res. 11 (1983) 1475-89.

[26] G. Edwalds-Gilbert and C. Milcarek, Regulation of poly(A) site use during mouse B-cell development involves a change in the binding of a general polyadenylation factor in a B-cell stage-specific manner, Mol. Cell. Biol. 15 (1995) 6420-9.

[27] M. Caputi and A.M. Zahler, Determination of the RNA binding specificity of the heterogeneous nuclear ribonucleoprotein (hnRNP) H/H'/F/2H9 family, J. Biol. Chem. 276 (2001) 43850-9. 
[28] J.O. Langland, S.M. Pettiford and B.L. Jacobs, Nucleic acid affinity chromatography: preparation and characterization of double-stranded RNA agarose, Protein Expr. Purif. 6 (1995) 25-32.

[29] M.P. Washburn, D. Wolters and J.R. Yates, 3rd, Large-scale analysis of the yeast proteome by multidimensional protein identification technology, Nat. Biotechnol. 19 (2001) 242-7.

[30] A.J. Link, J. Eng, D.M. Schieltz, E. Carmack, G.J. Mize, D.R. Morris, B.M. Garvik and J.R. Yates, 3rd, Direct analysis of protein complexes using mass spectrometry, Nat. Biotechnol. 17 (1999) 676-82.

[31] I. Talukdar, W. Szeszel-Fedorowicz and L.M. Salati, Arachidonic acid inhibits the insulin induction of glucose-6-phosphate dehydrogenase via p38 MAP kinase, J. Biol. Chem. 280 (2005) 40660-7.

[32] L.P. Stabile, S.A. Klautky, S.M. Minor and L.M. Salati, Polyunsaturated fatty acids inhibit the expression of the glucose-6- phosphate dehydrogenase gene in primary rat hepatocytes by a nuclear posttranscriptional mechanism, J. Lipid Res. 39 (1998) 1951-63.

[33] G. Agren, O. Wilander and E. Jorpes, Cyclic changes in the glycogen content of the liver and the muscles of rats and mice: Their bearing upon the sensitivity of the animals to insulin, and their influence on the urinary output of nitrogen, Biochem. J. 25 (1931) 777-85.

[34] H. Kamma, H. Satoh, M. Matusi, W.W. Wu, M. Fujiwara and H. Horiguchi, Characterization of hnRNP A2 and B1 using monoclonal antibodies: intracellular distribution and metabolism through cell cycle, Immunol. Lett. 76 (2001) 49-54. 
[35] H. Kamma, H. Horiguchi, L. Wan, M. Matsui, M. Fujiwara, M. Fujimoto, T. Yazawa and G. Dreyfuss, Molecular characterization of the hnRNP A2/B1 proteins: tissue-specific expression and novel isoforms, Exp. Cell Res. 246 (1999) 399-411.

[36] P. Malik and J.B. Clements, Protein kinase CK2 phosphorylation regulates the interaction of Kaposi's sarcoma-associated herpesvirus regulatory protein ORF57 with its multifunctional partner hnRNP K, Nucleic Acids Res. 32 (2004) 5553-69.

[37] Y. Ke, J. Ash and L.F. Johnson, Splicing signals are required for S-phase regulation of the mouse thymidylate synthase gene, Mol. Cell. Biol. 16 (1996) 376-83.

[38] L. Siculella, F. Damiano, S. Sabetta and G.V. Gnoni, n-6 PUFAs downregulate expression of the tricarboxylate carrier in rat liver by transcriptional and posttranscriptional mechanisms, J. Lipid Res. 45 (2004) 1333-40.

[39] J.D. Walker, L.A. Burmeister, A. Mariash, J.F. Bosman, J. Harmon and C.N. Mariash, Insulin increases the processing efficiency of messenger ribonucleic acid-S14 nuclear precursor, Endocrinology 137 (1996) 2293-9.

[40] A. Tong, J. Nguyen and K.W. Lynch, Differential expression of CD45 isoforms is controlled by the combined activity of basal and inducible splicing-regulatory elements in each of the variable exons, J. Biol. Chem. 280 (2005) 38297-304.

[41] A.M. Zahler, C.K. Damgaard, J. Kjems and M. Caputi, SC35 and heterogeneous nuclear ribonucleoprotein $\mathrm{A} / \mathrm{B}$ proteins bind to a juxtaposed exonic splicing enhancer/exonic splicing silencer element to regulate HIV-1 tat exon 2 splicing, J. Biol. Chem. 279 (2004) 10077-84. [42] K. Bomsztyk, O. Denisenko and J. Ostrowski, hnRNP K: one protein multiple processes, Bioessays 26 (2004) 629-38. 
[43] M. Mikula, A. Dzwonek, J. Karczmarski, T. Rubel, M. Dadlez, L.S. Wyrwicz, K. Bomsztyk and J. Ostrowski, Landscape of the hnRNP K protein-protein interactome, Proteomics 6 (2006) 2395-406.

[44] M. Caputi, A. Mayeda, A.R. Krainer and A.M. Zahler, hnRNP A/B proteins are required for inhibition of HIV-1 pre-mRNA splicing, EMBO J. 18 (1999) 4060-7.

[45] A. Goren, O. Ram, M. Amit, H. Keren, G. Lev-Maor, I. Vig, T. Pupko and G. Ast, Comparative analysis identifies exonic splicing regulatory sequences--The complex definition of enhancers and silencers, Mol. Cell 22 (2006) 769-81.

[46] W. Szeszel-Fedorowicz, I. Talukdar, B.N. Griffith, C.M. Walsh and L.M. Salati, An exonic splicing silencer is involved in the regulated splicing of glucose-6-phosphate dehydrogenase mRNA, J. Biol. Chem. epub (2006).

[47] A.C. Azim, J.H. Knoll, A.H. Beggs and A.H. Chishti, Isoform cloning, actin binding, and chromosomal localization of human erythroid dematin, a member of the villin superfamily, J. Biol. Chem. 270 (1995) 17407-13.

[48] M.D. Chiara, P. Champion-Arnaud, M. Buvoli, B. Nadal-Ginard and R. Reed, Specific protein-protein interactions between the essential mammalian spliceosome-associated proteins SAP 61 and SAP 114, Proc. Natl. Acad. Sci. U. S. A. 91 (1994) 6403-7.

[49] J. Ostrowski, D.S. Schullery, O.N. Denisenko, Y. Higaki, J. Watts, R. Aebersold, L. Stempka, M. Gschwendt and K. Bomsztyk, Role of tyrosine phosphorylation in the regulation of the interaction of heterogenous nuclear ribonucleoprotein $\mathrm{K}$ protein with its protein and RNA partners, J. Biol. Chem. 275 (2000) 3619-28. 
[50] J. Xie, J.A. Lee, T.L. Kress, K.L. Mowry and D.L. Black, Protein kinase A phosphorylation modulates transport of the polypyrimidine tract-binding protein, Proc. Natl. Acad. Sci. U. S. A. 100 (2003) 8776-81.

[51] M. Maggipinto, C. Rabiner, G.J. Kidd, A.J. Hawkins, R. Smith and E. Barbarese, Increased expression of the MBP mRNA binding protein HnRNP A2 during oligodendrocyte differentiation, J. Neurosci. Res. 75 (2004) 614-23.

[52] A. Ostareck-Lederer, D.H. Ostareck, K.P. Rucknagel, A. Schierhorn, B. Moritz, S. Huttelmaier, N. Flach, L. Handoko and E. Wahle, Asymmetric arginine dimethylation of heterogeneous nuclear ribonucleoprotein $\mathrm{K}$ by protein-arginine methyltransferase 1 inhibits its interaction with c-Src, J. Biol. Chem. 281 (2006) 11115-25.

[53] T. Li, E. Evdokimov, R.F. Shen, C.C. Chao, E. Tekle, T. Wang, E.R. Stadtman, D.C. Yang and P.B. Chock, Sumoylation of heterogeneous nuclear ribonucleoproteins, zinc finger proteins, and nuclear pore complex proteins: a proteomic analysis, Proc. Natl. Acad. Sci. U. S. A. 101 (2004) 8551-6.

[54] M. Blaustein, F. Pelisch, T. Tanos, M.J. Munoz, D. Wengier, L. Quadrana, J.R. Sanford, J.P. Muschietti, A.R. Kornblihtt, J.F. Caceres, O.A. Coso and A. Srebrow, Concerted regulation of nuclear and cytoplasmic activities of SR proteins by AKT, Nat. Struct. Mol. Biol. $12(2005)$ 1037-44. 


\section{Figure Legends}

Fig. 1. The structure of the G6PD RNA probes used in the identification of RNA binding proteins. (A) The G6PD gene contains 13 exons and 12 introns of which exon 12 is known to regulate splicing in primary hepatocytes [19]. The exon 12 probe contained the entire exon 12 sequence. The Exon 11-13 probe included exons 11 and part of exon 13 and the surrounding introns. The Exon $12 \Delta^{1}$ and $\Delta^{2}$ probes had $5^{\prime}$ deletions of 37 and 47 nucleotides from the exon, respectively. (B) The sequence from nt 35-93 is diagrammed. The lines beneath the sequence indicate the sequence of 15 or 30 nt RNA oligonucleotides used in the UV crosslinking and RNA affinity assays. An oligonucleotide (oligo) containing an hnRNP A1 binding site was used as a positive control in these assays. The non-specific oligonucleotide represents a random sequence of nucleotides predicted not to bind to RNA binding proteins.

Fig. 2. Detection of RNA binding proteins by UV crosslinking analysis. (A) Mice were starved for 24 hrs and then half were refed a high-carbohydrate diet for an additional $24 \mathrm{hrs;}$ liver nuclear extracts were prepared and UV crosslinked to the exon 12 RNA probes diagrammed in Fig. 1A. The bands indicated by asterisks indicate non-specific protein binding. $\mathrm{A}$ and $\mathrm{B}$ refer to bands of $60 \mathrm{kDa}$ and $37 \mathrm{kDa}$, respectively, that changed in intensity between starved and refed mice. (B) The protein bands A and B were quantified using ImageQuant software. The percent-decrease was calculated by dividing the phosphor imager units from starved by the value from refed samples. The values represent the mean plus or minus the standard error of six different nuclear extracts. 
Fig. 3. The $60 \mathrm{kDa}$ and $37 \mathrm{kDa}$ proteins regulated by starvation and refeeding bind to $\mathrm{nt} 65-79$ of exon 12. Mouse liver nuclear extracts from the livers of mice that were starved (S) or refed (R) were UV crosslinked to end-labeled RNA oligonucleotides (oligo) to the indicated regions of exon 12 or to the uniformly labeled full-length exon 12 probe (Exon 12). The hnRNP A1 consensus sequence was included as a positive control. The non-specific (NS) oligonucleotide is an RNA oligonucleotide that was designed to lack known sites for splicing factor binding. A and $\mathrm{B}$ refer to the $60 \mathrm{kDa}$ and the $37 \mathrm{kDa}$ bands, respectively. The numbers 1-6 represent protein bands unique to each oligonucleotide.

Fig. 4. RNA affinity assay to purify RNA binding proteins. RNA oligonucleotides (oligo) were covalently linked to adipic acid beads and used to pull-down RNA binding proteins. The region of exon 12 represented by each oligonucleotide is indicated under the gel. The RNA bound beads were incubated with nuclear extracts (100 $\mu \mathrm{g}$ of protein) from the livers of starved (S) and refed (R) mice. The eluted proteins were separated by size on an SDS polyacrylamide gel and visualized using Sypro Ruby. A and B refer to the $60 \mathrm{kDa}$ and $37 \mathrm{kDa}$ proteins. Beads alone were the adipic acid beads without linked RNA. The non-specific (NS) oligonucleotide was a negative control.

Fig. 5. The $60 \mathrm{kDa}$ and $37 \mathrm{kDa}$ proteins binding to full-length exon 12 and $\mathrm{nt} 50-79$ are the same. The uniformly labeled exon 12 probe was incubated with mouse liver nuclear extract from starved mice in the presence of $0,100,1000$, and 10,000-fold Molar excess of competitor. The first competitor was unlabeled nt 50-79, and the second competitor was the non-specific (NS) RNA oligonucleotide. 
Fig. 6. RNA affinity assay for LC-MS/MS identification of the proteins within bands A and B. Adipic acid beads bound to the indicated RNA oligonucleotides were incubated with nuclear extract (500 $\mu \mathrm{g}$ of protein) from starved mouse livers. The boxes represent the regions that were excised from the gel prior to trypsin digestion. The input lane was $10 \%$ of the amount of protein used in the RNA affinity assay. NS was the non-specific oligonucleotide.

Fig. 7. Confirmation of protein identities by two-dimensional gel electrophoresis and MALDITOF analysis. Liver nuclear extracts (500 $\mu \mathrm{g}$ of protein) from starved and refed mice were incubated with adipic acid beads linked to the RNA oligonucleotide, nt 50-79. The purified proteins were eluted from the beads and analyzed by isoelectric focusing in a $\mathrm{pH}$ gradient from 3 to 10 followed by size separation in $10 \%$ polyacrylamide. The image shown is a Sypro Ruby stain of protein in the gel. Each spot was excised from the gel and protein identity was determined using MALDI-TOF analysis and MASCOT software. The asterisks are p47, dematin, and SAP 114.

Fig. 8. HnRNP L, K and A2/B1 differentially bind to the exon 12 RNA regulatory element in starved versus refed mice. RNA oligonucleotides to nt $65-79$, nt 50-79 of exon 12 , or the nonspecific (NS) oligonucleotide were covalently linked to adipic acid beads and incubated with mouse liver nuclear extracts (100 $\mu \mathrm{g}$ of protein) from starved $(\mathrm{S})$ and refed $(\mathrm{R})$ mice. The proteins were eluted from the beads and $2 \mu \mathrm{l}$ of eluted proteins were analyzed by Western analysis using the indicated antibodies (IB). Beads alone were adipic acid beads without a 
linked RNA oligonucleotide. The input lane was $10 \%$ of the amount of nuclear extract used the RNA affinity assay. 


\section{A}

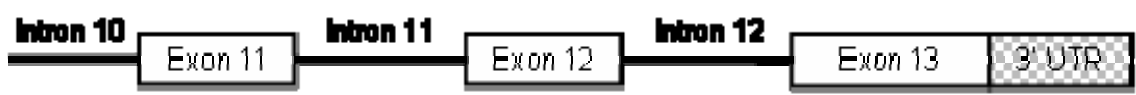

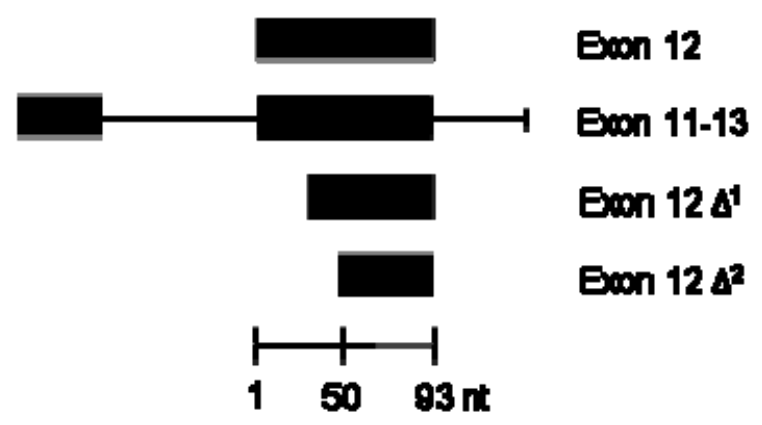

Flaure 1 
B

Exon 12 secuence $(n+35$ to 93

COACTGCTGCACAAGATTGATCGAGAAAAGCCCCAGCCCATCCCCTATGTATATGGCAG

$35-49$

$50-64$

65-79

$79-93$

50-79

hnRMP A1 Olgo: UAGGGACUUAGGGUG

Non-Specilic ollgo: CAAAAGCAUGCAAAA

Fiqure 1 


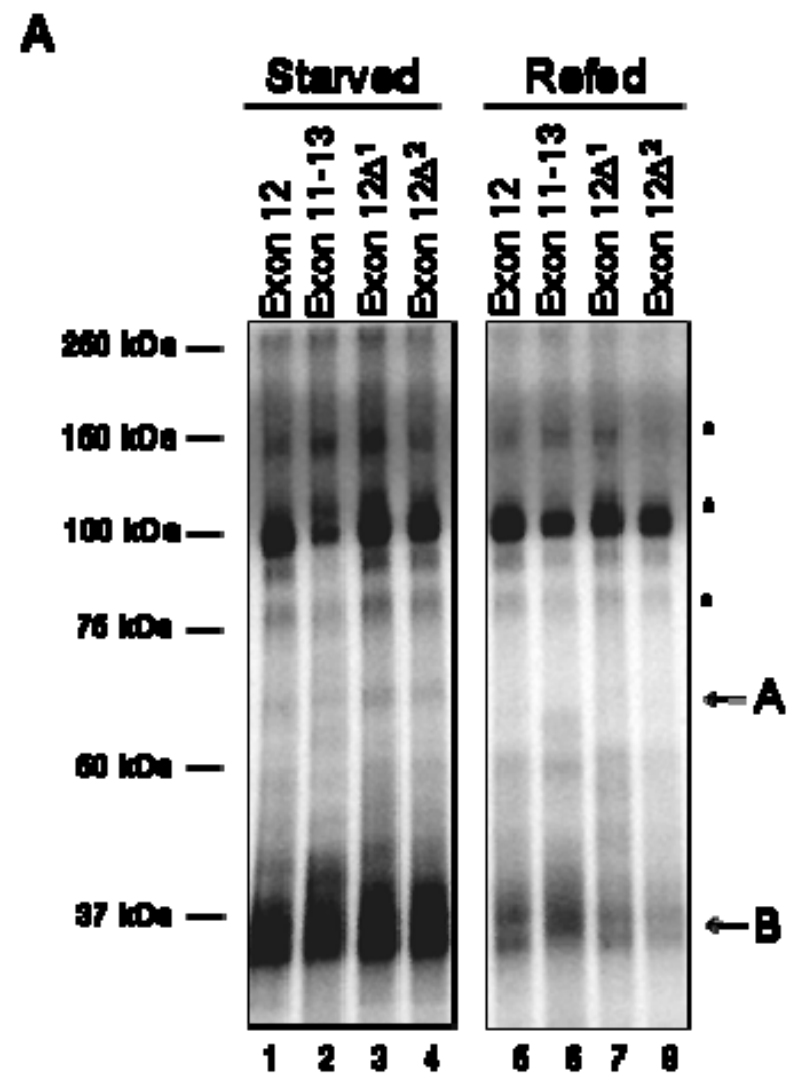

Flaure 2 
B

\begin{tabular}{lcc}
\hline & \multicolumn{2}{c}{$\mathrm{A}$ \% Decrease } \\
\hline Exon 12 & $49.9 \pm 4$ & $46.3 \pm 9$ \\
Exon 11-13 & $31.4 \pm 5$ & $51.0 \pm 6$ \\
Exon 12 $\Delta^{1}$ & $45.5 \pm 8$ & $48.0 \pm 15$ \\
Exon 12 $\Delta^{2}$ & $58.5 \pm 6$ & $56.9 \pm 12$ \\
\hline
\end{tabular}

Figure 2 


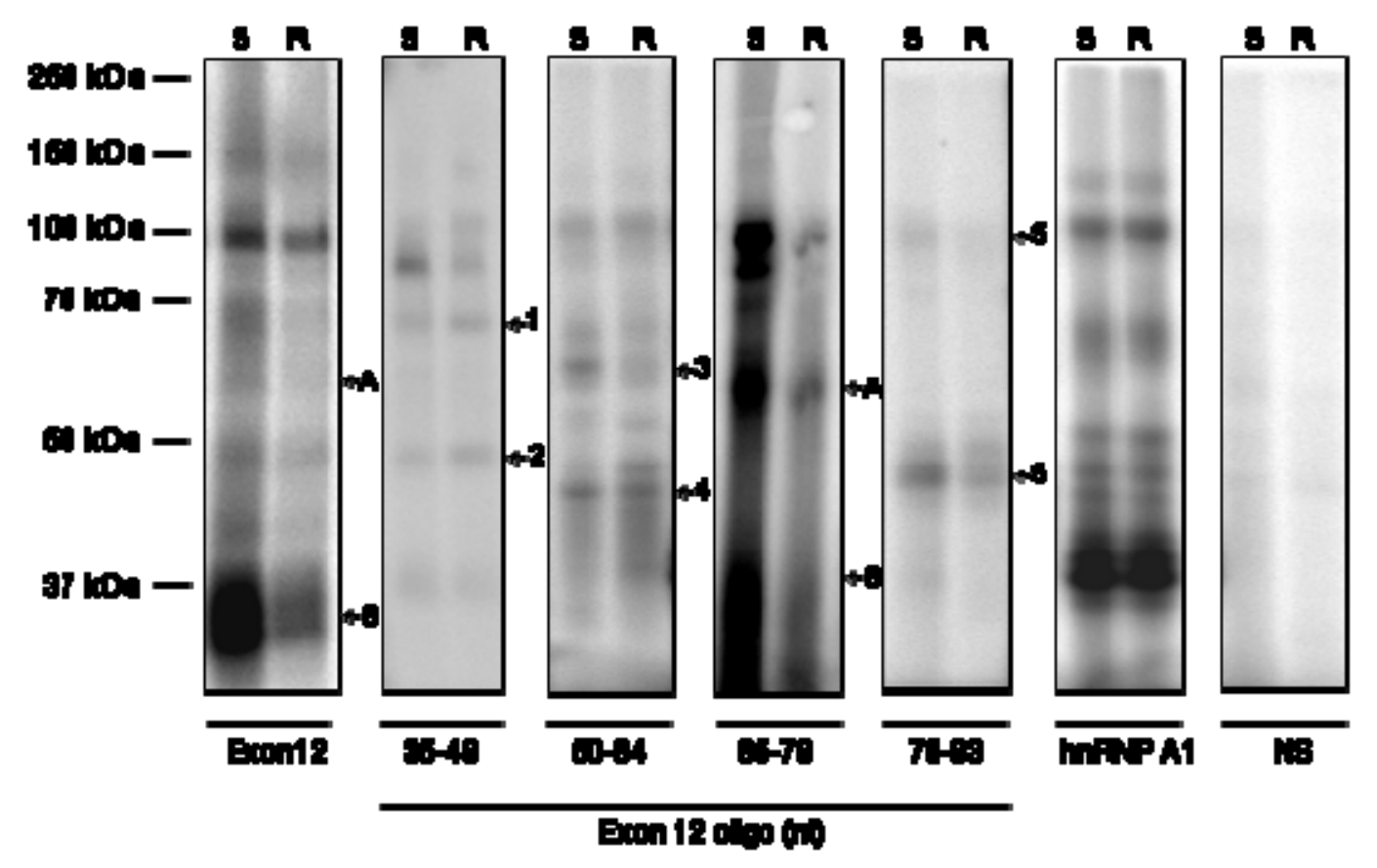

Flaure 3 


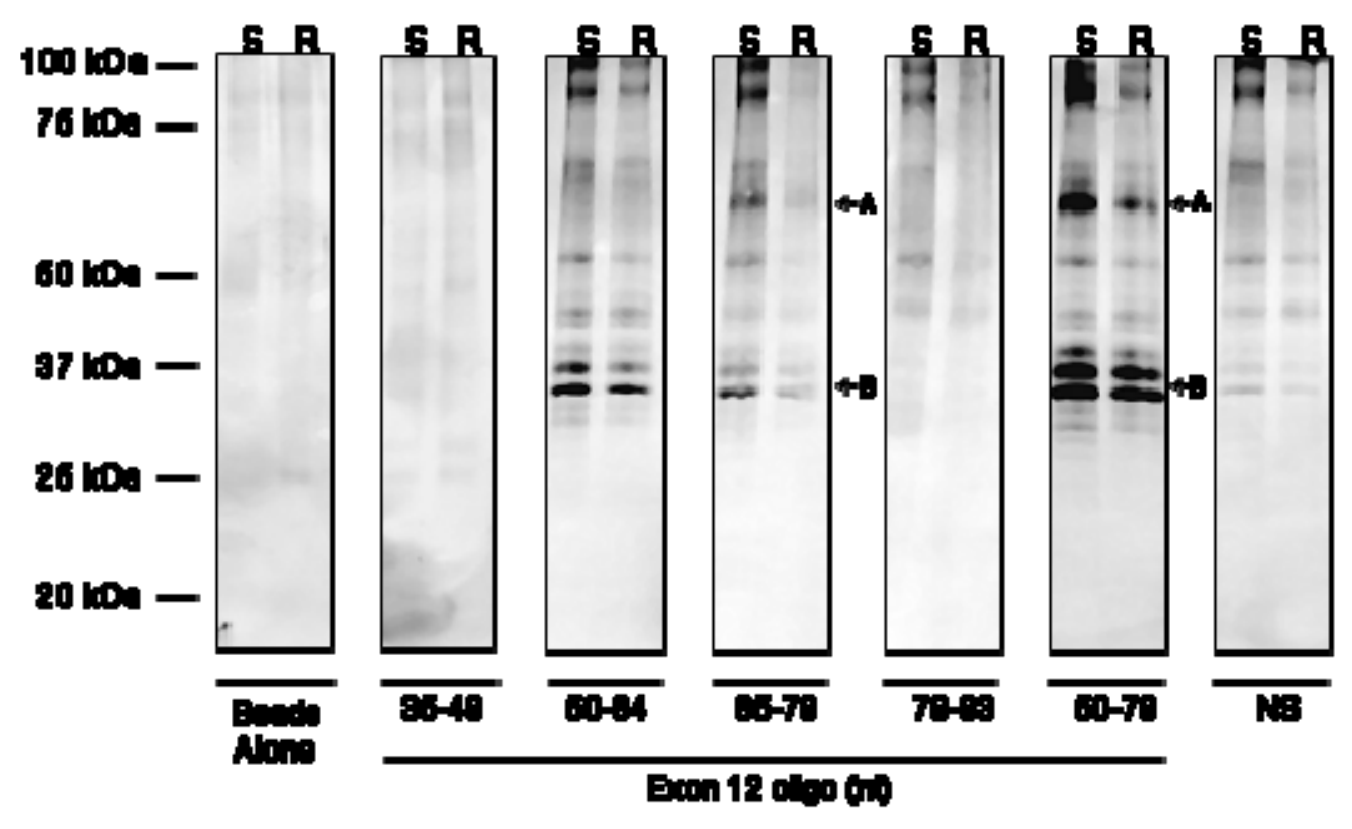

Flaure 4 


\begin{tabular}{lll} 
B & \multicolumn{2}{c}{ B } \\
\cline { 2 - 3 } & \% Decrease \\
\hline $65-79 n t$ & $60 \%$ & $53 \%$ \\
$50-79 n t$ & $51 \%$ & $44 \%$ \\
\hline
\end{tabular}

Fiqure 4 


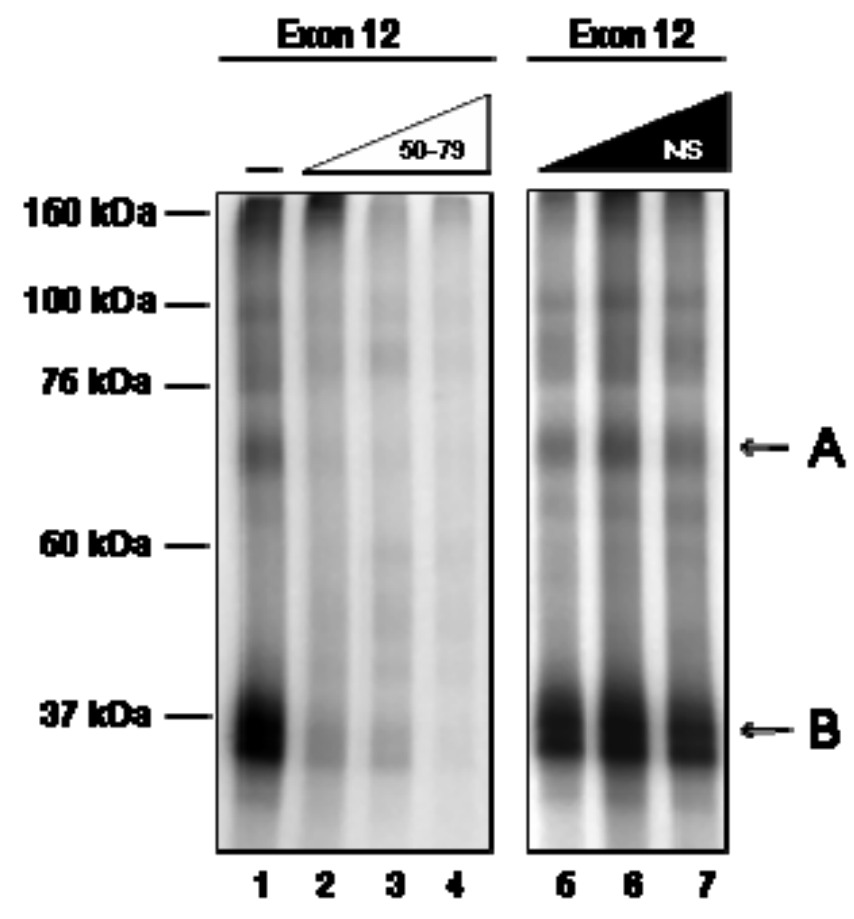

Fiaure 5 


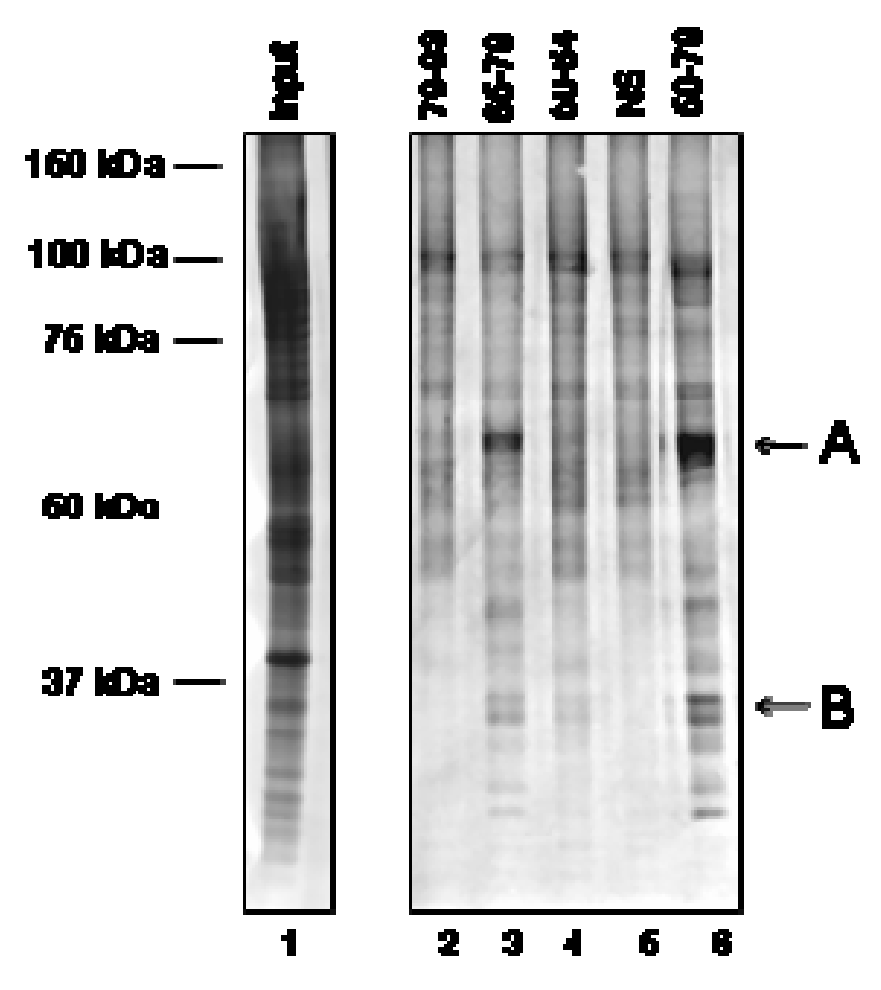

Fiqure 6 


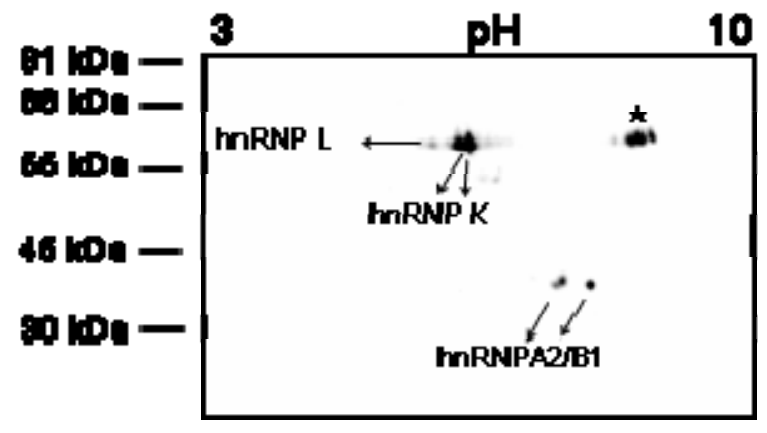

Strued

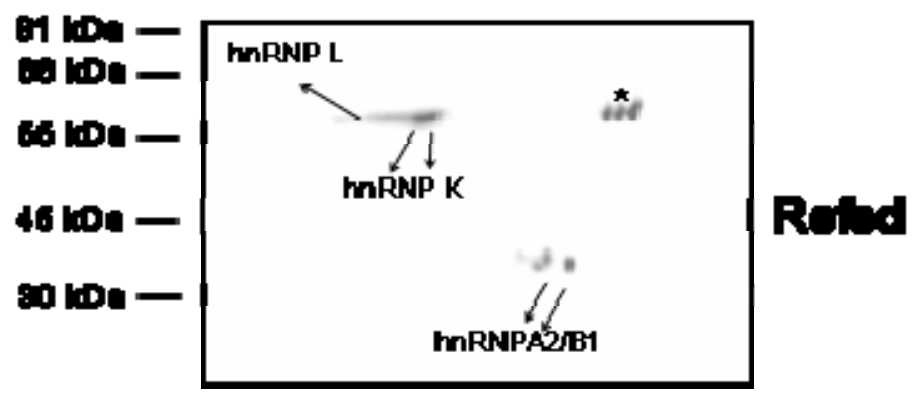

Flaure 7 


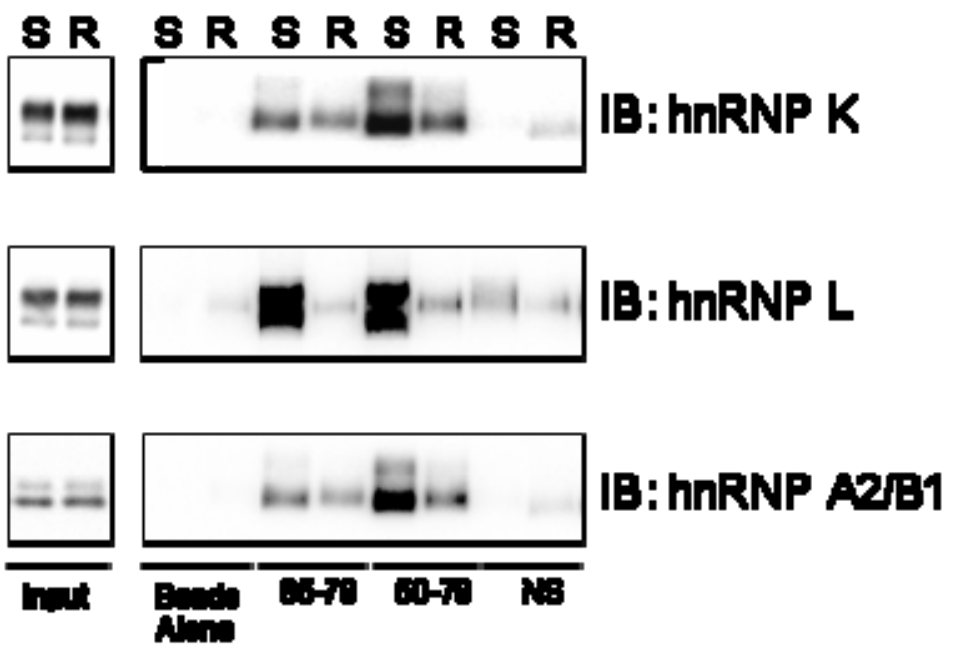

Flaure 8 


\section{Chapter 4}

\section{Differential binding of hnRNP K, L and A2/B1 to an Exonic Splicing Silencer element located within exon 12 of Glucose-6-Phosphate Dehydrogenase mRNA}




\section{DISCUSSION}

G6PD is a gene that is essential in fatty acid metabolism. The production of NADPH by the G6PD reaction is essential for the production of reducing equivalents required for the de novo synthesis of fatty acids. This unique characteristic makes G6PD a lipogenic enzyme. The regulation of G6PD by nutritional factors like polyunsaturated fatty acids is essential for regulating fatty acid synthesis and therefore polyunsaturated fatty acids inhibits G6PD expression [1-3]. However, G6PD is unique compared to other members of the lipogenic gene family in that the regulation by polyunsaturated fatty acids does not occur via a transcriptional mechanism [1-3]. G6PD seems to be solely regulated by a posttranscriptional mechanism. The regulation of teh rate of splicing of G6PD is thought to be the sole mechanism to control gene expression of G6PD in primary hepatocytes and intact liver. Previous work has shown that G6PD contains an important cis-acting element within exon 12 that is responsible for the regulation of polyunsaturated fatty acids [4-6]. Additional work has shown that intact animals starved for $24 \mathrm{~h}$ mimic the same pattern of regulation observed in primary cells incubated with polyunsaturated fatty acids. Therefore we hypothesized that a region within exon 12 was a protein binding site for either SR proteins or hnRNP proteins and the regulation of these proteins would regulate the rate of splicing of G6PD mRNA. Predominantly, these sequences have been called exon splicing enhancer and silencer and are usually short sequences (4-20 nucleotides) within exons [7].

Protein identification and characterization required the assembly of several techniques around a well established nuclear extract. In order to identify these proteins we used HeLa cell nuclear extracts a cervical cancer cell line that does not mimic the regulation of G6PD observed in either primary cells or intact animals, but this cell line is the most useful for development of 
new techniques. HeLa cells were used to purify nuclear extracts capable of producing a fully complement of proteins required for splicing, transcription, and translation. According to already established methods we used UV crosslinking with HeLa cell nuclear extracts and exon 12 RNA probes to detect unique proteins bound to regions within exon 12. A series of protein bands were detected bound to the full-length exon 12, Exon $12 \Delta^{1}$, and Exon $12 \Delta^{2}$. This informed us that a cis-acting element within 47-93 nucleotides was required for protein binding. At this time we established a method in the laboratory of using RNA oligos to further characterize the binding site of proteins within exon 12 (ref). Therefore a series of 15 nucleotide oligos were used to further characterize the protein specific sequences. The sequence that produced the strongest pattern of protein binding was a region within 50-79 nucleotides of exon 12 . This sequence was then used in an RNA affinity purification method using adipic-acid dihydrazideagarose beads to purify RNA binding proteins. The proteins were later sequenced by LCMS/MS analysis and revealed the identification of hnRNP K, L, I, E1, and A2/B1 bound to nucleotides 50-79 of exon 12. The protein identification was confirmed by Western blot analysis with the exception of hnRNP E1.

The reason we focused our identification to the region of 50-79 nucleotides was because we were characterizing the proteins bound to regions of exon 12 within intact animals. In addition, we knew from previous studies that starvation and refeeding induced a 12-15 fold change in G6PD mRNA expression. Therefore we set out to isolate nuclear extracts from these two different paradigms and use these nuclear extracts to characterize the nature of proteins bound to exon 12. Upon successful isolation of proteins we observed in starved versus refed animals that the pattern of protein binding was similar in these two different nuclear extracts. However, the intensity of these bands was dramatically different in starved versus refed animals. 
The two bands that we focused are attention on were at $60 \mathrm{kDa}$ and $37 \mathrm{kDa}$. These two bands changed consistently with respect to dietary manipulation of the mice in over twelve different nuclear extract preparations. Further characterization of the binding site for these two protein bands revealed a similar region as observed using the HeLa cell nuclear extracts. The region from 50-79 nucleotides of exon 12 was able to recapitulate the same pattern of protein binding as the full-length exon 12. In addition, this sequence was able to show the differential pattern of protein binding. At this time we purified these two protein bands with the adipic acid dihydrazide-agarose beads and found via LC-MS/MS analysis that hnRNP K, L and A2/B1 were the major constituents of band A and B, respectively. This matched those previously described proteins observed bound in HeLa cell nuclear extracts.

Proteins identification revealed three main proteins, hnRNP K, L, and A2/B1, that were consistently observed in human and mouse nuclear extracts bound to a similar region within exon 12. Based upon the information we know about hnRNP K, L, and A2/B1 these proteins act more like exonic splicing silencer proteins and therefore we believe this sequence from nucleotides 50-79 mimics an ESS both in vivo and in vitro studies. Further analysis of these proteins in both HeLa cell nuclear extracts and mouse liver nuclear extracts will be conducted to show the relationship between these proteins and the splicing efficiency of G6PD mRNA. Our hypothesis is further modified to state that hnRNP K, L, A2/B1 differentially binds to G6PD mRNA in the presence of intact animals starved and refed. The differential pattern of protein binding does suggest that those hnRNPs are inhibiting the splicing efficiency of G6PD mRNA splicing in animals starved for $24 \mathrm{~h}$ compared to those animals refed for $24 \mathrm{~h}$. This is the first report of hnRNP proteins regulating the constitutive splicing of G6PD mRNA in response to the starvation/refeeding paradigm. 


\section{Reference List}

[1] D.L.Hodge and L.M.Salati, Nutritional regulation of the glucose-6-phosphate dehydrogenase gene is mediated by a nuclear posttranscriptional mechanism, Arch. Biochem. Biophys. 348 (1997) 303-312.

[2] L.P.Stabile, D.L.Hodge, S.A.Klautky, and L.M.Salati, Posttranscriptional regulation of glucose6-phosphate dehydrogenase by dietary polyunsaturated fat, Arch. Biochem. Biophys. 332 (1996) 269-279.

[3] L.P.Stabile, S.A.Klautky, S.M.Minor, and L.M.Salati, Polyunsaturated fatty acids inhibit the expression of the glucose-6-phosphate dehydrogenase gene in primary rat hepatocytes by a nuclear posttranscriptional mechanism, J. Lipid Res. 39 (1998) 1951-1963.

[4] B.Amir-Ahmady and L.M.Salati, Regulation of the processing of glucose-6-phosphate dehydrogenase mRNA by nutritional status, J. Biol. Chem. 276 (2001) 10514-10523.

[5] W.Szeszel-Fedorowicz, I.Talukdar, B.N.Griffith, C.M.Walsh, and L.M.Salati, An exonic splicing silencer is involved in the regulated splicing of glucose 6-phosphate dehydrogenase mRNA, J. Biol. Chem. 281 (2006) 34146-34158.

[6] H.Tao, W.Szeszel-Fedorowicz, B.mir-Ahmady, M.A.Gibson, L.P.Stabile, and L.M.Salati, Inhibition of the splicing of glucose-6-phosphate dehydrogenase precursor mRNA by polyunsaturated fatty acids, J. Biol. Chem. 277 (2002) 31270-31278.

[7] Z.M.Zheng, Regulation of alternative RNA splicing by exon definition and exon sequences in viral and mammalian gene expression, J. Biomed. Sci. 11 (2004) 278-294. 


\section{APPENDIX SECTION}

Appendix I: Identification of RNA Binding Proteins in Nuclear Extracts from Primary Rat Hepatocytes

Appendix II: Additional data on identification of RNA binding proteins in Mouse liver nuclear extracts

\section{Appendix III: Complete Methods}

\section{Appendix IV: Copyright Permission forums}




\section{Appendix I}

\section{Identification of RNA Binding Proteins in Nuclear Extracts from Primary Rat Hepatocytes}

Primary rat hepatocytes were isolated from rats starved for $24 \mathrm{~h}$ and platted on collagen coated plates prior to treatment. The hepatocytes were treated with insulin $(0.04$ $\mu \mathrm{M})$ plus or minus arachidonic acid $(175 \mu \mathrm{M})$. The presence of arachidonic acid decreases G6PD mRNA by more then 50\% [1,2]. Nuclear Extracts were prepared from cells after $24 \mathrm{~h}$ of treatment and incubated with exon 12 RNA oligos prior to UV crosslinking $[3,4]$. The region of exon 12 from nucleotides 43-72 was recently identified as an exon splicing silencer sequence involved in inhibition of G6PD expression by arachidonic acid [5]. Therefore we generated RNA oligos from nucleotides 50-93 to identify proteins binding within this region in primary rat hepatocytes (Figure 1B). Proteins bound differed across nucleotides 50-64, 65-79, and 79-93. As with both HeLa cells and primary rat hepatocytes, proteins of 60 and $37 \mathrm{kDa}$ were observed with the oligo to nucleotides $65-79$. HnRNP $\mathrm{K}$ is know to bind to $\mathrm{C}$-rich regions and the oligo from nucleotides 65-79 has 2 strong C-rich patches [6-8] with 3 or more contiguous $\mathrm{C}$ residues. These regions from nucleotides 65-67 and 71-73 were mutated to A's. These RNA oligos were UV crosslinked to primary hepatocytes nuclear extracts. The $\Delta 65-67$ oligo showed a dramatic reduction in protein binding, but the $\Delta 71-73$ nucleotide oligo showed less of a difference as compared to nucleotides $65-79$ in extracts from primary rat hepatocytes. The 
smaller change in G6PD expression (50\%) in hepatocytes treated with arachidonic acid may make it impossible to detect changes in the proteins bound to sequences within exon 12 using UV crosslinking techniques. 
A Exon 12 sequence $50 \mathrm{nt}$ to $93 \mathrm{nt}$

GATTGATCGAGAAAAGCCCCAGCCCATCCCCTATGTATATGGCAG

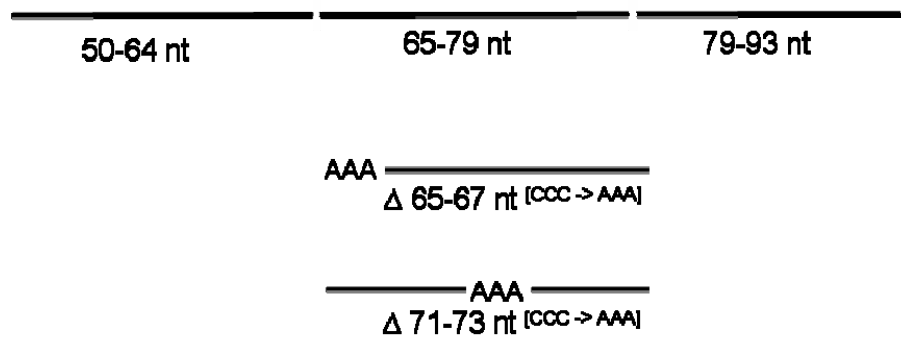

hnRNP A1 oligo

UAGGGACUUAGGGUG

Non-specific oligo

CAAAAGCAUGCAAAA

Flgure 1

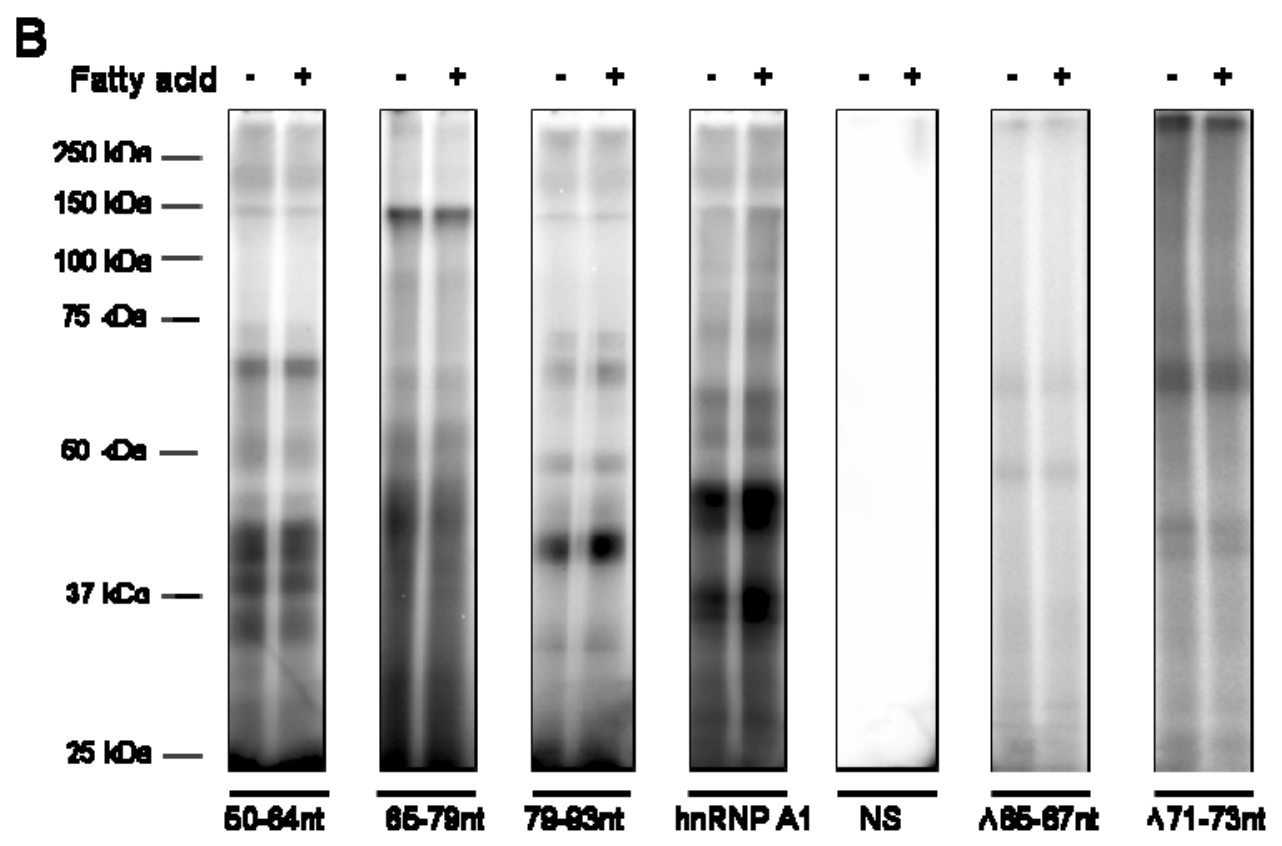

Figure 1 


\section{Appendix II}

\section{Additional data on identification of RNA binding proteins in Mouse liver nuclear extracts}

Mice were fed a low-fat diet (1\% Safflower Oil w/w) and a high-fat diet (65\% Safflower Oil w/w) for a full week. The mice were sacrificed and mouse liver nuclear extracts were isolated. This dietary paradigm results in a 2-4 fold inhibition of G6PD mRNA in those mice fed a high-fat diet as compared to those mice fed a low-fat diet. The mouse liver nuclear extracts from both low-fat and high-fat mice were UV crosslinked to the fulllength exon 12 probe. The visualization of bands resulted in the proteins at 25, 37, 45, 60, and $100 \mathrm{kDa}$. The pattern of protein bands was similar to those bands originally observed in starved and refed mice liver nuclear extracts [9]. The pattern of protein bands was similar between low-fat and high-fat mice suggesting that the small change in G6PD mRNA expression can not be determined with UV crosslinking assays. This same pattern of protein binding was observed in three separate nuclear extract preparations.

The region of exon 12 from nucleotides 43-72 was recently identified as an exon splicing silencer sequence involved in inhibition of G6PD expression by arachidonic acid [5]. Therefore we generated RNA oligos from nucleotides 50-93 to identify proteins binding within this region in mouse liver nuclear extracts (Figure 1A). Mouse liver nuclear extracts were isolated from those mice that were starved for $24 \mathrm{~h}$ and those mice that were refed for 24. This dietary paradigm results in greater then 12-15 fold changes in the amount of G6PD mRNA expression $[10,11]$. The large change in G6PD mRNA 
accumulation causes a differential pattern of protein binding across nucleotides 65-79 within exon 12. Therefore, proteins bound differed across nucleotides 50-64, 65-79, and 79-93. The change in protein binding to nucleotides $65-79$ is not due to an overall change in protein concentration or a change in glycogen concentration [9] suggesting that this change is responsible for the posttranscriptional regulation of G6PD mRNA.

Identification of these proteins bound to nucleotides 65-79 showed the presence of hnRNP $\mathrm{K}, \mathrm{L}$, and A2/B1 according to LC-MS/MS analysis, MALDI-TOF analysis, and Western analysis [9].

HnRNP $\mathrm{K}$ is known to bind to C-rich patches and the oligo from nucleotides 65-79 has 2 strong $\mathrm{C}$-rich patches [6-8] with 3 or more contiguous $\mathrm{C}$ residues. These regions from nucleotides 65-67 and 71-73 were mutated to A's in the presence of nucleotides 6579. These RNA oligos were UV crosslinked to mouse liver nuclear extracts isolated from starved and refed mice. The $\Delta 65-67$ oligo showed a dramatic reduction in protein binding, but the $\Delta 71-73$ nucleotide oligo showed less of a difference as compared to nucleotides 65-79 in extracts from primary rat hepatocytes. The $\Delta 71-73$ abrogated the differential pattern of protein binding whereas the $\Delta 65-67$ abolished any protein binding to nucleotides 65-79. The protein binding of hnRNP $\mathrm{K}$ to mRNA occurs through a region within hnRNP K referred to as the K-homology domain $(\mathrm{KH})$ domain and current information suggest that these $\mathrm{KH}$ domains mediate the binding to RNA sequences. The robust change in protein binding by removing these three C's does disrupt the binding site of hnRNP K. Therefore mutations of these C's abolish protein binding and purification of RNA binding proteins by RNA affinity purification. 


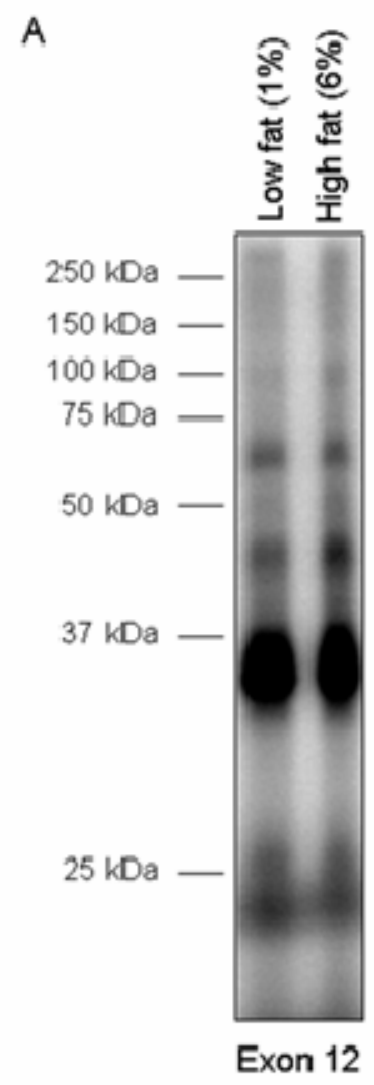

Flgure 1 


\section{A Exon 12 sequence $50 \mathrm{nt}$ to $93 \mathrm{nt}$} GATTGATCGAGAAAAGCCCCAGCCCATCCCCTATGTATATGGCAG

$\overline{50-64 \mathrm{nt}} \frac{79-79 \mathrm{nt}}{79-93 \mathrm{nt}}$

$$
\begin{aligned}
& \text { AAA } \overline{\Delta 65-67 \mathrm{nt}[\text { [CCC - AAA] }} \\
& \text { AAA } \\
& \triangle 71-73 \text { nt [CCC }>\text { AAA] }
\end{aligned}
$$

hnRNP A1 oligo

$$
\text { UAGGGACUUAGGGUG }
$$

Non-specific oligo

CAAAAGCAUGCAAAA

Figure 2

B

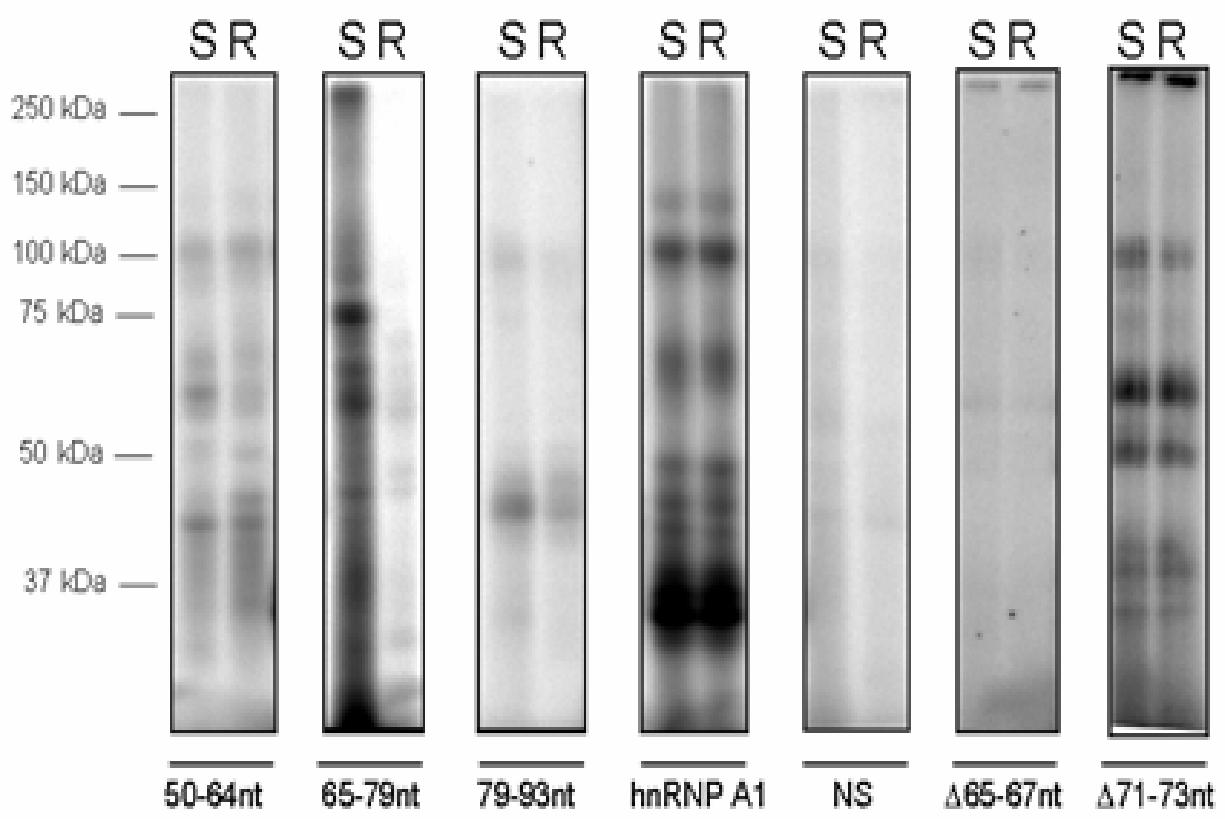

Figure 2 


\section{$\underline{\text { Appendix III }}$}

\section{Methods}

\section{Animal care}

Male C57BL/6 mice (HILL TOP) 4 weeks old were adapted to a normal $12 \mathrm{hr}$ light and dark cycle for 7 days while maintained on a standard chow diet (Harlan Teklad). Mice were switched to a fat-free diet with glucose as the carbohydrate source (PURINA MILL) supplemented with 1\% (by weight) safflower oil (SIGMA) as a source of essential fatty acids. The diet was prepared fresh daily, and the safflower oil was stored under $\mathrm{N}_{2}$ to minimize oxidation. Mice received the high carbohydrate, low fat diet ad libitum for 7 days.

a) Starved/Refed Paradigm — On day eight, the food was removed for a $24 \mathrm{~h}$ starvation period (both starved and refed mice) followed by returning the diet for $24 \mathrm{~h}$ (refed mice).

b) High-fat/Low-fat Paradigm — Mice were trained to consume the low-fat basal diet (1\% polyunsaturated fatty acids in the form of safflower oil) or high-fat (basal diet plus $6 \%$ safflower oil) diet for one week as previously described [11]. On day 8, all mice were sacrificed at the beginning of the feeding cycle period.

\section{Nuclear Extract Preparation}

Mice were sacrificed and the livers of the mice were homogenized in buffer I $(0.25$ M sucrose, $60 \mathrm{mM} \mathrm{KCl,} 15 \mathrm{mM} \mathrm{NaCl}, 15 \mathrm{mM}$ HEPES pH 7.4, 2 mM EDTA, $0.5 \mathrm{mM}$ EGTA, $0.15 \mathrm{mM}$ Spermine, $0.5 \mathrm{mM}$ Spermidine and $14 \mathrm{mM}$ ß-mercaptoethanol) in a 
Dounce homogenizer. The livers were homogenized with 12 strokes of pestle B (loose) and 12 strokes of pestle A (tight). The homogenizate was layered over buffer II ( $0.75 \mathrm{M}$ Sucrose, $60 \mathrm{mM} \mathrm{KCl}, 15 \mathrm{mM} \mathrm{NaCl}, 15 \mathrm{mM}$ HEPES pH 7.4, 2 mM EDTA, $0.5 \mathrm{mM}$ EGTA, $0.15 \mathrm{mM}$ Spermine, $0.5 \mathrm{mM}$ Spermidine and $14 \mathrm{mM}$ ß-mercaptoethanol) and centrifuged at $100 \mathrm{~g}$ for $10 \mathrm{~min}$ at $4^{\circ} \mathrm{C}$. The brownish-red pellet was resuspended with buffer III (2.0 M Sucrose, $60 \mathrm{mM} \mathrm{KCl,} 15 \mathrm{mM} \mathrm{NaCl}, 15 \mathrm{mM}$ HEPES pH 7.4, $0.1 \mathrm{mM}$ EDTA, $0.1 \mathrm{mM}$ EGTA, $0.15 \mathrm{mM}$ Spermine, $0.5 \mathrm{mM}$ Spermidine and $14 \mathrm{mM}$ Bmercaptoethanol) and the homogenate was layered over $1 \mathrm{ml}$ of buffer III in a Beckman polyallomer centrifuge tubes (Beckman) and centrifuged in an SW 50.1 ultracentrifuge rotor at $120,000 \mathrm{xg}$ for $1 \mathrm{hr} 4 \mathrm{~min}$ at $4^{\circ} \mathrm{C}$. The white pellet was resuspended in extraction buffer from the Dignam protocol [3] with the previous mentioned modifications [4]. The pellet was homogenized in a dounce homogenizer for $5 \mathrm{~min}$ and placed at $4^{\circ} \mathrm{C}$ for $30 \mathrm{~min}$ followed by centrifugation at $10,000 \mathrm{~g}$ for $10 \mathrm{~min}$ at $4^{\circ} \mathrm{C}$. The residual supernatant was referred to as the nuclear extract. Protein concentration was measured by the Bradford assay and the corresponding concentrations were in the range of 1 to $2 \mu \mathrm{g} / \mu \mathrm{l}$. The nuclear extracts were frozen and stored at $-80^{\circ} \mathrm{C}$. The quality of the nuclear extracts was measured by silver stained $10 \%$ SDS-PAGE.

\section{RNA Isolation}

RNA isolated from the liver of mice that were starved and refed was stored in RNAlater (Ambion). RNA was isolated from the liver by the method of Chomczynski and Sacchi [12]. Briefly, the liver of the mice was homogenized using a polytron for $15 \mathrm{~s}$ using short pulses in solution D (10 ml) [12]. The homogenate was mixed with $1 \mathrm{ml}$ of 2 
M sodium acetate, $\mathrm{pH} 4.0$, and $10 \mathrm{ml}$ of water-saturated phenol (Fisher) and $2 \mathrm{ml}$ of chloroform/isoamyl alcohol (fisher) (49:1 ratio) and incubated for $15 \mathrm{~min}$ at $4^{\circ} \mathrm{C}$. The nucleic acid layer and the protein layer were separated by centrifugation for $30 \mathrm{~min}$ at $4,000 \mathrm{~g}$ at $4^{\circ} \mathrm{C}$. The upper layer contained the RNA and was removed from the phenol chloroform layer and precipitated by the addition of an equal volume of isopropanol and stored at $-20^{\circ} \mathrm{C}$ for $12 \mathrm{hrs}$ followed by centrifugation at $5,000 \mathrm{~g}$ for $30 \mathrm{~min}$ at $4^{\circ} \mathrm{C}$; the residual pellet was washed in 70\% ethanol and resuspended in DEPC-H20. The quality of the RNA was determined by the 28 and 18 s ratio as determined by gel electrophoresis.

\section{Purification of RNA binding proteins}

RNAs were covalently linked to adipic acid dihydrazide-agarose beads by modification of a published procedure $[13,14]$. Briefly, 1000 pmol of RNA were placed in a $400 \mu 1$ reaction mixture containing $100 \mathrm{mM}$ sodium acetate, $\mathrm{pH} 5.0$, and $5 \mathrm{mM}$ sodium $\mathrm{m}$ periodate. Reaction mixtures were incubated for $1 \mathrm{~h}$ in the dark at room temperature. The RNA was then ethanol-precipitated and resuspended in $500 \mu \mathrm{l}$ of $0.1 \mathrm{M}$ sodium acetate, $\mathrm{pH}$ 5.0. Adipic acid dihydrazide-agarose beads (400 $\mu \mathrm{l})$ (Sigma) were washed four times in $10 \mathrm{ml}$ of $0.1 \mathrm{M}$ sodium acetate, $\mathrm{pH}$ 5.0. After the final wash, $1000 \mu \mathrm{l}$ of $0.1 \mathrm{M}$ sodium acetate, $\mathrm{pH} 5.0$, was added to the beads, and the slurry was then mixed with the periodatetreated RNA and rotated for $12 \mathrm{~h}$ at $4^{\circ} \mathrm{C}$. The beads with the bound RNA were pelleted and washed three times in $1 \mathrm{ml}$ of $2 \mathrm{M} \mathrm{NaCl}$ and three times in $1 \mathrm{ml}$ of buffer $(20 \mathrm{mM}$ HEPES-KOH, pH 7.6, 10\% v/v glycerol, 150 mM KCl, 0.2 mM EDTA) and $200 \mu \mathrm{g} / \mathrm{ml}$ tRNA to block nonspecific protein binding to the beads. The beads containing immobilized RNA were incubated in a reaction mixture containing $100 \mu \mathrm{g}$ of HeLa cell 
nuclear extract with $300 \mu \mathrm{l}$ of buffer (20 mM HEPES-KOH, pH 7.6, 10\% v/v glycerol, $150 \mathrm{mM} \mathrm{KCl}, 0.2 \mathrm{mM}$ EDTA) plus $2.5 \mathrm{mM}$ ATP, $2.0 \mathrm{mM} \mathrm{MgCl}_{2}, 1000 \mathrm{ng} / \mathrm{ml} \mathrm{tRNA}$ for $30 \mathrm{~min}$ at $30^{\circ} \mathrm{C}$. Beads were pelleted by centrifugation and washed four times with $1 \mathrm{ml}$ of buffer.

MS/MS analysis

Proteins binding to the RNA coated beads were separated by size in a $10 \%$ polyacrylamide gel. The proteins bands of interest were visualized by Colloidal Coomassie (Invitrogen) and excised from the gels. The gel slices were digested with $\operatorname{trypsin}(2 \mu \mathrm{g} / \mathrm{ml})$ overnight at $37^{\circ} \mathrm{C}$. The digested peptides were dried and reconstituted in $5 \%$ acetonitrile, $0.1 \%$ formic Acid and then loaded onto a $\mathrm{C}_{18}$ column using a helium pressure cell. Protein peptides were eluted from the column using a linear acetonitrile gradient of 5-50\% over 60 minutes with a flow rate $300 \mathrm{~nL} /$ minute. The ion-trap mass spectrometer (ThermoFinnigan LCQ Deca PLUS) was programmed to perform a full MS scan followed by MS/MS scans of the five most abundant ions present. Raw data files were compared to the SwissPro database using SEQUEST software to identify proteins that match the peptide fragments. Protein identifications were confirmed with manual sequencing of the peptides.

Western Blot Analysis

Eluted proteins from the adipic acid dihydrazide-agarose beads bound to RNA oligos were removed by SDS loading buffer $(0.1 \mathrm{M}$ dithiothreitol, $2 \%$ sodium dodecyl sulfate (SDS), $80 \mathrm{mM}$ Tris $\mathrm{pH}$ 6.8, 10\% glycerol, 0.2\% bromphenol blue). The proteins were 
loaded onto a $10 \%$ polyacrylamide gel and transferred to immunoblot PVDF membrane (Bio-Rad) at $100 \mathrm{~V}$ for $1.5 \mathrm{~h}$. The membranes were blocked in $5 \%$ nonfat dry milk overnight at $4^{\circ} \mathrm{C}$. The membranes were then incubated with primary antibody diluted in $5 \%$ bovine serum albumin for $1 \mathrm{~h}$ at RT. The primary antibodies against hnRNP A2/B1 and SR proteins were obtained from ImmuQuest. Antibodies conjugated to horseradish peroxidase were used as a secondary antibody to detect hnRNP A2/B1 and SR proteins. The immunocomplexes were detected by enhanced chemiluminescence (Pierce). Images were visualized with film (Pierce) and quantified by densitometry using Image Quant TL software (Molecular Dynamics). 


\section{Reference List}

[1] L.P.Stabile, S.A.Klautky, S.M.Minor, and L.M.Salati, Polyunsaturated fatty acids inhibit the expression of the glucose-6-phosphate dehydrogenase gene in primary rat hepatocytes by a nuclear posttranscriptional mechanism, J. Lipid Res. 39 (1998) 1951-1963.

[2] H.Tao, W.Szeszel-Fedorowicz, B.mir-Ahmady, M.A.Gibson, L.P.Stabile, and L.M.Salati, Inhibition of the splicing of glucose-6-phosphate dehydrogenase precursor mRNA by polyunsaturated fatty acids, J. Biol. Chem. 277 (2002) 31270-31278.

[3] J.D.Dignam, R.M.Lebovitz, and R.G.Roeder, Accurate transcription initiation by RNA polymerase II in a soluble extract from isolated mammalian nuclei, Nucleic Acids Res. 11 (1983) 1475-1489.

[4] G.Edwalds-Gilbert and C.Milcarek, Regulation of poly(A) site use during mouse B-cell development involves a change in the binding of a general polyadenylation factor in a B-cell stage-specific manner, Mol. Cell Biol. 15 (1995) 6420-6429.

[5] W.Szeszel-Fedorowicz, I.Talukdar, B.N.Griffith, C.M.Walsh, and L.M.Salati, An exonic splicing silencer is involved in the regulated splicing of glucose 6-phosphate dehydrogenase mRNA, J. Biol. Chem. 281 (2006) 34146-34158.

[6] K.Klimek-Tomczak, L.S.Wyrwicz, S.Jain, K.Bomsztyk, and J.Ostrowski, Characterization of hnRNP K protein-RNA interactions, J. Mol. Biol. 342 (2004) 1131-1141.

[7] A.Paziewska, L.S.Wyrwicz, J.M.Bujnicki, K.Bomsztyk, and J.Ostrowski, Cooperative binding of the hnRNP K three KH domains to mRNA targets, FEBS Lett. 577 (2004) 134-140.

[8] M.Yano, H.J.Okano, and H.Okano, Involvement of $\mathrm{Hu}$ and heterogeneous nuclear ribonucleoprotein $\mathrm{K}$ in neuronal differentiation through p21 mRNA post-transcriptional regulation, J. Biol. Chem. 280 (2005) 12690-12699.

[9] B.N.Griffith, C.M.Walsh, W.Szeszel-Fedorowicz, A.T.Timperman, and L.M.Salati, Identification of hnRNPs K, L and A2/B1 as candidate proteins involved in the nutritional regulation of mRNA splicing, Biochim. Biophys. Acta (2006).

[10] B.Amir-Ahmady and L.M.Salati, Regulation of the processing of glucose-6-phosphate dehydrogenase mRNA by nutritional status, J. Biol. Chem. 276 (2001) 10514-10523.

[11] L.P.Stabile, D.L.Hodge, S.A.Klautky, and L.M.Salati, Posttranscriptional regulation of glucose6-phosphate dehydrogenase by dietary polyunsaturated fat, Arch. Biochem. Biophys. 332 (1996) 269-279. 
[12] P.Chomczynski, A reagent for the single-step simultaneous isolation of RNA, DNA and proteins from cell and tissue samples, Biotechniques 15 (1993) 532-537.

[13] M.Caputi, A.Mayeda, A.R.Krainer, and A.M.Zahler, hnRNP A/B proteins are required for inhibition of HIV-1 pre-mRNA splicing, EMBO J. 18 (1999) 4060-4067.

[14] J.O.Langland, S.M.Pettiford, and B.L.Jacobs, Nucleic acid affinity chromatography: preparation and characterization of double-stranded RNA agarose, Protein Expr. Purif. 6 (1995) 25-32. 


\section{$\underline{\text { Appendix IV }}$}

Copyright Permission 


\section{Copyright Permission for Figure 5 in Chapter 1}

\section{CONTENT USERS • Business • Academic • Service Providers RIGHTSHOLDERS • Publishers • Authors}

New Search | Create Order | View Orders | Choose a New Service

Work With RLS Order

Account\#: 3000080621

\begin{tabular}{|c|c|c|c|c|c|}
\hline Order ID & $\begin{array}{c}\text { Document } \\
\text { Reference }\end{array}$ & Title & $\begin{array}{c}\text { Circulation/ } \\
\text { Distribution }\end{array}$ & $\begin{array}{c}\text { Republication } \\
\text { Format }\end{array}$ & $\begin{array}{c}\text { Request } \\
\text { Date }\end{array}$ \\
\hline 1514242 & & $\begin{array}{c}\text { NUTRITIONAL REGULATION OF } \\
\text { G6PD MRNA SPLICING }\end{array}$ & 1 & Dissertation & $\begin{array}{c}\text { Oct 27, } \\
2006\end{array}$ \\
\hline
\end{tabular}

Cancel Order Credit Line Information Order Item From Another Publication Pre-Invoice Information

Permission Request Details (Click here for Help)

Choose an item to view or modify by clicking on the Order Detail ID.

\begin{tabular}{|c|l|l|l|c|}
\hline \multicolumn{1}{|c|}{ Title of Publication } & \multicolumn{1}{|c|}{$\begin{array}{c}\text { Type of } \\
\text { Content }\end{array}$} & \multicolumn{1}{c|}{ Content Description } & \multicolumn{1}{c|}{$\begin{array}{c}\text { Response } \\
\text { Status }\end{array}$} \\
\hline 1 & $\begin{array}{l}\text { JOURNAL OF BIOLOGICAL } \\
\text { CHEMISTRY }\end{array}$ & $\begin{array}{l}\text { Figure/ } \\
\text { Diagram/ } \\
\text { Table }\end{array}$ & $\begin{array}{l}\text { FIGURE 8, VOL. 277, NO. 34, JBC } \\
\text { ARTICLE }\end{array}$ & Granted \\
\hline & Order Detail ID: 16125383 & Cancel Item & Add Another Item From This Same Publication & Total Fee: 3.00 \\
\hline
\end{tabular}




\section{Copyright Permission for Table 1, Figure 1, 3, \& 4}

\section{CONTENT USERS • Business • Academic • Service Providers RIGHTSHOLDERS • Publishers • Author}

New Search | Create Order | View Orders | Choose a New Servic

Work With RLS Order

Account\#: 3000080

\begin{tabular}{|c|c|c|c|c|c|}
\hline Order ID & $\begin{array}{c}\text { Document } \\
\text { Reference }\end{array}$ & Title & $\begin{array}{c}\text { Circulation } \\
\text { Distribution }\end{array}$ & $\begin{array}{c}\text { Republication } \\
\text { Format }\end{array}$ & $\begin{array}{c}\text { Request } \\
\text { Date }\end{array}$ \\
\hline 1515999 & & $\begin{array}{c}\text { GLUCOSE-6-PHOSPHATE } \\
\text { DEHYDROGENASE MRNA } \\
\text { REGULATION BY NUTRITIONAL } \\
\text { FACTORS }\end{array}$ & 1 & Dissertation & $\begin{array}{c}\text { Nov 02, } \\
2006\end{array}$ \\
\hline
\end{tabular}

\begin{tabular}{l|l|l|l|} 
Cancel Order & Credit Line Information & Order Item From Another Publication & Pre-Invoice Information
\end{tabular}

\begin{tabular}{|l|l|l|l|c|}
\hline 2 & $\begin{array}{l}\text { JOURNAL OF BIOLOGICAL } \\
\text { CHEMISTRY }\end{array}$ & $\begin{array}{l}\text { Figure/ } \\
\text { Diagram/ } \\
\text { Table }\end{array}$ & FIGURE 8 AND 9 & Granted \\
\hline & Order Detail ID: $\underline{16133709}$ & Cancel Item & Add Another Item From This Same Publication & Total Fee: 3.00 \\
\hline
\end{tabular}

Choose an item to view or modify by clicking on the Order Detail ID. You may now click the Search button at the top or bottom of the page to request permission to use another publication. 


\section{Copyright Permission for Chapter 3}

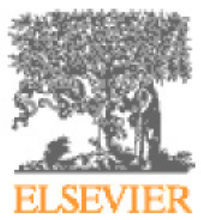

Dear Brian N. Griffith

We hereby grant you permission to reproduce the material detailed below at no charge in your thesis subject to the following conditions:

1. If any part of the material to be used (for example, figures) has appeared in our publication with credit or acknowledgement to another source, permission must also be sought from that source. If such permission is not obtained then that material may not be included in your publication/copies.

2. Suitable acknowledgment to the source must be made, either as a footnote or in a reference list at the end of your publication, as follows:

"Reprinted from Publication title, Vol number, Author(s), Title of article, Pages No., Copyright (Year), with permission from Elsevier".

3. Reproduction of this material is confined to the purpose for which permission is hereby given.

4. This permission is granted for non-exclusive world English rights only. For other languages please reapply separately for each one required. Permission excludes use in an electronic form. Should you have a specific electronic project in mind please reapply for permission.

5. This includes permission for UMI to supply single copies, on demand, of the complete thesis. Should your thesis be published commercially, please reapply for permission.

Yours sincerely

Jennifer Jones

Rights Assistant 


\section{Curriculum Vitae}




\section{Brian Nelson Griffith, PhD, MS}

\section{Assistant Professor of Biochemistry \\ Functional Biology Department \\ West Virginia School of Osteopathic Medicine}

\section{Address and Phone}

Office

West Virginia School of Osteopathic Medicine

400 North Lee Street, Lewisburg, WV 24901

Voice: (304) 647-6225

Fax: (304) 645-4859

Email: bgriffith@wvsom.edu

$\underline{\text { Home }}$

120 Shady Oaks lane

Lewisburg, WV 24901

(304) 661-4993

\section{Education}

B.A. Alderson-Broaddus College, Philippi, WV, 1999 Chemistry (Cum Laude). Major: Chemistry; Minor: liberal arts

B.S. Alderson-Broaddus College, Philippi, WV, 1999 Biology (Cum Laude). Major: Biology; Minor: liberal arts

M.S. West Virginia University, Morgantown, WV, 2002. Biochemistry. Major: Medical Biochemistry

Ph.D. West Virginia University, Morgantown, WV, 2006. Biochemistry and Molecular Pharmacology. Major: Medical Biochemistry

\section{Research and Professional Experience}

1999

Undergraduate Research Project

Alderson-Broaddus College

Laboratory of Dr. Tom Jones

Research project: An ecological study of the streams in north central West Virginia. Streams in north-central West Virginia have been impacted for years by coal mining and it was the goal of this project to access the ecological damage 
of coal mines on streams located in north-central West Virginia by evaluating the ecology of those local streams.

Masters thesis

West Virginia University

Department of Biochemistry

Laboratory of Dr. Lisa M. Salati

Research project: The study of Glucose-6-Phosphate Dehydrogenase (G6PD) gene regulation in HepG2 cells by glucose induction and the study of G6PD mRNA localization by Fluorescent in situ Hybridization (FISH). The goal of this research was to study the effects of mRNA localization in the nucleus of cells. The research was conducted using fluorescent probes and confocal microscopy.

2002-2003

Graduate Student

West Virginia University

Department of Biochemistry Laboratory of Dr. Lisa M. Salati

Research project: The identification of RNA binding proteins responsible for the posttranscriptional gene regulation of Glucose-6-Phophate Dehydrogenase gene regulation. The goal of this project was to identify proteins involved in the splicing of G6PD mRNA by evaluating and identifying proteins bound to regions of G6PD mRNA.

2003-2005

American Heart Association pre-doctoral fellowship award

West Virginia University

Department of Biochemistry and Molecular Pharmacology Laboratory of Dr. Lisa M. Salati

Research project: The identification of splicing regulatory proteins involved in the regulation of Glucose-6-Phosphate Dehydrogenase by nutritional status. The goal of this project was to identify proteins involved in the splicing of G6PD mRNA by evaluating and identifying proteins bound to regions of G6PD mRNA.

Teaching 
2000

2001-2002

2003

2003

2004

2004

Biochemistry Lab 139 at West Virginia University.

As the instructor I was responsible for setting up the laboratory and troubleshooting problems with the labs. In addition the instructor was responsible for grading laboratory reports.

Medical School Small groups for Medical Students As a facilitator in small groups I would lead the discussion of biochemistry relevant topics in an open group format. The small group procedure is a vital part of the medical student's education.

Biochemistry (CHEM-370) at Alderson-Broaddus College The Biochemistry course is an advanced course in biochemistry principles including $\mathrm{pH}$, enzyme kinetics, DNA, RNA, metabolism, and all other principles applicable to Biochemistry. As an instructor I prepared all the course material including exams, quizzes, homework assignments, and all the lectures (PowerPoint). As an instructor I also was responsible for preparing and designing labs for the students. Each laboratory required troubleshooting the experiments prior to the student's labs.

Biochemistry Laboratory (CHEM-370) at Alderson-Broaddus College The Biochemistry lab was designed to prepare students to understand biochemistry by utilizing a variety of labs including enzyme kinetics, DNA plasmid generations, western blot analysis, as well as the basic principles of Henderson-Hasselbalch equations, and MichaelisMenten enzyme kinetics. As the lab instructor I designed the laboratory manual and was responsible for all laboratory preparation.

Human Biology at Fairmont State College

Human Biology is designed to give non-majors an introduction into human biology by providing a fun and interactive environment to learn about basic biological process such as evolution, Nucleic acids, bacteria, viruses, metabolism, the respiratory system, the circulatory system, and the immune system. As an instructor I designed the lectures, quizzes, exams, and all other material included with course preparation.

Human Biology Laboratory at Fairmont State College The human biology laboratory is designed to give non-major students a chance to interact with biology on a personal basis. The laboratory included various labs that corresponded with the material covered in class and as the instructor I was responsible for laboratory preparation and student grades. 
Biochemistry 621 at the West Virginia School of Osteopathic Medicine

Biochemistry 621 encompasses all areas of biochemistry including metabolism and molecular biology. I taught $21 \mathrm{hrs}$ in the medical school biochemistry course including both traditional and molecular aspects of biochemistry.

2005-2006

Nutrition 627 at the West Virginia School of Osteopathic Medicine

I taught 12 hrs of Nutrition including all the basic nutrition and I also focused on children nutrition during early adolescent and continuing into adulthood. The course also spent a great deal of time focusing on geriatric patients including patients suffering from malnutrition.

2006

Problems based learning co-facilitator for second year medical school students

Facilitator for the problem based learning curriculum at West Virginia School of Osteopathic Medicine

\section{Experimental Techniques}

Polymerase chain reaction (PCR)

Ribonucleic Acid Assay (RPA)

Northern analysis

Southern analysis

Western analysis

Confocal microscope

Fluorescent microscope

Compound light microscope

1D and 2D gel analysis

In vitro splicing assay

ELISA plate reader

\section{Computer Software}

Microsoft PowerPoint

Microsoft Word

Microsoft Excel

Image Quant

Confocal microscope software

M-fold program (RNA folding)

SOLE professional
UV crosslinking analysis

Purification of Proteins

Fluorescent in situ hybridization

Fluorescent immunohistochemistry

Cell Culture

Plasmid synthesis and purification

Sub-cloning procedures

Whole mount in situ analysis

MS/MS analysis

Isolation of Rat hepatocytes

Typhoon gel analyzer
Adobe Photoshop

Adobe Acrobat

GCG software (Wisconsin package)

2D spot finder (2D gel analysis)

Fluorescent microscope software

LXR Testing Software

TurningPoint software 


\section{Awards and Honors}

- Alderson-Broaddus College President's list

*Maintained a 4.0 GPA for 5 consecutive semesters

- Member of National Honor Society at Alderson-Broaddus College

- American Chemical Society Award of Northern West Virginia

${ }^{*}$ Recipient of an American chemistry society award for having the

highest GPA for all chemistry majors in north-central West Virginia

- Member of Who's Who among American College Students

- Dharmacon Presentation Award at Rustbelt RNA meeting

*Awarded a Dharmacon presentation award for the second best

presentation at the Rustbelt RNA society meeting

- Awarded Pre-doctoral fellowship from American Heart Association

${ }^{*}$ Awarded a predoctoral American Heart Association grant for my

work as a graduate student at West Virginia University

- Research Day E.J. Van Liere presentation finalist

*Awarded a research award for my presentation on my research during the E.J. Van Liere research day event held at West Virginia University. The award is given to the three best research talks at the E.J. Van Liere research day

\section{Invited Presentations}

- Davis and Elkins College undergraduate research symposium

- Rustbelt RNA meeting 2002

- Research Day E.J. Van Liere Presentation

- Rustbelt RNA meeting 2004

- West Virginia School of Osteopathic Medicine invited seminar

\section{Abstracts}

- Rustbelt RNA meeting 2002

- Annual RNA society meeting 2002

- West Virginia University Research Day (E.J. Van Liere Research Day)

- Rustbelt RNA meeting 2004

- Annual RNA society meeting 2004

- Annual RNA society meeting 2006

\section{Grants}

- American Heart Association pre-doctoral fellowship Award. 2004-2006 Mid-Ohio Valley Affiliate. 18,000 per year. 


\section{Committee Responsibilities}

- Graduate Student Organization 2004-2005

*Responsibilities included monthly meetings to discuss graduate student issues. Other responsibilities included inviting seminar speakers to our annual GSO seminar series. My goal was to invite Dr. Lewis Cantley the leading investigator in the Phosphoinositide 3-Kinase Pathway.

- WVSOM Curriculum Committee 2006-2009

${ }^{*}$ Curriculum Committee is responsible for monitoring the current and future curriculum at WVSOM. In addition, the curriculum committee is also responsible for implementing course and system reviews and approval of course and system syllabi. As curriculum secretary I am responsible for scheduling, production of minutes, and the drafting of proposals.

\section{Publications}

Waggoner JR, Huffman J, Griffith BN, Jones LR, Mahaney JE. Improved expression and characterization of Ca2+-ATPase and phospholamban in HighFive cells. Protein Experimental Purification. 2004 Mar;34(1):56-67.

Martirosyan A, Leonard S, Shi X, Griffith BN, Gannett P, Strobl J. Actions of a Histone Deacetylase Inhibitor, NSC3852, Reactive Oxygen Species to Cell Differentiation and Apoptosis in MCF-7 Human Mammary Tumor Cells. J Pharmacol Exp Ther. 2006 Feb 23

Szeszel-Fedorowicz W, Talukdar I, Griffith BN, Walsh CM, Salati LM. An exonic splicing silencer is involved in the regulated splicing of glucose-6-phosphate dehydrogenase mRNA. J Biol Chem. 2006 Sep 15; Epub ahead of print

Griffith BN, Walsh CM, Szeszel-Fedorowics W, Timperman, A and Salati LM. Identification of hnRNPs $\mathrm{K}, \mathrm{L}$ and $\mathrm{A} 2 / \mathrm{B} 1$ as candidate proteins involved in the nutritional regulation of mRNA splicing. Epub ahead of print, BBA, October 2006

\section{References}

Dr. Lisa M. Salati

Department of Biochemistry

\& Molecular Pharmacology

West Virginia University

Morgantown, WV 26506 
(304) 293-7759

Dr. Dianna S. Beattie

Department of Biochemistry

\& Molecular Pharmacology

West Virginia University

Morgantown, WV 26506

(304) 293-7522

Dr. John Enz

Department of Natural Science

Alderson-Broaddus College

Philippi, WV 26416

(304) 457-6245 